\title{
Neue Literatur
}

\author{
Unter Mitwirkung von
}

E. Åkerberg-Landskrona, H. de Haan-Wageningen, J. HackbarthMüncheberg, E. Menner-Halle, H. Stubbe-Berlin-Dahlem, M. S. PeaseCambridge, B. Schulz-München, W.v. Wettstein-Müncheberg, K. Strogaja-Leningrad, E. Oehler, Müncheberg. S. Wagner, Oerlikon

zusammengestellt von

\section{H. Kuckuck-Eisleben, E. Oehler-Müncheberg und R. Schick-Neu-Buslar}

(Im Interesse möglichster Vollständigkeit der Literaturlisten richten wir an die Autoren einschlägiger Arbeiten die Bitte, an die Redaktion Sonderdrucke oder Hinweise einzusenden, vor allem von Arbeiten, welche an schwer zugänglicher Stelle veröffentlicht sind.)

(Abgeschlossen am 1. November 1936)

\section{Lehrbücher, zusammenfassende Darstellungen, Sammelreferate über Vererbungs- und Abstammungslehre. - Arbeiten von mehr theoretischem Inhalt über Vererbung und Artbildung}

Abderhalden, E., 1936. Neue Wege der Vererbungsforschung. Der Naturforscher. 18. $145-147$.

Allen, Ch. E., 1935. The genetics of bryophytes. Bot. Review. 1. 269-291.

Americ. Association of Physical Anthropologists, 1936. Proceedings of seventh annual meeting at the Jale University, New Haven, Conn. Americ. Journal of Physical Anthropology. Suppl. zu Bd. 21. $19 \mathrm{~S}$.

Anon., 1936. Genetics and ecology in relation to selection. Nature. 138. 748-749.

Armstrong, H. E. and G. D. H. Carpenter, 1936. Insect coloration. Nature. 138. $242-243$ and 686.

Barendrecht, G., 1936. De toepassing der wetten van Mendel. Erfelijkheid bij de mens. 2. $120-136$.

Barigozzi, C., 1936. I rapporti fra assetto cromosomico e sistematica. (Résume in franz., englisch, deutsch.) Archivio zoologico italiano. Suppl. zu XXIII. $1-52$.

Baur, E., E. Fischer und F. Lenz, 1936. Menschliche Erblehre. 4. neubearb. Auflage. München: Lehmanns Verlag. 1. VIII, 796 S. 8. 13 Taf. 209 Textfig.

Bodewig, E., 1936. Mathematische Untersuchungen zum Mendelismus und zur Eugenetik. Genetica. 18. 116-186. 2 Textf.

Boehm, H., 1936. Erbkunde. Berlin: C. Heymann. 93 S. $4^{0}$.

Boeuf, E., 1936. Les bases scientifiques de l'amélioration des plantes (Biologie, génétique, écologie, biométrie statistique). Paris: P. Lechevalier. $543 \mathrm{~S}$.

Boven, W., 1936. L'hérédité des affections schizophréniques. Ann.-méd. psychol. $94^{\ominus}$ Année. $267-269$.

Brožek, A., 1935. A simple method of mechanically developing Mendelian empiric frequency-ratios with and without linkage. Mém. Soc. Roy. sci. Bohême 1935. 12. 1-6.

Burğdörfer, Fr., H. Boehm, G. Friese und H. Linden, 1936. Grundlagen der Erb- und Rassenpflege. Handbücherei f. d. öffentl. Gesundheitsdienst. 2. IX, 359 S. 
Buttersack, 1936. Sind Mutationen notwendig? Schweizerische medizin. Wochenschrift. 66. Jahrg. $785-788$.

Caullery, M., 1935. Les conceptions modernes de l'héridité. (Bibliothèque de philosophie scien.) Paris: E. Flammarion 1935: $316 \mathrm{~S}$. $49 \mathrm{Abb}$.

Costa, D., 1936. Das rassenkundliche Schrifttum des Jahres 1935. Fortschr. Neur. 8. Jahrg. $421-436$.

Cuénot, L. et J. Rostand, 1936. Introduction à la génétique. Paris: Tournier et Constans. $136 \mathrm{~S} .7$ Taf.

Darlington, C. D. and H. C. Osterstock, 1936. Projection method of demonstrating chromosomes in situ. Nature. 138. 79.

Demerec, M., 1935. Unstable genes. Bot. Review. 1. 233-248.

Diehl, K. u. Frh. 0. v. Versehuer, 1936. Der Erbeinfluß bei der Tuberkulose. Jena: Fischer. 2. VIII, $172 \mathrm{~S}$. $8^{\circ}$. 114 Textf.

Dobzhansky, T., 1936. Position effects on genes. Biological Reviews. 11. 364-384.

East, E. M., 1936. Genetic aspects of certain problems of evolution. Amer. Naturalist. 70. $143-158$.

Eickstedt, E. Frh. v., 1936. Die rassischen Grundlagen des deutschen Volkes. Schriften zur völkischen Billdung. $63 \mathrm{~S} .8^{0}$. 1 Taf.

Fischer, A. und F. Schwanitz, 1936. Die Bedeutung der Polyploidie für die ökologische Anpassung und die Pflanzenzüchtung. Der Züchter. 8. 225-231. 3 Textf.

Franceschetti, A., 1936. Vererbung und Auge. (Berichtsjahr vom 1. Oktober 1934 bis 1. Oktober 1935.) Z. f. Augenheilk. 88. 319-328.

Frankenberg, G. v., 1936. Unzweckmäßigkeiten in der Natur. Der Naturforscher. 13. 39-43. 7 Textf.

Frischeisen-Köhler; I., 1936. Mutationen und Modifikationen nach Hitzebehandlung. (Sammelreferat der Arbeiten von V. Jollos und H. H. Plough and P. T. Ives.) Der Züchter. 8. 243-248.

Fyfe, T. L. and C. D. Darlington, 1936. The external forces acting on chromosomes. Nature. 138. 366. 1 Textf.

Geiringer, H., 1936. Zur Weinbergschen Probandenmethode. Rev. Fac. Sci. Univ. Istambul, N. s. 1, H. 3. $10-36$.

Gratia, A. et Po Manil, 1936. Virus des plantes et hérédité. C. r. Soc. Biol. Paris. 122. $814-815$.

Gregor, T. W. et alii, 1936. Experimental Taxonomy. I. New Phytologist. 35. 323-350. 3 Textf.

Groos, K., 1936. Vererbte Gewohnheit? Beobachtungen und Vermutungen. Nederl. Tijdschr. Psychol. 4. 85-95.

Groß, W., 1936. Rassengedanke und Wissenschaft. Ziel und Weg. 6. Jahrg. 566-573.

Gustafsson, Å., 1936. UUber verschiedene Sensibilität und Stabilität der Chromosomen. Botaniska Notiser. Jahrg. 1936. 488-512. 1 Textf.

Haase-Bessell, G., 1936. Chromatin, Chromosomen, Gene. Planta. 25. 240-257.

Haldane, F. B. S., 1936. The amount of heterozygosis to be expected in an approximately pure line. Journal of Genetics. 32. 375-392.

Hance, R. T., 1936. Mendelism for the blind. Laboratory courses in biological sciences successfully tought to the sightless. J. Hered. 27. 151-154.

Haskins, C. P. and E. V. Enzmann, 1936. A determination of the magnitude of the cell ,sensitive volume" associated with the white-eye mutation in X-rayed Drosophila. II. Proc. nat. Acad. Sci. U.S.A. 22. 397-400.

Heilbronn, A. und W. Prager, 1936. Beiträge zum Mutationsproblem. (I. Mitt.) Rev. Fac. Soi. Univ. Istanbul, N. s. 1, H. 3, 37-43.

Hellpach, W., 1936. Erfahrungen und Grundsătze über Schauverfahren. Zeitschr. f. Rassenkunde. 4. 164-172.

Huxley, T. S.. 1936. Natural selection and evolutionary progress. Nature. 138. 603-605.

Jankowsky, W., 1936. Les bases et les limites de l'anthropologie. Revue Anthropologique. 46. Jahrg. 254-265. 
Jones, D. F., 1936. Atypical growth. Amer. Naturalist. 70. 86-92.

Jones, O. P., 1936. Bibliography of American Hematological Literature (1933). Folia haematologica. 55. $437-479$.

Just, E. E., 1936. A single theory for the physiology of development and genetics. Amer. Naturalist. 70. 267-312.

Just, G., 1936. Die Vererbung. 2. erw. Auflage. Breslau: F. Hirt. 188 S. $8^{0} .59$ Textf.

Kaniewski, K., 1935. Die gesteigerte Wüchsigkeit der Bastarde im Lichte des Mendelismus. Warszawa: Drukarnia Artystyczna. $24 \mathrm{~S}$.

Kosswig, C. und L., 1936. Beziehungen zwischen Genetik und Chromosomenstruktur bei Drosophila. (Sammelreferat.) Der Züchter. 8. 124-136. 19 Textf.

Kostoff, D., 1936. Virus and genic reactions in morphogenetic, physiogenetic and phylogenetic aspects. Phytopathol. Zeitschr. 9. 387--405. 12 Textf.

Kretzsehmer, E., 1936. Körperbau und Charakter. Untersuchungen zum Konstitutionsproblem und zur Lehre von den Temperamenten. 11. und 12. Aufl. Berlin: J. Springer. IX, $243 \mathrm{~S} .4^{0}$. 45 Textf.

Kroll, F. W., 1936. Systemerkrankungen des Rückenmarkes, Degenerativerkrankungen. Fortschr. f. Neur. 8. Jahrg. 196-218.

Kröning, F., 1935. Das Krebsproblem vom Standpunkt des Genetikers. Med. Welt. 1558 bis 1562 .

Kulz, W., 1936. Marquis de Lapouge zum Gedenken. Volk und Rasse. 11. Jahrg. Heft 6. 255-258. 1 Textf.

Lahenzinski, F., 1936. Sammelreferat aus der polnischen hämatologischen Literatur des Jahres 1934. Folia haematologica. 56. 123-126.

Laughlin, H. H., 1936. The coil-spring properties of chromosomes. Genetica. 18. 126-145. 7 Textf.

Lehmann, W., 1936. Vererbung und Rasse (2. verb. Aufl.). Potsdam u. Leipzig: Bonness u. Hachfeld. 32 S. $4^{0}$.

Loeffler, L., 1936. Der Auslesegedanke als Forderung in der Medizin. München: J. F. Lehmanns Verlag. $14 \mathrm{~S}$.

Lottrup, M. C., 1936. Sammeireferat ́iber dänische (hämatologische) Literatur (1933-34). Folia haematologica. 55. 283-304.

Lwoff, A., 1936. Remarques sur une propriété commune aux génes, aux principes lysogénes et aux virus des mosaiques. Ann. Inst. Pasteur. 56. 165-170.

MacBride, E. W., 1936. Insect Coloration and Natural Selection. Nature. 138. 365.

Mather, K., 1936. Segregation and linkage in autotetraploids. Journal of Genetics. 132. 287-314. 3 Textf.

Mather, K., 1936. Competition between bivalents during chiasma formation. Proc. of the Royal Society B. 120. 208-227.

Matsumura, A., 1936. The fifty years history of the Anthropological Society of Tokyo. Zeitschr. f. Rassenkunde. 4. 173-194.

MeCrie, 1936. Sammelreferat aus der englischen (hämatologischen) Literatur. Folia haematologica. 55. $138-160$.

Mittmann, O., 1936. Über die Schnelligkeit der relativen Vermehrung vorteilhafter Mutationen. Nachr. v. d. Ges. d. Wiss. zu Göttingen. Math.-physik. Kl., Fachgr. 6. N. F. 2. $107-127$.

Muller, H. J., 1936. Über die Bestimmung des Verhältnisses der Mutationsrate zur Strahlendosis. Strahlenther. 55. 72-76.

Muller, H. J., 1936. Über die Wirkung der Röntgenstrahlen auf die Erbmasse. Strahlenther. 55. $207-224$.

Mully, K., 1935. Darstellende Variationsforschung in den Naturwissenschaften (speziell in der Anthropologie). Verhandl. d. schweiz. naturf. Ges. 116. Jahresversamml. 356-359. 1 Textf.

Nabours, R. K., 1936. Species from the genetic standpoint. Amer. Naturalist. 70. 191-192.

Nachtsheim, H., 1936. Gleichlaufende Erbänderungen. Der Naturforscher. 13. 73-77. 1 Taf. 5 Textf. 
Navaschin, M. und H. Gerassimowa, 1936. Natur und Ursachen der Mutationen. I. Das Verhalten und die Zytologie der Pflanzen, die aus infolge Alterns mutierten Keimen stammen. Cytologia. 7, No. 3. 324. 26 Textf.

Pickhan, A., N. W. Timoféeff-Ressovsky und K. G. Zimmer, 1936. Versuche an Drosophila melanogaster über die Beeinflussung der mutationsauslösenden Wirkung von Röntgen- und Gammastrahlen durch Hochfrequenzfeld (Kurzwellen) und Ätthernarkose. Strahlenther. 56. 488-496.

Pictet, A., 1936. La zoogéographie expérimentale dans ses rapports avec la génétique. Mém. Mus. Hist. natur. Belg. 2, s. 3. 233-282.

Ploetz. A., 1936. Lebensbild Eugen Fischers. Archiv f. Rassen- u. Ges.biol. 30. 85-87.

Rees, Th., 1936. Heilkunde, Biologie und exakte Wissenschaft. Münchner medizin. Wochenschrift. 83. Jahrg. 1562-1564.

Reichel, H:, 1936. Über eine verbesserte Methode der Berechnung der Abhängigkeit von Merkmalen (Vierfelderrechnung). Genetica. 18. 146-156. 2 Textf.

Rossier, P. H., 1936. Französische hämatologische Literatur (II. Semester 1933). Folia haematologica. 55. 115-137.

Routil, R., 1936. Statistische Forschungsmethoden in Natur und Geisteswissenschaft, deren Anwendung in Anthropologie und Ethnologie. Mitteilungen d. Anthropologischen Gesellsch. in Wien. 66. 231-260. 7 Textf.

Rouyi, A., 1935. Der internationale Kongreß für Bevölkerungswissenschaft vom 26. August bis 1. Sept. in Berlin (Sammelreferat). Reichsgesundheitsblatt. 10. Jahrg., H. 45. 960-964.

Sax, K., 1935. The cytological analysis of species-hybrids. Bot. Review. 1. 100-117.

Sax, K., 1936. Chromosome coiling in relation to meiosis and crossing 'over. Genetics, 21. $324-338$.

Scbäfer, W., 1936. Über die Zunahme der Isozygotie (Gleicherbigkeit) bei fortgesetzter Bruder-Schwester-Inzucht. Zeitschr. f. ind. Abst.- u. Vererbgsl. 72. 50-79. 1 Textf.

Schindewolf, Ö., 1936. Paläontologie, Entwicklungslehre und Genetik. Kritik und Synthese. Berlin: Borntraeger. V, $108 \mathrm{~S} .4^{0}$. 34 Textf.

Schulz, B., 1936. Methodik der medizinischen Erbforschung unter bes. Berücksichtigung der Psychiatrie. Ieipzig: G. Thieme. $189 \mathrm{~S} .4^{0}$. 1 Taf. 16 Textf.

Schwanitz, F., 1936. Gibt es eine Vererbung erworbener Eigenschaften? Ziel und Weg. 6. Jahrg. 573-577.

Sehwanitz, F., 1936. Die Bedeutung des Plasmas für die Vererbung. Volk und Rasse. 11. Jahrg., H. 7. 288-295. 8 Textf.

Sirks, M. J., 1936. Eine historisch wichtige Abbtldung Naegelis. Genetica. 18. 390-391. 1 Textf.

Sodemann, W. A. u. H. J. Musser, 1936. Review of the American literature on pernicious Anemia for 1933-35. Folia haematologica. 56. 97-122.

Ssacharow, W. W., 1936. Jod als chemischer Faktor, der auf den MutationsprozeB wirkt. Genetica. 18. 193-216.

Stern, C., 1936. Interspecific sterility. Amer. Naturalist. 70. 123-142.

Tammes, T., 1936. Die Bedeutung von Dr. Maria Anna van Herwerden für die Genetik und die Eugenetik. Genetica. 18. 3-9. 1 Taf.

Tschermak-Seysenegg, A., 1936. Über graphische Darstellung der Mendelschen Spaltung. Medizinische Klinik. 32. Jahrg. 1502-1505. 4 Textf.

Trubina, M. G., 1935. Gibt es prämutative Prozesse in den Genen ? (Russ,; m. engl. Zus.) Biol. Z. 4. $917-922$.

Unger, H., 1935. Befruchtung und Vererbung. Neues Volk. 3. Jahrg., Nr. 10. 32-33.

Vishnevsky, B. N., 1936. Anthropology in U.S.S.R. in the course of 17 years (1917-34). Amer. Journ. of Physical Anthropology. 21. 1-17.

Watson, D. M. S. et alii, 1936. The present state of the theory of natural selection. Proc. of the Royal Society. 121. 43.

Weber, E., 1935. Rassenphysiologisehes Schrifttum in deutscher Sprache. 2. Teil der Jahresübersicht 1932. Zeitschr. f. Rassenphysiologie. 7. 192. 
Weber, E., 1936. Rassenphysiologisches Schrifttum in deutscher Sprache. 2. Teil der Jahresübersicht 1932. Zeitschr. f. Rassenphysiologie. 8. 48 u. 77-84.

Weninger, J., 1936. Menschliche Erblehre und Anthropologie. (Zur Methode der Erbforschung.) Wiener klin. Wochenschr. 49. Jahrg. 801-806.

Werthemann, A., 1935. C̈ber Erblehre, Rassenhygiene und Eugenik. Schweiz. medizin. Wochenschr. 65. Jahrg. 693-697.

Wettstein, F. v., 1936. Gesichertes und Problematisches zur Geschlechtsbestimmung. Ber. d. deutsch. Bot. Ges. 54. Gen. Vers. H. 1-38.

Wirth, D., 1936. Sammelreferat Veterinärmedizin 1934 (Hämatologie). Folia haematologica. 55. $266-282$.

Wirth, D., 1936. Sammelreferat Veterinärmedizin. Folia haematologica. 55. 423-436.

Wolsky, A., 1936. Über Zusammenhänge zwischen Entwickiungsphysiologie und Genetik in der experimentellen Morphologie. Arb. ung. biol. Forschungsinst. 8. 186-195.

\section{Experimentelle Arbeiten und Beobachtungen über Vererbung, Bastardierung, Variabilität und Artbildung}

\section{a) Pflanzen}

Åkerberg, E., 1936. Studien über die Samenbildung bei Poa pratensis L. Botaniska Notiser. Jahrg. 1936. 213-280. 2 Textf.

Alam, Z., 1936. Self-sterility in Eruca sativa. Journ. of Genetics. 132. 257-276.

Alleizette, Ch. de, 1936. Un nouvel hybrid d'Orchis ( 0 . latifolia $\times 0$. laxiflora) $\times 0$. Chassignei Nob. Bull. de la Soc. botanique de France. 83. 290-292.

Anderson, J. A., 1936. Studies on the nature of rust resistance in wheat. VII. Chemical analysis of hybrid lines of wheat differing in their rust reactions. Canad. J. Res. 14, Sect. C. $1-10$.

Andersson-Kottö, I. and A. E. Gairdner, 1936. The inheritance of apospory in Scolopendrium vulgare. Journ. of Genetics. 32. 189-228. 12 Taf.

Anon., 1936. Oenotheras at Wisley, 1933-35. Journ. of the Royal Horticultural Society. 61. $162-166$.

Antonoff, S., 1936. Beitrag zum zytogenetischen Studium der Artbastarde Triticum turgidum $\times$ Triticum durum, Triticum durum $\times$ Tritıcum monococeum und Secale cereale $\times$ Secale montanum. Der Züchter. 8. 240-243. 7 Textf.

Armstrong, J. M., 1936. Hybridization of Triticum and Agropyrum. I. Crossing results and description of the first generation hybrids. Canad. J. Res. 14, Sect. C. 190-202.

Arnason, T. J., 1936. Cytogenetics of hybrids between Zea Mays and Euchlena mexicana. Genetics. 21. $40-60$.

Ashby, E., 1936. Hybrid vigor in maize. Amer. Naturalist. 70. 179-181.

Atabekowa, 1936. Die Wirkung der Röntgenbestrahlung ruhender und keimender Samen. Protoplasma (Berl.). 2.5. $234-260$.

Barglowsky, D., 1936. Untersuchungen über den Polymorphismus der Tuberkelbazillen. Beiträge zur Klinik der Tuberkulose. 88. 139-155.

Becker, Th., 1936. Untersuchungen über Sexualität bei Tilletia tritici (Bjerk) Wint. im Rahmen der Immunitätszüchtung. Phytopath. Zeitschr. 9. 187-228. 8 Textf.

Bond, T. E. T., 1936. Phytophthora infestans (Mont.) Debary and Cladosporium fulvum Cooke on varieties of tomato and potato and on grafted solanaceus plants. Ann. appl. Biol. 23. $11-29$.

Brodie, H. J., 1936. The bastage phenomenon in Lenzites betulina. Genetica. 18. 61-73. 2 Taf.

Brown, A. M., 1936. Studies on the interfertility of pour strains of Puccinia Helianthi. Canadian Journal of Research. 14. 361-367.

Camus, A. et P. Jovet, 1936. Sur les Calomagrostis lanceolata Roth.. C. epigeios Roth. et leurs hybrides. Bull. de la soc. botanique de France. 83. 257-265. 2 Textf.

Carbone, D. e A. V. Alexandri, 1936. Nuove ricerche sull'immunità vaccinale nelle piante. Riv. Biol. 20. 24-4l. 
Casella, D., 1935. Un ibrido d'innesto melangolo-limetta e l'apiatura dell'arancio ovale. Annali d. x. staz. sper. di fruticoltura e di agrumicolt. di Acireale. N. S. 2.

Catcheside, D. G., 1936. Origin, nature, and breeding behaviour of Oenothera Lamarckiana trisomics. Journ. of Genetics. 33. 1-24. 17 Textf.

Caty, R., 1936. Note sur les pigmentations d'organes végétatifs chez le riz. Rev. Bot. appl. 16. $190-192$.

Cleland, R. E., 1936. Some aspects of the cyto-genetics of Oenothera. Bot. Review. 2. $316-348$.

Correns, C. $\dagger, 1936$. Vererbungsversuche mit buntblättrigen Sippen. 12. Petunia hybrida forma albomutabilis. Weitergeführt und herausgegeben von $H$. Kappert. Sitzber. d. Preuß. Akad. d. Wiss. Math.-phys. Kl.

Dalmasso, G., I. Comso e G. Dell'olio, 1936. Gli ibridi produttori diretti a Conegliano. Annali d. sperim. agraria. 17-19.

Daniel, L., 1936. L'hérédité acquise chez le poireau bulbifère. C. r. Acad. Sci. Paris. 203. $394-396$.

David, R., 1936. Recherches sur la biologie et l'intersexualité de Talictrus salvator Mont. Bull. biologiques de la France et de la Belgique. 70. 332-357. 18 Textf.

Dellinghausen, M. v., 1936. Entwicklungsgeschichtlich-genetische Untersuchungen an Epilobium. VII. Über vergleichende Viskositätsmessungen an zwei genetisch verschiedenen Plasmen. Planta. 25. 282-301. 6 Textf.

Demerec, M., 1935. Behavior of chlorophyll in inheritance. Biol. 3. 80-86.

Deshpande, R. B., 1935. Pungency in chillies (Capsicum annuum): A mendelian character. Current Sci. 4. 418.

Dickson, H., 1936. Studies in Coprinus sphaerosporus. III. The inheritance of factors affecting the grwoth-rates at different temperatures of certain strains. Ann. of Bot. 50. $219-246$.

Dickson, H., 1936. Observation on inheritance in Coprinus macrorhizus. Annals of Botany. 50. 719-734. 2 Taf. 2 Textf.

Dietel, P., 1936. Über die Variabilität der Größe der Teleutosporen der Uromyces-Arten auf Euphorbia Cyparissias. Annales mycologici. 34. 53-56.

Dresel, E. G. u. H. Mury, 1936. Neue Umwandlungsergebnisse des Bacterium typhi flavum in das Bacterium typhi Eberth-Gaffky. Archiv f. Hygiene u. Bakteriologie. 116. $27-44$.

Ebbenharst Tengbergen, J. van und W. F. de Mol, 1936. Röntgenbestrahlung von Tulpen, Hyazinthen usw. Strahlenther. 56. 215-227.

Eger, H., 1936. Zur Frage der Bakterienvariabilität. (Untersuchungen über das Bacterium typhi flavum Dresel.) Archiv f. Hygiene u. Bakteriologie. 116. 16-26.

Einset, 0., 1935. Cross pollination trials with bud mutations of the apple. Die Gartenbauwissenschaft. 9. 157.

Emerson, S., 1936. A genetic and cytological analysis of Oenothera pratincola. Journ. of Genetics. 32. 315-342. 4 Textf.

Erwin, A. T., 1936. Notes on Cucurbita moschata, Duch. Iowa State Coll. J. Sci. 10. $213-221$.

Eyster, W. H. and D. Burpee, 1936. Inheritance of doubleness in the flowers of the nasturtium. J. Hered. 27. 51-60.

Fleischmann, R., 1935. Die Kornreihenanzahl an Maiskolben. Pflanzenbau. 12. Jahrg. 199. 3 Textf.

Frets, G. P., 1936. Hereditary variability in the $F_{3}$ seed generation after cross-fertilization of bean races. Proc. roy. Acad. Amsterd. 39. 432-440.

Gairdner, A. E., 1936. The inheritance of factors in Cheiranthus cheiri. Journ. of Genetics. 32. $479-486$. 1 Taf.

Garber, R. J., R. B. Dustman and C. R. Burnham, 1936. Yield and composition of eared and earless maize plants in a selfed line segregating barren stalks. J. amer. Soc. Agronomy. 28. 85-91.

Gerassimova, H., 1936. Experimentell erhaltene haploide Pflanze von Crepis tectorum. Planta. 25. 696-702.6 Textf. 
Göhring, G., 1935. Zur Frage der „Degenerationsformen“ der Gonokokken. Arch. f. Hygiene u. Bakteriologie. 114, H. 5, 313-314.

Graze, H. u. G. Schlenker, 1936. Versuche zur Klärung der reziproken Verschiedenheiten von Epilobium-Bastarden. III. Vergleichende Untersuchungen über den Wuchsstoffgehalt bei verschiedenen Biotypen von Epilobium hirsutum. Jahrb. f. wiss. Bot. 82. $687-695$.

Greisenegger, J. K., 1935. Die Eigenschaften der Weizen und deren Beziehungen zueinander. Pflanzenbau. 13. Jahrg. 4.

Hackbarth, J., 1936. Versuche über Photoperiodismus. III. Die photoperiodische Reaktionsweise einiger Lupinenarten. Der Züchter. 8. 81-92. 12 Textf.

Haldane, T. B. S., 1936. Linkage in Primula sinensis. Journ. of Genetics. 32. 373-374.

Haldane, T. B. S., 1936. Some natural populations of Lythrum Salicaria. Journ. of Genetics. 32. 393-398.

Hammerschmidt, J., 1935. Gruppenbildung der Diphteriebazillen. Klin. Wochenschr. 14. Jahrg. 946--966.

Harland, S. C., 1936. Duplicate genes for corolla colour in Gossypium barbadense L. und G. Darwinii Watt. Zeitschr. f. ind. Abst.- u. Vererbgsl. 71. 417--419.

Heilbronn, A., 1935. Über die Mutabilität mono- und digenomatischer Farne. Rev. Fac. Sci. Univ. Istanbul. 1. $56-60$.

Hennig, K., 1935. Untersuchungen über den Primingehalt verschiedener Primelarten. Die Gartenbauwisserischaft. 9. 427.

Herbst, W., 1936. Venturia pirina Aderhold. I. Zur Formenmannigfaltigkeit des Pilzes. Die Gartenbauwissenschaft. 10. 428. 13 Textf.

Hinderer, G., 1936. Versuche zur Klärung der reziproken Verschiedenheiten von EpilobiumBastarden. II. Wuchsstoff und Wachstum bei reziprok verschiedenen EpilobiumBastarden. Jahrb. f. wiss. Bot. 82. 669-686. 14 Textf.

Holton, C. S., 1936. Inheritance of chlamydospore characteristics in oat smut fungi. J. agricult. Res. 52. 535-540.

Husain, M. A., A. N. Puri and K. N. Trehan, 1936. Cell sap acidity and the incidence of white-fly. (Bemesia gossypipoda) on cottons. Current Sci. 4. 486-487.

Hutchinson, T. B., 1936. The genetics of Cotton. XVI. Some observation on the inheritance of form and size. Journ. of Genetics. 32. 399-410. 4 Textf.

Imai, Y., 1935. Ursprung und Entwicklung, Vererbung und Züchtung der japanischen Trichterwinde. Die Gartenbauwissenschaft. 9. 135. 7 Textf.

Imai, Y., 1936. Geno- and plasmotypes of variegated pelargoniums. Journ. of Genetics. 33. 169-196. 6 Taf. 17 Textf.

Issler, E., 1936. Espèces, sous-espèces, hybrides observés pendant la Session de la Société botanique de France en juin 1935 à Paris. Bull. de la Soc. botanique de France. 83. $215-223$.

Janaki-Ammal, E. K., 1936. Cyto-genetic analysis of Saccharum spontaneum L. I. Chromosome studies in some Indian forms. Indian J. agricult. Sci. 6. 1-8.

Janaki-Ammal, E. K. and T. S. N. Singh, 1936. Cyto-genetic analysis of Saccharum spontaneum L. II. A type from Burma. Indian J. agricult. Sci. 6. 9-10.

Johnson, L. P. V., 1935. The inheritance of delayed germination in hybrids of Avena fatua and Avena sativa. Canad. J. Res. 13. Sect. C. 367-387.

Jones, D. F., 1936. Segregation of color and growth-regulating genes in somatic tissue of maize. Proc. nat. Acad. Sci. U. S. A. 22. $163-182$.

Jung, E., 1935. Untersuchungen über die Variabilität und Eigenschaftsangleichung zweier Roggensorten bei geregeltem Vizinismus. Zeitschr. f. Züchtung, Reihe A. 20. 475. 3 Textf.

Kadam, B. S., 1936. Genetic analytic of Rice. I. Grain shedding. Proc. of the Indian Academy of Sciences. 4. 224-229.

Kadam, B. S., G. G. Patil and V. K. Patankar, 1936. Double awned spikelets in rice. Current Sci. 4. 739 .

Kanna, B., 1935. Chlorophyll deficient rice seedling induced by X-rays. Journ. of the Coll. of Agric. Imp. Univ. Tokyo. 13. 363-371. 1 Taf. 
Kappert, H., 1936. Spontane Mutationen bei Matthiola incana R. Br. Der Züchter. 8. 117-124. 4 Textf.

Karasawa, K., 1936. Crossing experiments with Glycine soja and Glycine ussuriensis. Jap. Journ. of Botany. 8. 113-118. 3 Textf.

Katayama, Y., 1935. Karyogenetic studies on X-rayed sex cells and their derivates in T. monococcum. Journ. of the Coll. of Agric. Imp. Univ. Tokyo. 13. 333-362. 2 Taf. 40 Textf.

Katayama, Y., 1935. Further investigations on synthezised octoploid Aegilotricum. Journ. of the Coll. of Agric. Imp. Univ. Tokyo. 13. 397-414. 1 Taf. 14 Textf.

Katayama, Y., 1936. Unstable wrinkled and stable wrinkloid flowers of the Japanese morning glory. Journ. of Coll. of Agric. Imp. Univ. Tokyo. 13. 443-452. 1 Taf. 3 Textf.

Kattermann, G., 1935. Genetische Ergebnisse bei Weizenroggenbastarden bis $\mathrm{F}_{4}$. Pflanzenbau. 12, Jahrg. 131. 1 Textf.

Kattermann, G., 1936. Genetische Ergebnisse bei Weizenroggenbastarden bis $F_{4}$. Pflanzenbau. 13. Jahrg. 15. 5 Textf.

Kempton, J. M., 1936. Modification of a Mendelian ratio in maize by pollen treatments. J. agricult. Res. 52. $81-121$.

Kirnossowa, L., 1936. Der Einfluß hoher Temperatur auf das Mutieren der ruhenden Embryonen von Crepis tectorum. Planta. 25. 491-501. 6 Textf.

Knapp, E., 1936. Zur Genetik von Sphaerocarpus. Ber. d. deutsch. Bot. Ges. 54, Gen.Vers.-H. 58-69. 3 Taf. 1 Textf.

Knapp, E., 1936. Heteroploidie bei Sphaerocarpus. Ber. d. deutsch. Bot. Ges. 54. 346 bis 361. 1 Taf.

Koenig, P. und L. Rave, 1935. Beiträge zur Tabaksystematik und -genetik. I. Sortenmerkmale am deutschen Tabak. Landwirtschaftliche Jahrbücher. 81. 425. 7 Textf.

Köhler, Fr., 1936. Variabilitätsstudie an zwei Stämmen von Mucor mucilagineus Bref. Flora. 30. $365-376.6$ Textf.

Kostoff, D., 1936. Studies on the polyploid plants. XI. Amphidiploid Triticum Timopheevi Zhnk. $\times$ Triticum monococcum L. Zeitschr. f. Züchtung, Reihe A. 21. 41. 3 Textf.

Krievius-Hofmanis, L., 1935. On the inheritance of flower colour in Verbascum phoeniceum L. (Prelim. Rep.). Latv. biol. Biedr. Raksti. 5. 61-65.

Krumbholz, G., 1935. Beiträge zur Morphologie der Apfelblüte. I. Mitteilg. Über die Zahl der Samenanlagen in den Blüten in ihrer Abhängigkeit vom Genotypus und der Stellung der Blüte im Blütenstand. Die Gartenbauwissenschaft. 9. 509. 3 Textf.

Kuckuck, H., 1936. Über vier neue Serien multipler Allele bei Antirrhinum majus. Zeitschr. f. ind. Abst.- u. Vererbgsl. 71. 429-440. 1 Textf.

Lamprecht, H., 1936. Zur Genetik von Phaseolus vulgaris. XIII. Ein neues Grundgen für Testafarben, ein weiteres Testafarbgen sowie etwas über Blütenfarben. (With a summary in English.) Hereditas. 22. 241-268. 1 Textf.

Lehmann, E., 1936. Versuche zur Klärung der reziproken Verschiedenheiten von EpilobiumBastarden. I. Der Tatbestand und die Möglichkeit seiner Klärung durch differente Wuchsstoffbildung. Jahrb. f. wiss. Botanjk. 82. 657-668. 4 Textf.

Lendner, A., 1936. L'alcoolisme héréditaire chez le haricot (Phaseolus vulgaris). C. r. Soc. Physique Genéve. 53. 26-28.

Levan, A., 1936. Different results in reciprocal crosses between diploid and triploid allium. Nature. 138. 508.

Lilienfeld, F. A., 1936, Karyologische und genetische Studien an Fragaria. II. Ist Fragaria elatior eine autopolyploide Pflanze? Jap. Journ. of Botany. 8. 119-149. 18 Textf.

Lindegren, C. C., 1936. A six-point map of the sex-chromosome of Neurospora crassa. J. Genet. 32. 243-256.

Lohwag. H.. 1936. Ein Ascomvcet mit gametischem und sporophytischem Mycel. Öst. Lit. Zuivuin. ves. 10u-10y. o 1extr.

Madans, G. u. H. Schindler, 1935. Die Verweiblichung männlicher Maisblüten als ernährungsphysiologische Erscheinung. Deutsche medizin. Wochenschr. 61. Jahrg. 1649 bis 1651 . 
Marheinke, L., 1936. Über den Einfluß von Außenfaktoren auf das Blütenfarbmuster von Petunia hybrida grandiflora, Calliopsis bicolor, Mimulus tigrinus und Primula malacoides. Jahrb. f. wiss. Bot. 83. 593-656. 17 Textf.

McKinney, H. H., 1935. Evidence of virus mutation in the common mosaic of tobacco. J. agricult. Res. 51. 951-981.

Meewes, K. H., 1936. Studien über Kokken. Zentralbl. f. Bakteriologie. II. 94. 1-33.

Melle, van, 1936. Mutations somatiques. Leur valeur et leur rôle dans l'amélioration des plantes. Rev. Bot. appl. 16. 97-104.

Melville, R., 1936. Natural hybrids of Primula elatior. Proc. of the Linnean Society. 148. $161-164$.

Merkensehlager, F., 1936. Die Konstitution der Sojabohne. Die Erneuerung der Pflanze. 32. 189. 4 Textf.

Meyer, Fr., 1936. Odontoglossum in der Natur und Züchtung. Gartenflora. 85. 67-71. 6 'Textf.

Meyer, Fr., 1936. Odontoglossum. II. Bastarde mit den nächstverwandten Gattungen. Gartenflora. 85. 152-156. 3 Textf.

Miège, E., 1936. Sur la descendence et la constitution des lignées à fleurs polycarpiques dans un hybride de Triticum vulgare H. Ann. des sciences naturelles: Botanique. 18. 95-104. 5 Textf.

Miège, E., 1936. L'influence du milieu sur la stabilité des espèces élémentaires d'Hordeum. Ann. des sciences naturelles : Botanique. 18. 105-109.

Moag, H., 1935. Beiträge zur Ampelographie (VI. Mitteilg.). Die Gartenbauwissenschaft. 9. 293. 27 Textf.

Moewus, F., 1936. Faktorenaustausch, insbesondere der Realisatoren bei ChlamydomonasKreuzungen. Ber. d. deutsch. Bot. Ges. 54. Gen.-Vers.-H. 45-57. 3 Textf.

Moffett, A. A., 1936. The genetics of Tropaeolum maius. Journ. of Genetics. 33. 151-161.

Mol, W. de, 1936. Untersuchungen über den Einfluß der Temperatur auf das Entstehen von Modifikationen und Mutationen bei niederländischen Hyazinthenvarietäten. Die Gartenbauwissenschaft. 10. 183. 30 Textf.

Mudra, A., 1936. Weiteres über Zellsaftkonzentration beim Getreide. Zeitschr. f. Züchtnng, Reihe A. 21. 59. 2 Textf.

Müller, K. O., 1936. Die Variabilität der Virulenz und der biologischen Spezialisation bei Phytophtora infestans. Die Naturwissenschaften. 24. Jahrg. H. 35. 552. 1 Textf.

Mung, H., 1936. Über Umzüchtungen von Einzelkulturen des Bacterium typhi flavum in das typische Bacterium typhi Eberth-Gaffky. Arch. f. Hygiene u. Bakteriologie. 116. $45-77.2$ Taf.

Müntzing, A., 1936. Über die Entstehungsweise 56chromosomiger Weizen-Roggen-Bastarde. Der Züchter. 8. 188-191. 2 Textf.

Neatby, K. W., 1936. Factor relations in wheat for resistance to Puccinia graminis tritici, Puccinia glumarum and Erysiphe graminis. Phytopathology. 26. 360-374.

Negodi, G., 1935. Ulteriori ricerche sulla distribuzione e sulla trasmissione dei sessi in Urtica cannabina L. Ann. di Bot. 21. 33-39.

Negodi, G., 1935. Studi sulla sessualità di Silene Roemeri Friv. Ann. di Bot. 21. 61-73.

Negrul, A. M., 1936. Variabilität und Vererbung des Geschlechts bei der Rebe. Die Gartenbauwissenschaft. 10. 215. 18 Textf.

Negrul, A. M., 1936. Inzucht und Heterosis bei der Rebe. Der Züchter. 8. 137-145. 8 Textf.

Nieves, R., 1936. Die Vererbung der Widerstandsfähigkeit gegen den Steinbrand (Tilletia tritici Rasse 5 M. A.) in der Kreuzung Barletta $\times$ Florence. (Spanisch.) Physis (Buenos Aires). 12. 51-63.

Noda, K., 1935. Hybrid vigor in tomato. (Japanisch.) Jap. J. Genet. 11. 124-128.

Oka, T. H., 1936. The progeny of tetraploid tomatoes (Prelim. rep.). Jap. J. Genet. 12. $89-92$.

Ono, H. und D. Satô, 1935. Intergenra hibridigo en cichorieae. II. Hibridoj de Crepidiastrum lanceolatum var. latifolium kaj Paraixeris denticulata. (Esperanto.). Jap. J. Genet. 11. 169-178. 
Padwick, G. W., 1936. Biologic strains of Ophiobolus graminis Sacc. Ann. appl. Biol. 23. $45-56$.

Percival, J., 1936. Aegilotricum ovata-turgidum a fertile species hybrid. Ann. of Bot. 50. $427-436$.

Powers, L., 1936. The nature of the interaction of genes affecting four quantitative characters in a cross between Hordeum deficiens and Hordeum vulgare. Genetics. 21. 398-420.

Rademacher, B., 1935. Genetisch bedingte Unterschiede in der Neigung zu physiologisch bedingten Störungen beim Hafer (Flüssigkeit, Dörrfleckenkrankheit, Urbarmachungskrankheit, Blattröte). Zeitschr. f. Züchtung, Reihe A. 20. 210. 5 Textf.

Rajewsky, B., R. Krebs, H. Zicklor, 1936. Mutationen durch Höhenstrahlung. Die Naturwissenschaften. 24. Jahrg., H. 39. 619.

Raju, M. J., 1936. Studies on the bacterial plant groups. II. Variation in the infective power of the nodule bacteria of Cowpera group. Centralbl. f. Bact. u. Parasit. 94. 337-348. 5 Textf.

Renner, 0., 1936. Kurze Mitteilungen über Oenothera. I. Über eine dominante, semiletale Mutation (taeniata) im flavescens-Komplex der Oenothera suaveolens. Flora. 30. 441-453. 7 Textf.

Renner, O., 1936. Zur Entwicklungsgeschichte randpanaschierter und reingrüner Blätter von Sambucus, Veronica, Pelargonium, Spiraea, Chlorophytum. Flora. 30. 454-466. 14 Textf.

Rhind, D., 1935. A note on photo-periodism in sesanum. Indian J. agricult. Sci. 5. 729-736.

Rhoades, M. M. and B. MeClintock, 1935. The cytogenetics of maize. Bot. Review. 1 . $292-325$.

Rischkow, V. L., 1936. Buntblättrige Chimären und der Ursprung des Mesophylls bei Dicotyledonen. Genetica. 18. 313-336. 11 Textf.

Roemer, Th., 1935. Blütenbiologische Forschungen an Kulturpflanzen. Pflanzenbau. 12. Jahrg. 223. 3 Textf.

Roemer, W., 1935. Fruchtbarkeits- und Vererbungsstudien bei Brassica-Art-Kreuzungen. Zeitschr. f. Züchtung, Reihe A. 20. 377. 24 Textf.

Rohmeder, E., 1936. Zusammenhang zwischen Zapfenfarbe und Knospenentfaltung der Fichte. Forstl. Centralbl. 58. 253-261.

Rubner, R., 1936. Beitrag zur Kenntnis der Fichtenformen und Fichtenrassen. Thar.: Forstl. Jahrb. 87. 101-176. 66 Textf.

Rudloff, C. F., 1935. Venturia inaequalis (Cooke) Aberhold. III. Zur Formenmannigfaltigkeit des Pilzes. Die Gartenbauwissenschaft. 9. 105. 14 Textf.

Sansome, F. W. and S. S. Zilva, 1936. Polyploidy and vitamin C. Biochem. J. 30. 54-56.

Segret, L., 1936. Ranunculus Felixii Segret (R. hololencus $\times$ R. tripartitus). Bull. de la soc. botanique de France. 83. 214-215.

Simonet, M., 1935. Observations sur quelques espèces et hybrides d'Agropyrum. I. Revision de l'Agropyrum juceum (L.) P. B. et l'A. elongatum (Host.) P. P. d'après l'étude cytologique. Bull. Soc. bot. France. 82. 624-632.

Sinotô, Y. und H. Ono, 1935. Intergenra hibridigo en Cichorieae. I. Hibridoj de Crepis capillaris kaj Paraxacum platycarpum. (Esperanto.) Jap. J. Genet. 10. 160-163.

Sörgel, G., 1936. Über heteroploide Mutanten bei Allomyces Kniepii. Nachr. v. d. Ges. d. Wiss. zu Göttingen. Math.-physik. Kl., Fachgr. 6. N. F. 2. 155-170.

Sosa-Bourdouil, C., 1936. Sur les hybrides entre Pisum sativum L. et Pisum Jomardii Schrank. Bull. Soc. bot. France. 83. 69-71.

Sosa-Bourdouil, C. et F. Miège, 1936. Etude des hybrides entre Zea et Euchlaena. I. Hérédite du Taux de l'azote chez Zea mays $\times$ Euchlaena mexicana. Bull. biologique de la France et de la Belgique. 70. 358-369. 4 Textf.

Sehkwarnikow, P. K., 1936. Einfluß hoher Temperatur auf die Mutationsrate bei Weizen, Planta. 25. 471-480. 16 Textf.

Sehkwarnikow, P. K., 1936. Wirkung hoher Temperatur auf die Mutationsrate von Crepis bei verschiedener relativer Luftfeuchtigkeit. Planta. 25. 689-695. 2 Textf. 
Schlenker, G. u. G. Mittmann, 1936. Versuche zur Klärung der reziproken Verschiedenheiten von Epilobium-Bastarden. IV. Internodienwachstum und Zellstreckung bei Epilobium hirsutum unter dem Einfluß synthetischer $\beta$-Indolessigsäure. Jahrb. $f$. wiss. Bot. 83. 315-323. 5 Textf.

Schlenker, G., 1936. Experimentelle Untersuchungen in der Sektion Beccabunga Grisb. der Gattung Veronica. Flora. 30. 305-350. 1 Taf. 25 Textf.

Schlösser, L. A., 1936. Genetik und Entwicklungsphysiologie einer Blütenmißbildung bei der Tomate. Zeitschr. f. ind. Abst.- u. Vererbgsl. 71. 305-321. 10 Textf.

Schmidt, M., 1935. Venturia inaequalis (Cooke) Aderhold. IV. Weitere Beiträge zur Rassen. frage beim Erreger des Apfelschorfes. Die Gartenbauwissenschaft. 9. 364. 7 Textf.

Schmidt, M., 1936. Venturia inaequalis (Cooke) Aderhold. V. Weitere Untersuchungen über die auf verschiedenen Bäumen lebenden Populationen des Apfelschorfpilzes. Gartenbauwissenschaft. 10 . 422-427.

Sehmidt, W., 1936. Rassenbiologische Fragen bei unseren Waldbäumen. Der Naturforscher. 13. $253-258.7$ Textf.

Schmucker, Th. u. H. Griffel, 1936. Entwicklungsphysiologische und morphologische Untersuchungen über Blüten und Blütenveränderungen. Planta. 25. 384-418. 26 Textf.

Stakman, E. C., 1935. Die Bestimmung physiologischer Rassen pflanzenpathogener Pilze. Nova acta Leopoldina. N. F. 3. 279-336. 5 Taf.

Stein, E., 1936. Erbliche, durch Radiumbestrahlung erzeugte Zell- und Gewebeentartung beim Löwenmaul (Antirrhinum majus). Die Naturwissenschaften. 24. Jahrg., H. 22. 337. 6 Textf.

Straib, W., 1936. Auftreten und Verbreitung biologischer Rassen des Gelbrostes (Puccinia glumarum [Schm.] Erikss. et Henn.) im Jahre 1934. Arb. a. d. Biologischen Reichsanstalt f. Land- u. Forstwirtschaft. 91. 455.

Tabuchi, K., 1935. The mutable behaviour of delicate genes in the Japanese morning glory. Journ. of the Coll. of Agric. Imp. Univ. Tokyo. 13. 373-395. 3 Taf. 5 Textf.

Tabuchi, K., 1935. A study on the mutability of the willow leaf in the Japanese morning glory. Journ. of the Čll. of Agric. Imp. Univ. Tokyo. 13. 415-430. 3 Taf. 6 Textf.

Tatebe, T., 1936. Genetic and cytological studies on the $F_{1}$ hybrid of scarlet or tomato eggplant (Solanum integrifolium Poir.) $\times$ eggplant (Solanum melongena L.). The Botanical Magazine. 50, 457-462. 20 Textf.

Tavear, A., 1936. Beitrag zur Vererbungsart der Spindelfärbung an vierkornreihigen Maiskolben. Zeitschr. f. ind. Abst.- u. Vererbgsl. 71. 341-352. 1 Textf.

Teleźyński, H., 1935. Cytological studies on the unstable race of Petunia violacea, Lindl. with mosaic flower patterns. Bull. internat. Acad. polon. Sci., Cl. Sci. math. et natur. S. B. 1, Nr. 4/7. $219-234$.

Ternovsky, M. F., 1935. Erscheinungen der Polyploidie bei Artenbastarden von Nicotiana. Zeitschr. f. Züchtung, Reihe A. 20. 268. 11 Textf.

Uhl, Fr., 1936. Ungewöhnliche Blüten und Blütenstände bei Galanthus nivalis L. und Taraxacum officinale W. Mitt. d. Bayr. Bot. Ges. 4. 277-279.

Ullmann, W., 1936. Natürliche und künstliche Bastardierung zwischen Gräserarten und -gattungen. Forsch.dienst. 1. 655-684.

Uphof, J. C. Th., 1935. Wissenschaftliche Beobachtungen und Versuche an Agrumen. VII. Die Morphologie der Dornen. Die Gartenbauwissenschaft. 9. 219. 10 Textf.

Uphof, J. C. Th., 1935. Wissenschaftliche Beobachtungen und Versuche an Agrumen. VIII. Morpholog. Studien an einem Pfropfbastard zwischen der Apfelsine Rineapple (Citrus sinensis Osbeck) und der Bigarade (C. aurantium L.). Die Gartenbauwissen. schaft. 9. 421. 6 Textf.

Upcott, M., 1936. The parents and progeny of Aesculus carnea. Journ. of Geneties. 33. 135-150. 2 Taf. 24 Textf.

Vogel, G., 1936. Die männliche haploide Generation von Pinus silvestris und ihre Beziehungen zur Hohlkornbildung. Berlin, Phil. Diss. Berlin: Triltsch u. Huther. 51 S. $8^{0}$.

Wakar, B. A., 1936. Neue dreifache Weizenbastarde. Der Züchter. 8. 249-255. 8 Textf.

William, c. H. B. and C. Cameron, 1936. Fertile Sugar Cane $\times$ Millet hybrid. Nature. 137. 830. I Textf. 
Winge, 0̈., 1936. Linkage in Pisum. C. r. Trav. Labor. Carlsberg Sér. physiol. 21. 271-393.

Wit, F., 1936. Contributions to the genetics of the China Aster. Dissertatie Groningen. 104 S. 12 Textf.

Witsch, H. v, 1936. Zur genetischen Grundlage der Blütenscheckung bei Petunia hybrida grandiflora. Nachr. v. d. Ges. d. Wiss. zu Göttingen. Math.-physik. Kl., Fachgr. 6. N. F. 6. $201-213$.

Woodworth, C. M., 1936. Inheritance of seedling stem color in a broomcorn-sorghum cross. J. amer. Soc. Agronomy. 28. 325-327.

Yamamoto, Y., 1935. Über die Intersexe bei Rumex Acetosa. (Japanisch.) Jap. J. Genet. 11. $321-329$.

Yamamoto, Y., 1936. Über den Einfluß von Kaliumchlorat auf getrenntgeschlechtige Pflanzen. Jap. J. Genet. 12. 73-80.

Yamamoto, Y., 1936. Utber das Vorkommen von triploiden Pflanzen bei Mehrlingskeimlingen von Triticum vulgare Vill. Cytologia. 7, No. 3. 431. 14 Textf.

\section{b) Tiere}

Andersen, T., 1935. Utber die Blutgruppeneigenschaften der Schafe. Zeitschr. f. Rassenphysiologie. 7. $171-175$.

Antonius, 0., 1935. Über die Tigerfarbe des Pferdes, insbesondere des Norikers. Zeitschr. f. Gestütkunde u. Pferdezucht. 30. 57, 131. 1 Taf. 1 Textf.

Anerbach, Ch., 1936. The development of the legs, wings and halteres in wild type and some mutant strains of Drosophila melanogaster. Trans. Roy. Soc. Edinburgh. 58. 787 bis 815 .

Bagg, H. J., 1936. Functional activity of the mammary gland in relation to extra-chromosomal influence in the incidence of mammary tumors. Science (N. Y.). 1. 374-375.

Baltzer, F. und V. de Roche, 1936. Über die Entwicklungsfähigkeit haploider Triton alpestris-Keime und über die Aufhebung der Entwicklungshemmung bei Geweben lateraler bastardmerogonischer Kombinationen durch Transplantation in einen normalen Wirt. Revue suisse de zoologie. 43. 495-505.

Beauchamp, P. de, 1935. Observations sur les Dendrocoelum obscuricoles en élevages. C. r. Soc. Biol. Paris. 120. 1289-1290.

Beaument, J. de, 1936. Hymenoptères gynandromorphes. Bulletin de la Soc. vandoises des sc. nat. 59. 85-90. 3 Textf.

Bittner, J. J., 1936. Tumor incidence in reciprocal $F_{1}$ hybrid mice $-\mathrm{A} \times \mathrm{D}$ high tumor stocks. Proc. Soc. exper. Biol. a. Med. 34. 42-48.

Bonnier, G., 1936. Progeny Tests of Dairy Sires. Hereditas. 22. 145-166.

Bovey, P., 1936. Résultats de croisements entre diverses formes de Zygaena ephialtes $\mathbf{L}$. C. r. Soc. Biol. Paris. 122. 598-600.

Brandt, A. E., 1936. A note on dominant white and crest in poultry. Flecks and comb shape make possible identification of heterozygotes. J. Hered. 27. 79-82.

Breider, H., 1936. Eine Erbanalyse von Artmerkmalen geographisch vikariierender Arten der Gattung Limia. Zeitschr. f. ind. Abst.- u. Vererbgsl. 71. 441-499. 35 Textf.

Breider, H., 1936. Eine Allelenserie von Genen verschiedener Art. Zeitschr. f. ind. Abst.u. Vererbgsl. 72. 80-87. 9 Textf.

Breider, H., 1936. Weiteres über die Geschlechtsbestimmung und Geschlechtsdifferenzierung bei Limia vittata Poy. Zool. Anz. 114. 113-118. 3 Textf.

Bridges, C. B., 1936. The bar "gene" a duplication. Science (N. Y.). 1. 210-211.

Buchmann, W. u. N. W. Timoféeff-Ressovsky, 1936. Über die Wirkung der Temperatur auf den Mutationsprozeß bei Drosophila melanogaster. III. Behandlung der Weibchen mit Temperaturschoks. Zeitschr. f. ind. Abst.- u. Vererbgsl. 71. 335-340. 2 Textf.

Buchner, H., 1936. Experimentelle Untersuchungen über den Generationswechsel der Rädertiere. Zeitschr. f. ind. Abst.- u. Vererbgsl. 72. $1-49.14$ Textf.

Carbonero Bravo, L., 1936. Die Genetik in der Vogelzucht. Nueva Zootecnica. 7. 243 bis 247. 
Caspari, E., 1936. Zur Analyse der Matroklinie der Vererbung in der a-Serie der Augenfarbenmutationen bei der Mehlmotte Ephestia kühniella Z. Zeitschr. f. ind. Abst.u. Vererbgsl. 71. 546-555. 1 Textf.

Castle, W. E., 1936. Size inheritance in mice. Amer. Naturalist. 70. 209-217.

Castle, W. E., 1936. Further data on linkage in rabbits. Proc. nat. Acad. Sci. U.S.A. 22. $222-225$.

Castle, W. E., W. H. Gates, S. C. Reed and L. W. Law, 1936. Studies of a size cross in mice, II. Genetics. 21. 310-323.

Castle, W. E. and L. W. Law, 1936. Satin, a new hair mutation of the rabbit, with a chromosome map of the rabbit. J. Hered. 27. 235-240.

Castle, W. E. and S. C. Reed, 1936. Studies of inheritance in lop-eared rabbits. Genetics. 21. $297-309$.

Clemente, L. S., 1936. The lethal effect of homozygous purple and eyeless genes in Drosophila. Philippine J. Sci. 59. 177-187.

Cloudman, A. M. and C. C. Little, 1936. The genetics and tumour formation in mice, in relation to the gene $T$ for Brachyury. Journ. of Genetics. 32. 487-504.

Cochrane, F., 1936. Observations on eye colour development in Drosophila pseudo-obscura. Journ. of Genetics. 32. 183-189. 1 Textf.

Crew, F. A. E., 1936. A repetition of the Dongall's Lamarkian experiment. Journ. of Genetics. 33. 61-103. 11 Textf.

Csik, L., 1936. Einfluß der Temperatur auf die Genwirkung an Drosophila-Flügeln. Arb. ung. biol. Forschgsinst. 8. 371-391.

Csik, L., 1936. Gen- und Temperaturwirkung auf die Zellengröße der Drosophila-Flügel. Arb. ung. biol. Forschgsinst. 8. 392-404.

Csik, L., 1936. Die Zusammenarbeit einiger Gene bei der Determination der Borstenlänge von Drosophila melanogaster, nebst einigen Bemerkungèn über Epistasie. Biolog. Zentralblatt. 56, H. 7/8. 338. 1 Textf.

Dahr, P., 1936. Über A-B-O-Blutgruppen und M-N-Blutfaktoren anthropoider und niederer Affen. Zeitschr. f. Rassenphysiologie. 8. 145-163.

Dantehakoff, V., 1936. Réalisation du sexe à volonté par inductions hormonales. Bull. biologique de la France et de la Belgique. 70. 241-307. 3 Taf. 5 Textf.

Demerec, M., 1936. Frequency of ,cell-lethals" among lethals obtained at random in the X-chromosome of Drosophila melanogaster. Proc. nat. Acad. Sci. U.S.A. 29. 350-354.

Demerec, M. and M. E. Hoover, 1936. Three related X-chromosome deficiencies in Drosophila, differing in extent of deleted material, and in viability. J. Hered. 27. 207-212.

Dobzhansky, Th. and C. C. Tan, 1936. Studies on hybrid sterility. III. A comparison of the gene arrangement in two species, Drosophila pseudo-obscura and Drosophila miranda. Zeitschr. f. ind. Abst.- u. Vererbgsl. 72. 88-114. 1 Taf. 6 Textf.

Donald, H. P., 1936. New mutants and linkage data for Drosophila pseudo-obscura. Journ. of Genetics. 32. 229-242. 1 Taf.

Donald, H. P., 1936. On the genetical constitution of Drosophila pseudo-obscura, race A. Journ. of Genetics. 33. 103-122. 2 Textf.

Donald, H. P., 1936. On the suppression of tangled in Drosophila pseudo-obscura. Proc. of the Royal Society of Edinburgh. 56. 109-128. 2 Taf. 1 Textf.

Dry, F. W., 1936. The genetics of the Wensleydale breed of sheep. II. Colour, fertility, and intensity of selection. Journ. of Genetics. 33. 123-134.

Elder, J. H., 1936. Report of a case of inherited polymastia in chimpanzee. Anat. Rec. 65. $83-88$.

Eloff, G. and D. Moriwaki, 1936. A case of $50 \%$ crossing over in male Drosophila. Nature. 138. 34 .

Eloff, G., 1936. Behaviour of local Drosophila melanogaster during late larval stage. Nature. 138. 402.

Enzmann, E. V. and C. P. Haskins, 1936. Two unusual modifications of eye colour in Drosophila melanogaster. Nature. 138. 165-166.

Ezhikov, J., 1936. Individuelle Variabilität und Optimum. Biol. generalis (Wien). 12, Liefg. 1. 89-104. 
Federley, H., 1936. Sex-limited hereditary cancer in Lepidopterous Larvae. (Mit Zusammenfassung.) Hereditas. 22. 192-216. 13 Textf.

Foerster, R. E., 1935. Inter-specific cross-breeding of Pacific salmon. Trans. roy. Soc. Canada V. Biol. Sci. 3, s. 29. 21-33.

Friesen, H., 1936. Auslösung von Crossing-over bei Drosophila-Männchen durch Röntgenisierung der Imago. Genetica. 18. 187-192.

Friesen, H., 1936. Spermatogoniales Crossing-over bei Drosophila. Zeitschr. f. ind. Abst.u. Vererbgsl. 71. $501-526$.

Geissel, H., 1936. Entwicklungsdauer, Flügellänge und Vitalität ingezüchteter Mehlmottenstämme und ihrer Kreuzungen. Zeitschr. f. ind. Abst.- u. Vererbgsl. 71. 382-416. 16 Textf.

Gleichauf, R., 1936. Anatomie und Variabilität des Geschlechtsapparates von Drosophila melanogaster (Meigne). Zeitschr. f. wiss. Zool. 148. 1-66. 42 Textf.

Gordon, C., 1936. The frequency of heterozygosis in free living populations of Drosophila melanogaster and D. subobscura. Journ. of Genetics. 33. 25-60.

Green, G. V., 1936. Multiple lethal genes in the monse. J. Hered. 27. 181-182.

Green, G. V., 1936. Shifts in expressivity in the heterozygote of a dominant lethal gene in the mouse. J. of exper. Zoöl. 73. 231-262.

Greenshields, F., 1936. Tetraploidy and Hymenoptera. Nature. 138. 330.

Gregory, P. W., V. S. Asmundson and H. Goss, 1936. Glutathione concentration and hereditary size. V. Comparative studies with Barred Plymouth and White Leghorn embryos. J. of exper. Zoöl. 73. 263-284.

Gregory, P. W. and C. T. Blunn, 1936. Curly ${ }_{2}$, a recent dominant mutation in the Norway rat. J. Hered. 27. 39-40.

Grüneberg, H., 1936. Further data on the albino chromosome of the house mouse. Journ. of Genetics. 33. 255-266.

Grüneberg, H., 1936. Inheritance of Tail Tip pigmentation in the house mouse. Journ. of Genetics. 33. 343-345.

Hallauer, C., 1936. Immunitätsstudien bei Hühnerpest. IV. Über vererbte Immunität. Zeitschr. f. Hygiene u. Infektionskrankheiten. 118. 605-614.

Hamburger, V., 1936. The larval development of reciprocal species hybrids of Triton taeniatus, Leyd. (and Triton palmatus, Duges) $\times$ Triton cristatus, Lauv. J. of exper. Zoöl. 73. 319-373.

Hennig, W., 1936. Über einige Gesetzmäßigkeiten der geographischen Variation in der Reptiliengattung Draco L.: ,parallele" und „konvergente" Rassenbildung. Biolog. Zentralblatt. 56, 9/10. 449. 7 Textf.

Herbst, C., 1936. Untersuchungen zur Bestimmung des Geschlechtes. VI. Mittlg.: Neue Gedanken zur Geschlechtsbestimmung bei Tieren. Arch. f. Entwicklungsmech. 135. 178-201. 9 Textf.

Herre, W., 1936. Über den Nasenspiegel des Karakulschafes. Zeitschr. f. Züchtıng, Reihe B. 34. 399. 9 Textf.

Herre, W. und J. Langlet, 1936. Untersuchungen über Haut-, Haar- und Lockenbildung des Karakulschafes. Eine vorläufige Mitteilung. Zeitschr. f. Züchtung, Reihe B. 35. 401.

Holzer, J. F., 1936. Blutgruppenverteilung in Tirol. Zeitschr. f. Rassenphysiologie. 8. $133-144$.

Huestis, R. R. and E. Barto, 1936. Flexed-tailed promyscus. J. Hered. 27. 73-75.

Hutt, F. B., 1936. Genetics of the fowl V: The modified Trizzle. Journ. of Genetics. 32. 277-286. 1 Taf.

Irwin, M. R. and L. J. Cole, 1936. Immunogenetic studies of species and of species hybrids in doves, and the separation of speciens-specific substances in the backcross. J. of exper. Zoöl. 73. 85-108.

Irwin, M. R. and L. J. Cole, 1936. Immunogenetic studies of species and of species hybrids from the cross of Columba livia and Streptopelia risoria. J. of exper. Zoöl. 73. 309 bis 318 . 
Irwin, M. R., L. J. Cole and C. D. Gordon, 1936. Immunogenetic studies of species and of species hybrids in pigeons, and the separation of specific characters in backcross generations. J. of exper. Zoöl. 73. 285-308.

Jakubowa, F., 1935. Der Kampf ums Dasein bei der Schildlaus Chionaspis salicis L. Zool. Z. 14. $712-718$.

Key, K. H. L., 1936. Observations on rate of growth, coloration, and the abnormal sixinstar life-cycle in Locusta migratoria migratorioides, R. u. F. Bull. entomol. Res. 27. $77-85$.

Kikkawa, H., 1936. Two races of Drosophila montium. (A preliminary note.) Jap. J. Genet. 12. 137-141.

King, H. D., 1936. A waltzing mutation in the white rat. J. Mammal. 17. 157-163.

King, S., 1936. Hereditary defects of the corpus callosum in the mouse, Mus. musculus. J. comp. Neur. 64. 337-363. 18 Textf.

Koller, 0., 1935. Die Rassen des westafrikanischen Rotbüffels. Sitzber. d. Akad. d. Wiss. Wien. Math.-nat. Kl., Abt. 1. 419-453. 7 Textf.

Korteweg, R., 1936. Method for comparing the differences of the rate of disposition to cancer in specimens of different strains of mice. Genetica. 18. 337-349. 1 Textf.

Korteweg, R., 1936. On the manner in which the disposition to carcinoma of the mammary gland is inherited in mice. Genetica. 18. 350-371.

Kosminsky, P., 1936. Zum Problem der Intersexualität beim Schwammspinner (Lymantria dispar L.). Zeitschr. f. ind. Abst.- u. Vererbgsl. 71. 420-428.

KoBwig, C., 1936. Nicht homologe Heterochromosomen bei nächstverwandten Arten (Kreuzungen von Platypoecilus maculatus und Pl. xiphidium). Biolog. Zentralblatt. 56. 199.

KoBwig, C., 1936. Homogametische ZZ- und WW-Weibchen entstehen nach Artikreuzung mit dem im weiblichen Geschlecht heterogametischen Platypoecilus maculatus. Biolog. Zentralblatt. 56. 409.

Koßwig, C., 1936. Kleinere Mitteilungen über Art- und Gattungsbastarde von Zahnkarpfen. Zool. Anz. 114. 195-205. 12 Textf.

Kronacher, C., 1936. Eineiige Drillinge. Vorläufige Mitteilung. Zeitschr. f. Züchtung, Reihe B. 35. 413.

Kronacher, C. und F. Hogreve, 1936. Beiträge zur Kenntnis der Grundlagen der Beckenformen bei verschiedenen Schweinerassen, gewonnen an Hand röntgenologischer Studien. Zeitschr. f. Züchtung, Reihe B. 35. 161. 49 Textf.

Kronacher, C., unter Mitarbeit von 0. Sanders, 1936. Neue Ergebnisse der Zwillingsforschung beim Rind. Zeitschr. f. Züchtung, Reihe B. 34. 133. 205 Toxtf.

Krumbiegel, I., 1936. Morphologische Untersuchungen über Rassenbildung, ein Beitrag zum Problem der Artbildung und der geographischen Variation. Zool. Jahrb., Abt. Systematik. 68. 105-178. 1 Taf. 23 Textf.

Krumbiegel, I., 1936. Untersuchungen über gleichsinnige geographische Variation. Zool. Jahrb., Abt. Systematik. 68. $481-516.6$ Textf.

Kühn, A., E. Caspari und E. Plagge, 1935. Utber hormonale Genwirkungen bei Ephestia kühniella Z. Nachr. Ges. Wiss. Göttingen. Math.-physik. Kl., N. F. 2. 1-30.

Kühn, A. und K. Henke, 1936. Genetische und entwicklungsphysiologische Untersuchungen an der Mehlmotte Ephestia Kühniella Zeller. Abh. d. Ges. d. Wiss. zu Göttingen. Math.-phys. Kl. N. F. 15. 225-272. 17 Textf.

Laki, K., 1936. Utber das Augenpigment der Drosophila melanogaster. Arb. ung. biol. Forschungsinst. 8. $356-357$.

Lamprecht, 1936. Utber die Vererbung der Schweinefarben in Rassekreuzungen. Forsch.dienst. 1. $205-217$.

Lang, K., 1936. Ưber einige Fälle von Gynandromorphismus und Mißbildungen bei Endiaptomus gracilis (G. O. Sars). Fysiogr. Sällsk. Lund Förh. 5. 78-81.

Langlet, J., 1936. Zwillingsgeburten in der Karakul-Vollblutzucht. Zeitschr. f. Schafzucht. 25. 41. 5 Textf.

Letard, E., 1935. Une mutation nouvelle chez le lapin. Bull. Acad. vét. France. 8. 608-610.

Lindegren, C. C., 1936. A six-point map of the Sex-chromosome of Neurospora crassa. Journ. of Genetics. 32. 243-256. 1 Taf. 2 Textf. 
Luiers, H., 1936. Erbänderungen durch Radiowellen? Deutsche medizin. Wochenschr. 62. Jahrg. $1330-1332$.

Lüers, H., 1936. Shaker, eine erbliche Bewegungsstörung bei Drosophila funebris. Zeitschr. f. ind. Abst.- u. Vererbgsl. 72. $119-126$.

Lühmann, M., 1936. Untersuchungen über die Vererbung bei Bastardierung von Hausgans und Höckergans. T. 1. Hausgans, Höckergans und Bastard. Eine vergleichende Studie. Berlin. Phil. Diss. Berlin: Funk. 39 S.

MacDowell, E. G., 1936. Genetic aspects of mouse leukemia. Amer. J. Canc. 26. 85-101.

MaeDowell, E. C. and M. N. Richter, 1935. Mouse leukemia. IX. The rôle of heredity in spontaneous cases. Arch. of Path. 20. 709-724.

Manuta, C., 1935. Sul comportamento della permeabilità gliandolare ai pigmenti (flavoui e carotincidi) negli incroci $F_{1}$ tra varie razze di bachi da seta. Boll. Zool. 6. 277-284.

Manuta, C., 1936. Esperienze sul comportamento fisiologico del bianco dominante nei bachi da seta (Bombyx meri). Boll. Zool. 7. 89-93.

Martins, H. und Fr. Kröning, 1936. Meerschweinchenversuche zur Frage der Röntgenstrahlenwirkung auf die Keimdrüsen. Deutsche medizin. Wochenschr. 62. Jahrg. 1049.

Nachtsheim, G., 1936. Was ist eine reine Rasse? Der Kaninchenzüchter. 42. Jahrg. 353,369 . 9 Textf.

Nowikow, B. G., 1936. Die Analyse des Geschlechtsdimorphismus bei den Sperlingsvögeln (Passeres). II. Biolog. Zentralblatt. 56, H. 7/8. 415. 5 Textf.

Nowis, M.T., 1936. Inbreeding in Ephestia kühniella. Journ. of Genetics. 32. $179-182$.

Ökland, F., 1936. Gelingt beim Huhn eine willkürliche Geschlechtsbestimmung durch Sexualhormone? Biolog. Zentralblatt. 56, H. 3/4. 147.

Oordt, G. J. van und G. C. A. Junge, 1936. Die hormonale Wirkung der Gonaden auf Sommer- und Prachtkleid. III. Der Einfluß der Kastration auf männliche Kampfläufer (Philomachus pugnax). Roux' Areh. 134. 112-121.

Per Tuff und S. Berge, 1936. Vererbung der Wirbelzahl und der Körperlänge beim Schwein. Zeitschr. f. Züchtung. Reihe B. 35. 213. 4 Textf.

Pickard, T. N., 1936. A black-blue Dutch rabbit. Journ. of Genetics. 33. 337-342. 1 Textf.

Pickhan, A., N. W. Timoféeff-Ressovsky und.K. G. Zimmer, 1936. Versuche an Drosophila melanogaster über die Beeinflussung der mutationsauslösenden Wirkung von Röntgen- und Gammastrahlen durch Hochfrequenzfeld (Kurzwellen) und Äthernarkose. Strahlenther. 56. 488-496.

Pierantoni, U., 1936. Gli studii sulla endosimbiosi eredituria nelle origini e nei più recenti soiluppi. Archivio zoologico italiano. Suppl. zu 23. 137-195. 15 Textf.

Plagge, F., 1936. Der zeitliche Verlauf der Auslösbarkeit von Hoden- und Imaginalaugenfärbung durch den A-Wirkstoff bei Ephestia und die zur Ausscheidung einer wirksamen Menge nötige Zeitdauer. Zeitschr. f. ind. Abst.- u. Vererbgsl. 79. 127-137.

Prawochenski, R. T., 1936. A case of lethal genes in the horse. Nature. 137. 869.

Ramin, v., 1935. Fragen der Domestikationsforschung unserer Schweine und Fälle ihrer Verwilderung. Zeitschr. f. Schweinezucht. 42. 678.

Reck, B., 1936. Untersuchungen über Faktorenaustausch am X-Chromosom von Drosophila melanogaster. Zeitschr. f. ind. Abst.- u. Vererbgsl. 72. 138-205. 21 Textf.

Reed, S. C., 1936. Harelip in the house mouse. I. Effects of the external and internal environments. Genetics. 21. 339-360.

Reed, S. C., 1936. Harelip in the house mouse. II, Mendelian units concerned with harelip and application of the data to the human harelip problem. Genetics. 21. 361-374.

Robb, R. C., 1936. A study of mutations in evolution. III. The Equine foot. Journ. of Genetics. 33. 267-274. 2 Textf.

Roberts, E. and J. H. Quisenberry, 1936. Linkage studies in the rat. Amer. Naturalist. 70. $395-399$.

Roonwal, M. L., 1936. On the existence of two different types of striped eyes among solitary type specimens of the desert locust Schistocerca gregaria Forsk. Current Sci. 5. 24 . 
Rubaschew, S. J., 1935. Abweichungen von den Elternformen in der embryonalen Entwicklung der Bastarde von Coregonus Baeri Kessl. $\times$ Salmo Fario Lac. L. Acta zool. (Stockh.). 16. 387-408.

Rupprecht; K., 1936. Statistische Erhebungen über die Häufigkeit der Gebißanomalien beim Pferd. Leipzig, Met. vet. Diss. Berlin: Pfau. 41 S. $8^{0}$. 8 Taf.

Samim, V., 1936. Kreuzung zwischen dem ungarischen Rambouillet- und dem albanischen Zackelschaf. Zeitschr. f. Schafzucht. 25. 11. 5 Textf.

Sexton, E. W. and A. R. Clark, 1936. Variations in the white pigment of the eye in Gammarus chevreuxi Sexton, with a description of a new genetic type, the "clotted eye“. J. Mar. biol. Assoc. U. Kingd., N. s. 20. 691-699.

Sladden, D. E., 1935. Transference of induced food-habit from parent to offspring. II. Proc. roy. Soc. Lond. 119. $31-46$.

Speicher, B. R., 1936. Are Hymenoptera tetraploid? Nature. 138. 78.

Smith, H. F., 1936. Influence of temperature on crossing over in Drosophila. Nature. 138. 329.

Schäper, W., 1935. Über todbringende Erbanlagen (Letalfaktoren) in der Schweinezucht. Zeitschr. f. Schweinezucht. 42. 723. 2 Textf.

Schäper, W., 1936. Ist Flachhuf f(Platthuf) ein echter Erbfehler? Zeitschr. f. Gestütkunde u. Pferdezucht. 31. 13.

Schermer, S., 1935. Die Blutgruppen der Haustiere. Verh. 12. internat. tierärztl. Kongr. 3. $536-546$.

Sehermer, S. und A. Kaempffer, 1936. Die Blutgruppen des Pferdes und ihre praktische Bedeutung. Berl. tierärztl. Wochenschr. 145-146.

Schmidt, J., E. Lamprecht und H. Forstheff, 1936. Über die Vererbung des Körperbaues beim Schwein. Forsch.dienst. 1. 694-701.

Schmidt, J., E. Lamprecht und H. Staubesand, 1936. Untersuchungen über die Vererbung der Trächtigkeitsdauer, des Geburtsgewichtes und der Zitzenzahl beim Schwein. Zeitschr. f. Züchtung, Reihe B. 35. 55. 10 Textf.

Steiger, A. L. v., 1936. Über die Haargrundfarbe beim Jagdhund und ihre genetischen Beziehungen zum Nasen- und Irispigment. Der Züchter. 8. 261-271.

Steiner, H., 1935. Vererbungsstudien an Vogelbastarden. I. Einfache monohybride Mendelspaltung beim Artbastard von Amadina erythrocephala $\times$ A. fasciata. Verhandl. der schweiz. naturf. Ges. 116. Jahresvers. 348-349.

Stockard, Ch. R., 1935. Internal constitution and genic factors in growth determination. Cornell Veterinarian. 25. 299-312.

Stockard, Ch. R., 1936. An hereditary lethal for localized motor and preganglionic neurones with a resulting paralysis in the dog. Amer. J. Anat. 59. 1-53.

Stomps, Th., 1936. McDougall's proeven met ratten. Vakblad voor Biologen. 17. 165-170.

Strasburger, E. H., 1936. Über Störungen der Eientwicklung bei Kreuzungen von Epilachna chrysomellna F. mit Epilachna bifasciata F. Zeitschr. f. ind. Abst.- u. Vererbgsl. 71. 538-545. 5 Textf.

Stroeseo, G., 1936. Une nouvell série ,d'allèles multiples" déterminant le caractère „scalloped" et localisée dans le chromosome sexuel chez Drosophila melanogaster. Bull. biologiques de la France et de la Belgique. 1 Taf. 1 Textf.

Strohl, J. und W. Köhler, 1935. Die Wirkung eines pleiotropen Gens auf Färbung, Lebensdauer und Fortpflanzungsfähigkeit der Imago bei der Mehlmotte Ephestia kühniella Z. Nachr. Ges. Wiss. Göttingen. Math.-physik. Kl., N. F. 2. 31-55.

Sturtevant, A. H. and Th. Dobzhansky, 1936. Geographical distribution and cytology of "sex ratio" in Drosophila pseudoobscura and related species. Genetics. 21. 473 bis 490 .

Tanaka, Y., 1934. A hereditary „abnormal segregation" strain produced by X-ray irradiation. (Japanisch; m. engl. Zus.) Jap. J. Genet. 9. 197-207.

Tate, P. and M. Vincent, 1936. The biology of autogenous and anautogenous races of Culex pipiens L. (Diptera: Culicidae). Parasitology. 28. 115-145.

Thomsen, 0., 1936. Untersuchungen über Blutgruppenantigene bei Hühnern. II. Hereditas. 22. $129-144$.

Induktive Abstammungs- und Vererbungslebre. LXXII 
Timoféeft-Ressovsky, N. W. und M. Delbrück, 1936. Strahlengenetische Versuche über sichtbare Mutationen und die Mutabilität einzelner Gene bei Drosophila melanogaster. Zeitschr. f. ind. Abst.- u. Vererbgsl. 71. 322-324. 1 Textf.

Uvarov, B. P. and A. G. Hamilton, 1936. Phase variation and rate of development in the Algerian race of the migratory locust (Locusta migratoria L.). Bull. entomol. Res. 27. 87-90.

Verhoeff, K. W., 1936. Über die ersten durch Domestikation erzielten Isopoden-Rassen. (LIX. Isopoden-Aufsatz.) Z. Morph. u. Ökol. Tiere. 31. 673-681.

Wålstedt, I., 1936. Verschiedene Rassen bei Heterodera Schachtii Schmidt. Der Züchter. 8. 201-208. 1 Textf.

Weinert, H., 1936. Blutgruppenuntersuchungen an Gibbonaffen im Jahre 1934. Zeitschr. f. Rassenphysiologie. 7. 167-170.

Wexelsen, H., 1936. The frillback pigeon. J. Hered. 27. 161-163.

Wiedemann, G., 1936. Modellversuche zur Selektionswirkung von Faktormutationen bei Drosophila melanogaster. Genetica. 18. 277-290. 9 Textf.

Wolff, E., 1936. L'action de l'oestrone sur l'eviducte et le chaque des poussins femelles, intersexués et males. Comptes rendus des séances de la sor de Biologie. 123. 235-239.

Yamane, Y., 1936. Körpergröße und Spermiengröße. Eine vergleichende Untersuchung über die Größe der Spermien beim Pottval, Pferd und Kaninchen. Zeitschr. f. Züchtung. Reihe B. 34. 105.2 Textf.

Zimmermann, K., 1936. Die geographischen Rassen von Epilachna chrysomelina F. und ihre Beziehungen zu Epilachna capsensis Thunbg. Zeitschr. f. ind. Abst.- u. Vererbgsl. 71. 527-537. 11 Textf.

Zurbuchen, K. und F. Baltzer, 1936. Das Tempo der männlichen, weiblichen und intersexuellen Differenzierung bei Bonellia viridis und die Goldschmidtsche Theorie der Geschlechtsbestimmung. Revue Suisse de zoologie. 43. 489-494.

\section{c) Mensch}

Adam, F. et 0. Hansch, 1936. Une mère et ses trois fils (maniaques-dépressifs ou schizophrènes ?) simultanément internés. Ann. méd. psychol. 94 Année. 278.

Albrecht, K. und K. Bonhoeffer, 1936. Die Erbkrankheiten. Klinische Vorträge im 2. erbbiol. Kurs. Berlin, März 1936. Berlin: S. Karger. $178 \mathrm{~S} .8^{\circ}$.

Anonymus, 1935. Ein klassischer Vererbungsfall. Neues Volk. 3. Jahrg., H. 9. 10-11. 5 Textf.

Anonymus, 1935. Wie sich Rassen kreuzen. Neues Völk. 3. Jahrg., H. 10. 34-35. 3 Textf.

Anonymus, 1936. Die Bluterkrankheit als Schulbeispiel eines Erbleidens. Neues Volk. 1. 16-21. 8 Textf.

Anonymus, 1936. Gegen Aberglaube in der Rassenfrage. Neues Volk. 1. 25.

Babonneix, Brissot, Misset et Delsuc, 1936. Maladie de Bourneville (sclérose tubéreuse) à caractère familial et congénital avec association de symptômes de neurofibromatose (maladie de Recklinghausen). Ann. med. psychol. 94e Année. 102-110.

Barraquer, L. und J. de Gispert, 1936. Die Syringomyelie, eine familiäre und hereditäre Krankheit. (13 Fälle in 2 Generationen derselben Familie.) Dtsch. Z. Nervenheilk. 141. 146-157. 4 Textf.

Bauer, H. und J. Meller, 1936. Zur Frage der weiblichen Hämophilie. Zeitschr. f. klin. Medizin. 130. $445-460$.

Bauer, J., 1936. Über die Beziehungen der Vererbungslehre zur Endokrinologie. Schweiz. med. Wochenschr. 1936. 1. 456-460.

Beer, M. A., 1936. Klinisch-genetische Untersuchung über den angeborenen Klumpfuß. (Russisch.) Bulletin de biologie et de médecine expérimentale de l'U.S.S.R., Moscou. 6. $412-413$.

Bell, Julia and T. B. S. Haldane, 1936. Linkage in Man. Nature. 138. 759.

Belser, W., 1936. Die Vererbung der Paradentose. München, Med. Diss. Unterjesingen: Engelbert. 24 S. $8^{0}$. 
Berg, E., 1936. Kasuistischer Beitrag zur Frage von familiärem und erblichem Auftreten der Geschwülste beim Menschen. Freiburg i. B., Med. Diss. Freiburg i. B.: Goldschagg. $15 \mathrm{~S}$. $8^{0}$.

Bernreiter, G., 1936. Treten zu kleine Zähne im Unterkiefer hauptsächlich bei einem Konstitutionstyp auf und ist dieser dadurch besonders gekennzeichnet? München, Med. Diss. München: Bayr. Druck u. Verlags-Anstalt. 24 S. $8^{\circ}$.

Blum, V., 1936. Familiäre essentielle Hämaturie. Medizin. Klinik. 32. Jahrg. 1254-1255.

Boeters, H. und R. Dittel, 1936. Zwillingspathologische Ergebnisse bei Littlescher Krankheit. Deutsche medizin. Wochenschr. 62. Jahrg. 1455-1457.

Bonnevie, K., 1936. Abortive differentiation of the ear vesicles. Genetica. 18. 105-125. 3 Taf. 12 Textf.

Brander, 1935. Über exogenen Schwachsinn, nachgewiesen an Zwillingen. Jahrb. f. Kinderheilkunde. 3. Folge. 95. 313.

Brandt, W., 1936. Konstitutionsstudien. II. Die Bedeutung dreidimensionaler Brustkorb. und Bauchmessungen für die Praktiker; zugleich Mitteilung von Messungsergebnissen bei Drillingen. Medizin. Klinik. 32. Jahrg. 1094-1096.

Brewitz, W., 1936. Die Entnordung der Römer. Volk u. Rasse. 11. Jahrg., H. 9. 369-373. 10 Textf.

Brousseau, M. A., 1936. L'hérédité des affections circulaires. Ann. méd. psychol. 94e Année. $269-270$.

Bruhn, A. M., 1936. Beitrag zu den klinischen" und erbbiologischen Beziehungen bei der Huntingtonschen Chorea an Hand eines bisher noch nicht erfaßten Falles. Allg. Z. Psychiatr. 105. 35-50.

Budde, G., 1935. Ủber familiäres Auftreten der multiplen Sklerose. Würzburg, Med. Diss. Würzburg: Memminger. $46 \mathrm{~S}$. $8^{\circ}$.

Bunak, V. V., 1934. On the ,true sex-ratio“. (Russisch; m. engl. Zus.) Proceedings of the medico-biological institute, Moscou. 3. 195-212. 5 Taf. I Textf.

Bunak, V. V., 1936. Heredity and environment in the variability of structure of skin kapillars. (Russisch.) Bulletin de biologie et de médecine expérimentale de l'U.S.S.R. Moscou. 2. 316. 1 Taf.

Buras, P. C., 1936. Über Hand und Fingerleisten von Indern. Zeitschr. f. Morphologie u. Anthropologie. 35. $519-550$. 3 Taf. 7 Textf.

Burchard, E. M. L., 1936. Physique and Psychosis. An Analysis of the Postulated Relationship between Bodily Constitution and Mental Disease Syndrome. Comp. Psychol. Monogr. 13. 1-73.

Burmester, 1936. Demonstration eines Patienten mit Haemangiom des Gesichts und Rankenangiom des Gehirns und Frage der Sterilisierung. Allg. Z. Psychiatr. 105. 106-107.

Byxkin, J. A., 1934. On the heredity of paroxismal tachycardia. (Russisch; m. engl. Zus.) Proceedings of the medico-biological institute Moscou. 3. 189-194. 2 Textf.

Campbell, B., 1936. The foot musculature of an Australian, a Hawaiian and a Chinese. Americ. Journ. of Physical Anthropology. 21. 19-28. 1 Textf.

Carmena, M., 1935. Ist die persönliche Affektivität oder Nervosität hereditärer Herkunft ? (Spanisch.) Archivos Neurobiol. 15. 79-92.

Cipriani, L., 1936. Eine Rassenuntersuchung bei den Huzulen (Nordkarpathen). Zeitschr. f. Rassenkunde. 4. 124-145. 14 Textf.

Clauss, F., 1936. Germanen und Ursemiten. Der Naturforscher. 13. 112-116. 4 Textf.

Cockayne, E. A., 1936. Cleft Palate, Have lif, Dacryocystitis, and cleft hand and feet. Biometrica. 28. 60-63. 1 Taf. 4 Textf.

Conrad, K., 1936. Erbanlage und Epilepsie. II. Ein Beitrag zur Zwillingskasuistik: Die konkordanten Eineiigen. Z. Neur. 155. 254-297. 14 Textf.

Conrad, K., 1936. Erbanlage und Epilepsie. III. Ein Beitrag zur Zwillingskasuistik: Die diskordanten Eineiigen. Z. Neur. 155. 509-542. 9 Textf.

Curtius. Fr., 1936. Stoffwechselkrankheiten und Vererbung. Staatsmed. Abh. 13. $18 \mathrm{~S}$. $8^{\circ}$. 8 Textf.

Czonthower, S., 1936. Ergebnisse anthropologischer Untersuchungen in der Stomatologie. Wiener klin. Wochenschr. 49. Jahrg. 980-983. 
Davidenkow, S. N., 1935. On the principles of classification of hereditary forms of diseases. (Russisch; m. franz. u. engl. Zus.) Sowiet Psychoneurologie Charkow. 6. 19-29.

Davidenkow, S. N., 1936. Zur Frage der Heredität bei lateraler amyotrophischer Sclerose. (Russ.) Neuropathologie, Psychiatrie und Psychohygiene, Moskau. 4. 515-526. 5 Textf.

Debrunner, H., 1936. Der angeborene Klumpfuß. Deutsche Orthopädie. 10.131 S. 51 Textf.

Dereux, J. et A. Pruvost, 1936. Sclérose en plaques familiale. Revue neur. 65. $351-353$.

Dereux, J., 1936. Sur la sclérose en plaques familiale. Revue neur. 65. 534-535.

Dillon, J. G. and J.B. Gourewitseh, 1934. A twin study of pneumatisation of the nasal accessory sinuses, mastoid processes and the form and dimensions of the sella turcica. (Russisch; m. engl. Zus.) Proceedings of the medico-biological institute Moscou. 3. 68-72. 7 Taf. 2 Textf.

Diory, P. et E. Evrard, 1936. Myotonie dystrophique et débilité motrice. J. belge de Neur. 36 e Année. $386-396$.

Dreyfus, J. R., 1936. Exogene und endogene A- und Hypovitaminose. (Betrachtungen zur Zwillingsrachitis.) Jahrb. f. Kinderheilkunde. 3. Folge. 97. 352-356. 1 Textf.

Eberhard, E., 1936. Das Wesen des Feminismus. (Ưber die Beständigkeit anthropologischer

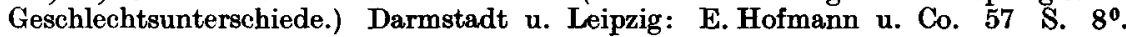

Edel, G., 1936. Beitrag zur Bedeutung der kongenitalen Anlagen und der erworbenen Pneumonien für die Entstehung der kindlichen Bronchiektasen. Arch. f. Kinderheilkunde. 108. 204-212.

Faber, A., 1936. Untersuchungen über die Erblichkeit der Skoliose. Leipzig, Med. Hab. Schr. Leipzig: Edelmann. 217-296. 80.

Fanconi, G., 1936. Der frühinfantile nephrotisch-glykosurische Zwergwuchs mit hypophosphatämischer Rachitis. Jahrb. f. Kinderheilkunde. 97. 3. Folge. 299-338. 12 Textf.

Fisher, R. A., 1936. Heterogenecity of linkage data for Friedrich's Atoxia and the spontaneous Antigens. Annals of Eugenics. 7. 17-21.

Fisher, R. A., 1936. Tests of significance applied to Haldane's data on partial sex-linkage. Annals of Eugenics. 7. 87-104.

Fleisehhauer, H., 1935. Über die angeborene Hüftverrenkung und ihr Zusammentreffen mit anderen Mißbildungen, in Sonderheit mit der Knieluxation, der Kniestreckkontraktur oder dem Klumpfuß. München, Med. Diss. Düsseldorf: Nolte. 15 S. $8^{0}$.

Fleischmann, Fr., 1936. Gemeinsames Vorkommen von Psoriasis und Ichthyosis. Erlangen, Med. Diss. Erlangen-Bruck: Krahl. 24 S. $8^{\circ}$.

Forrai, E., 1936. Die gemeinsamen familiären Erkrankungen von Magen, Gallenblase und Appendix. Wiener klin. Wochenschr. 49. Jahrg. 753-755.

Franceschetti, A. und P. Kiewe, 1936. Eine neue Indikationsstellung zur partiellen, nicht durchgreifenden (lamellierenden) Ceretoplastik: Die familiäre hereditäre Hornhaut. degeneration. Schweizerische medizin. Wochenschr. 66. Jahrg. 528-531. 2 Textf.

Francke, K. H., 1936. Vererbung der Megalocornea. Würzburg, Med. Dis. Düsseldorf: Nolte. 13 S. $8^{\circ}$.

Freytag, H., 1936. Ein Fall von hämolytischer Anämie, dessen gesunde Angehörige nur eine Resistenzverminderung aufweisen. Berlin, Med. Diss. Berlin: Deyhle. $13 \mathrm{~S}$. $\mathbf{8}^{0}$.

Frischeisen-Köhler, J., 1936. Zwillinge in den Familien von Hilfsschülern. Zeitschr. f. menschliche Vererbungs- $u$. Konstitutionslehre. 20. 1-8.

Fuhrmanns, R., 1935. Über Vorkommen, Erbgebundenheit und Behandlungsergebnisse bei 300 Bruchkranken. München, Med. Diss. Quakenbrück: Kleinert. 38 S. $8^{\circ}$.

Fuss, H., 1936. Zur Frage der Erblichkeit des „Turmschädels“. Medizin. Klinik. 32. Jahrg. $1184-1186$ u. $1219-1222$. $2+6$ Textf.

Futer, D., 1936. Familiäre Form von tropischer Störung zur Lehre vom Status dysraphicus. (Russisch.) Neuropathologie, Psychiatrie u. Psychohygiene Moskau. 3. 447-454. 4 Textf.

Gangele, 1935. Erbkrankheiten des Knochensystems. Medizin. Klinik. 31. Jahrg. 1295 bis 1299 . 
Garcin, R., 1936. Sclérose en plaques familiale ou paraplégie spasmodique familiale à forme de sclérose en plaques. Revue neur. 65. $58-60$.

Garrer, H., 1936. Zum Problem der Erbanlage bei Epilepsie. Wiener medizin. Wochenschr. 86. Jahrg. 852-857. 2 Textf.

Gasteiger, H., 1936. Über Erbkrankheiten des Sehorgans. Medizin. Klinik. 32. Jahrg. $1455-1458$.

Gates, R. R., 1936. Recent progress in blood-group investigations. Genetica. 18. 47-65.

Geipel, 1936. Bestehen korrelative Beziehungen zwischen Fingerleistenmustern und den Blutgruppen? Zeitschr. f. Rassenphysiologie. 7. 165-166.

Geyer, E., 1936. Studium am menschlichen Ohr. Stellung und Faltung der Ohrmuschel. Anthropologischer Anzeiger. 13. Jahrg. 101-111. 2 Taf. 4 Textf.

Geyer, E., 1936. Vorläufiger Bericht über die familienanthropologische Untersuchung des ostschwäbischen Dorfes Marienfeld im rumänischen Banat. Verhandlg. d. Gesellsch. f. physische Anthropologie. 7. 5-11. 8 Textf.

Giezelt, G. Fr., 1935. Diabetes mellitus bei Zwillingen. Leipzig, Med. Diss. Leipzig: Edelmann. $37 \mathrm{~S} . \mathbf{8}^{\circ}$.

Glitsch, W., 1936. Parkinsonsyndrom mit Magerkeit bei einem eineiigen Zwilling. Dtsch. Z. Nervenheilk. 141. $9-14$. 2 Textf.

Glitsch, W., 1936. Utber einen Einzelfall von sog. familiärer, akromegelinder Osteose. Zeitschr. f. menschl. Vererbungs- u. Konstitutionslehre. 20. 31-37. 6 Textf.

Gökay, F. K., 1936. Ein Fall von Thomsenscher Krankheit. Psychiatr.-neur. Wochenschr. 38. Jahrg. $349-350$.

Göppel, M., 1936. Über die Vererbung der Prognathie. München: Bayr. Druck- u. Verlagsanstalt. $34 \mathrm{~S}$. $8^{\circ}$.

Gozzano, M., 1936. Sulla istopatologia e la patogenesi della sclerosi laterale amiotrofica. Riv. Neur. 9. $165-216$ u. $304-324$.

Grewel, Fr., 1936. De Anthropologie der tandwisseling. Mensch en Maatschapij. 12. Jahrg. $408-415$.

Grothaus, E., 1936. Untersuchungen über den Erbgang der Dystrophia musculorum progressiva. Freiburg i. B., Med. Diss. Berlin: Springer. $10 \mathrm{~S}, \mathbf{8 0}^{0}$.

Grîneberg, H., 1936. Two independent inherited tooth anomalies in one family. J. Hered. 27. $225-228$.

Grünwald, K., 1936. Über 3 Fälle von Klippel-Feilschem Syndrom. Dtsch. Z. Nervenheilk. 141. 113-122. 8 Textf.

Gusinde, M., 1936. Erforschung der Bambuti-Pygmänen und ihrer Blutgruppen. Zeitschr. f. Rassenphysiologie. 8. 12-20. 4 Textf.

Haag, F. F., 1935. Untersuchungen über allergische Krankheiten. IV. Zur ursächlichen Behandlung von Asthma und Heufieber. Klin. Wochenschr. 14. Jahrg. 1024-1026.

Haldane, J. B. S., 1936. A search for incomplete sex-linkage in man. Ann. of Eugen. 7. $28-57$.

Halla, F., 1936. Mikrophthalmus und Keimschädigung. Wiener medizin. Wochenschr. 86. Jahrg. 606.

Hansing, 1936. Schwachsinn und erbliche Mißbildung. Allg. Z. Psychiatr. 105. $103-106$.

Heernu, J. et L. Massion-Verniory, 1936. Epilepsie-myoclonie. Ann. méd.-psychol. 94 Année. 124.

Herbst, E., 1936. Erbliche Spaltbildungen der Unterlippe mit schweren Kieferdeformationen und Intelligenzstörungen. Volk u. Rasse. 11. Jahrg., H. 7. 276-280. 6 Textf.

Herholz, 1936. Genotypische Faktoren bei Kropferkrankungen. Würzburg, Med. Diss. Würzburg: Mayr. $25 \mathrm{~S}$. $8^{0}$.

Hilgers, J., 1936. Ein Beitrag zur Erbbiologie der seltenen angeborenen Körperfehler an den Gliedmaßen. Orthop. 64. $288-298$.

Hofker, J., 1936. Erfelijkheid van psychische eigenschappen. Erfelijkheid bij de mens. 2. $137-146$.

HoImann, H., 1935. Über die Erblichkeit von Haarform und Haarfarbe. Gießen, Med. Diss. Würzburg: Triltsch. 29 S. 80. 
Hofmann, M., 1936. Vererbung von Spalthand und Spaltfuß. Beobachtungen an zwei Familien. München, Med. Diss. Speyer a. Rh.: Pilger-Druckerei. 31 S. $8^{0}$.

Hoppe, W., 1935. Ähnlichkeiten und Unterschiede an Zwillingsgebissen. Heidelberg, Med. Diss. Walldorf: Lamade. $12 \mathrm{~S} .8^{\circ}$.

Howells, W. M. and H. Hatelling, 1936. Measurements and correlations on Pelves of Indians of the southwest. Americ. Journ. of Physical Anthropology. 21. 91-106.

Ignatiew, M. V., 1934. The measurement of genotypical and paratypical influences on continuous characters by means of the twins method. (Russisch; m. engl. Zus.) Proceedings of the medico-biological institute Moscou. 3. 18-32. 2 Textf.

Ikemi, T., 1935. Die Richtigkeit des Mendelschen Gesetzes über die Vererbung des menschlichen Charakters. Jap. J. Genet. 11. 266-271.

Ikemi, T., 1935. Auftretenshäufigkeit des Fingerabdrucks. (Japanisch.) Jap. J. Genet. 11. $316-317$.

Ikemi, T., 1935. A study of heredity of character. Race Hyg. (Tokyo). 5, 1/2. 171-193.

Imai, Y. and D. Moriwaki, 1936. A probable case of cytoplasmic inheritance in man: a critique of Leber's disease. Journ. of Genetics. 33. 163-168.

Jacob, H., 1936. Eine Gruppe familiärer Mikro- und Mikreucephalie. Z. Neur. 156. 633 bis 645,3 Textf.

Jameison, G. R., 1936. Suicide and mental disease. A clinical analysis of one hundred cases. Arch. of Neur. 36. 1-12.

Jansse, M., 1936. Le mimisme humain et l'anthropologie du langage. Revue Anthropologique. 46. Jahrg. 201-215.

Jeney, E., 1936. Blutgruppenuntersuchungen und deren Bedeutung bei der Vererbung. Orvosképzés. 26. 28-36.

Jentsch, F. R., 1936. Über Nierenerkrankungen bei ein- und zweieiigen Zwillingen (nach Untersuchungen an württembergischen Zwillingen). Hamburg, Med. Diss. Hamburg: Evert. $19 \mathrm{~S} .8^{\circ}$.

Kabakoff, J. B. and J. A. Ryrkin, 1934. An investigation of the electrocardiogram in twins. Second communication. The role of heredity and environment in the variability of the electrocardiogram. (Russisch; m. engl. Zus.) Proceedings of the medicobiological institute Moscou. 3. 73-79. 3 Taf. 4 Textf.

Kabakoff, J. B., J. A. Ryrkin, J. B. Pourevitch, 1934. An investigation of the electrocardiogram in twins. Communication III. On the variability of the peak T. (Russisch; m. engl. Zus.) Proceedings of the medico-biological institute Moscou. 3. 80-85. 3 Taf. 3 Textf.

Karl, E., 1936. Die Fingerabdrücke als Rassenmerkmale und ihr Erbgang. Volk u. Rasse. 11. Jahrg., H. 7. 281-287. 6 Textf.

Kastein, G. W., 1936. Erfelijkheid en epileptische toevallen. Erfelijkheid bij de mens. 2. $147-160$.

Keiber, F., 1936. Neukaledonien - Mitteleuropa. Vergleich der Gesichtszüge. Zeitschr. f. Morphologie u. Anthropologie. 35. 377-393.

Keiber, F. und W: Krause, 1936. Die Größe meßbarer Rassenunterschiede in verschiedenem Lebensalter. Anthropologischer Anzeiger. 13. Jahrg. 135-139.

Kennedy, W. P. and J. MeFarhane, 1936. Blood groups in Iraq. Amer. Journ. of Physical Anthropology. 21. 87-89.

Kersten, G., 1935. Über das Vorkommen von latentem Diabetes in Diabetikerfamilien, zugleich ein Beitrag zur Frage der Erblichkeit des Diabetes. Leipzig, Med. Diss. Würzburg: Mayr. $30 \mathrm{~S} .8^{0}$.

Kienzler, L., 1936. Konstitutionelle Varianten im Erbkreis cerebralneurologischer Defektzustände. Marburg, Med. Diss. Marburg: Koch. 45 S. 80. 8 Taf.

Kirchmair, H., 1936. Ein Syndektilie-Stammbaum. Münchner medizin. Wochenschr. 83. Jahrg. $605-606$.

Kleiweg de Zwaan, J. P., 1936. Messungen an männlichen und weiblichen holländischen Unterkiefern. Ver. d. K. Akad. van wetenschappen te Amsterdam, Afd. Natuurkunde. 35. 29. $\mathrm{S}$ i Textf. 
Klimes, K. und E. Elemér, 1936. Beiträge zur Friedreichschen Ataxie. Dtsch. Z. Nervenheilk. 141. $200-205.4$ Textf.

Knaur, E. A., 1936. Erbforschung in einer schlesischen Bauernfamilie mit Thomsenscher Krankheit. Arch. Psychiatr. 105. 226-240. 2 Textf.

Knorre, G. v., 1936. Ein angeborener Ektodermaldefekt und seine Vererbung. Zeitschr. f. menschl. Vererbungs- u. Konstitutionslehre. 20. 66--72. 6 Textf.

Kohl, R., 1935. Beiträge zur Erblichkeit geistiger Störungen aus der Heil- und Pflegeanstalt Lohr am Main. Würzburg, Med. Diss. Lohr a. M.: Grote. 38 S. $8^{0}$.

Komai, T. und G. Fukuaka, 1936. Frequency of multiple births among the Japanese and related people. Amer. Journ. of Physical Anthropology. 21. 433-447. I Textf.

Köster, H., 1936. Zur Frage der Zahn- und Haaranomalien bei syndaktyler Spalthand- und Spaltfußbildung. Göttingen, Med. Diss. Göttingen: Dieterich. $15 \mathrm{~S} .8^{0}$.

Kneberg, M., 1936. Hair weight as a racial criterion. Amer. Journ. of Physical Anthropology. 21. $279-286$.

Kretzschmer, E., 1936. Konstitution und Rasse. Zeitschr. f. Rassenkunde. 4. 87-88.

Kühne, K., 1936. Die Zwillingswirbelsäule. (Eine erbgenetische Forschung.) Zeitschr. f. Morphologie u. Anthropologie. 35. 1-376. 171 Textf.

Kup, J. v., 1936. Beitrag zur Erblichkeit völliger männlicher Geschlechtsunfähigkeit. Zeitschr. f. menschl. Vererbungs- u. Konstitutionslehre. 20. 27-30.

Lang, Th., 1936. Beitrag zur Frage nach der genetischen Bedingtheit der Homosexualität. Z. Neur. 155. $702-713$.

Lang, W., 1936. Angeborener Schwachsinn. Volk u. Rasse. 11. Jahrg., H. 4. 130-133. 1 Textf.

Lange, B., 1936. Äußere und innere Entstehungsursachen der Tuberkulose. Der Naturforscher. 13. $109-112$.

Lange, C. de, 1935. Über erblichen Diabetes insigniotus. Jahrb. f. Kinderheilkunde. 95, 3. Folge. 1-14.

Laubenthal, F., 1936. Über ,kongenitale Wortblindheit“", zugleich ein Beitrag zur Klinik sog. partieller Schwachsinnsformen und ihrer erblichen Grundlagen. Z. Neur. 156. $329-360$. 1 Textf.

Leblane, E. et J. Bergerot, 1936. Nouvelle contribution à l'étude de l'anthropologie anatomique des Tuareg. Revue anthropolique. 46. Jahrg. 140-150.

Leckel, H., 1935. Über konstitutionelle Disposition zu schwerer Diphterie. Jahrb. f. Kinderheilkunde. 95. 3. Folge. 117-134.

Lehmann, W., 1935. Einige Erblichkeitsfragen in der Kinderklinik. Arch. f. Kinderheilkunde. 106. H. 4. 193-200. I Textf.

Lehmann, W., 1935. Neue Ergebnisse der Erbforschung. Medizin. Klinik. 31. Jahrg. $1211-1214$.

Leicher, H., 1935. Erbkrankheiten des Ohres. Medizinische Klinik. 31. Jahrg. 1096-1098.

Leisehner, A., 1936. Über die Blutgruppenverteilung bei Geisteskrankheiten. Mschr. Psychiatr. 93. 259-277.

Leonhard, K., 1936. Die defektschizophrenen Krankheitsbilder. Ihre Einteilung in 2 klinisch und erbbiologisch verschiedene Gruppen und in Unterformen vom Charakter der Systemkrankheiten. Sammlg. psych. u. neurol. Einzeldarstllg. 11. 134 S. $4^{0}$.

Levin, P. M., 1936. Multiple hereditary Meniangioblastomas of the nervous system. Arch. of Neur. 36. 384-391.

Levit, S. G., 1934. Some results and prospects of twin investigations. (Russisch.) Proceedings of the medico-biological institute Moscou. 3. 5-17. 1 Taf.

Lewis, A., 1936. A case of apparent dissimilarity of monozygotic twins. Annals of Eugenics. 7. 58-64. 11 Taf.

Ley, J. et G. W. Tordeur, 1936. Alexie et Agraphie d'evolution chez des jumeaux monozygotiques. J. belge de Neur. 36e Année. 203-222.

Lindvall, S. und F. Wahlgren, 1936. Fin Fall von Hermaphroditismus verus, Gynandro: morphismus. Virchows Arch. f. pathologische Anatomie u. Physiologie. 997. 1-15. 8 Textf. 
Little, G. C., 1936. The present status of our knowledge of heredity and cancer. J. amer. med. Assoc. 106. 2234-2236.

Loeffler, W., 1935. Exogene und endogene Faktoren in der Genese der Tuberkulosekrankheit. Schweizerische medizin. Wochenschr. 65. Jahrg. 863-866.

Lohoff, W., 1936. Erbhygienische Untersuchungen an Hilfsschulkindern in Oberhausen und Mülheim an der Ruhr. Arch. f. Rassen- u. Gesellschaftsbiologie. 30. 42-64.

Luce, F., 1936. Die Furchen des menschlichen Antlitzes und ihre anatomischen Grundlagen. Gegenbauers morpholog. Jahrbuch. 77. 432-466. 11 Textf.

Malkova, N. N., 1934. The roles of heredity and environment in the variability of bloodpressure and of pulse rate. (Russisch; m. engl. Zus.) Proceedings of the medico-biological institute Moscou. 3. 57-67. 10 Taf.

Malzberg, B., 1936. Migration and mental disease among negroes in New York state. Amer. Journ. of Physical Anthropology. 21. 107-113.

Manchesani, O., 1936. Üher erbliche Blindheit. Münchner medizin. Wochenschr. 83. Jahrg $1167-1171$.

Mathis, H., 1936. Zahnunterzahl und Mißbildungen der Iris. Z. Stomat. 34. 895-909.

Matzdorff, P., 1936. Beziehungen zwischen dem migränösen und dem epileptischen Formenkreise (Migräne, ophthalmoplegische Migräne, Menièreanfälle, epileptische Anfälle). Z. Neur. 156 . $574-593$.

Maude, H., G. Ronart et G. Deshaies, 1936. Hérédité des psychoses maniaques dépressives et discordantes. Ann. méd. psychol. 94e Année. 277.

MeNemar, Q. and L. M. Terman, 1936. Sex differences in variational tendency. Genet. Psychol. Monogr. 18. $1-65$.

Meige, H., 1936. Hérédité spasmodique: torticolis convulsif chez la mère, convulsions faciales chez la fille. Revue neur. 65. 631-632.

Meyer, H., 1936. Untersuchung über erbliche Belastung bei Paralytikern, die nach Malariabehandlung paranoid-halluzinatorische Zustandsbilder bieten. Mschr. Psychiatr. 94. $195-215$.

Michael, J. C. and P. M. Levin, 1936. Multiple telangiectases of the brain. A discussion of hereditary factors in their development. Arch of Neur. 36. 514-529.

Mirenowa, A. N., 1934. Psychomotor education and the general development of preschool children. Experiments with twin controls. (Russisch; m. engl. Zus.) Proceedings of the medico-biological institute Moscow. 3. 86-103. 7 Taf. 7 Textf.

Mirenova, A. N. and V. N. Kolbanovsky, 1934. A comparative evolution of methods for the development of combinative functions in preschool children. Experiments with twin controls. (Russisch; m. engl. Zus.) Proceedings of the medico-biological institute Moscow. 3. 104-118. 1 Taf. 15 Textf.

Moore, W. G. and P. Merrina, 1936. Camptodactylism and its variable expression. J. Hered. 27. 27-30.

Moszkowicz, L., 1936. Die Entstehung des Hermaphroditismus. Wiener klin. Wochenschr. 49. Jahrg. 545-551. 5 Textf.

Müller, H. und H. Klar, 1936. Was wissen wir über die multiple Sklerose, und was muß der praktische Arzt über sie wissen. Medizinische Klinik., 31. Jahrg. 625-630.

Muraz, G., 1936. Aperçu sur la mortalité infantile et contribution à l'étude de la tache mongolique dans une cité sinoannamite. Revue anthropologique. 46. Jahrg. 27-49.

Muyle, G. et R. Batselaere, 1936. Contribution à l'étude du syndrome dénommé ,:mains et pieds en fourche". J. belge de Neur. 36e Année. 441-455.

Natter, H., 1936. Ein Fall von lebend geborenen monamniotischen Zwillingen. München, Med. Diss. München: Händi. $18 \mathrm{~S} .8^{0}$.

Neugebauer, W., 1935. Neuere Ergebnisse auf dem Gebiet der Blutgruppenforschung. Medizin. Klinik. 31. Jahrg. 603-606.

Neugebauer, W., 1936. Neuere Ergebnisse der Blutgruppenforschung. Medizin. Klinik. 32. Jahrg. 636-639.

Nigmann, J., 1936. Über Hämophilie. Würzburg Med. Diss. Würzburg: Mayr. 28 S. $8^{0}$.

Oehler, F., 1936. Über die Erblichkeit der ekto-mesodermalen Blastomatosen unter besonderer Berücksichtigung der familiären Hirntumoren. Arch. Psychiatr. 105. 324-357. 
Österreicher, W., 1936. Heredefamiliäres Syndrom: Morbus Parkinson juvenilis mit spastischer Spinalparalyse bei Inzucht in einer psychopathischen Familie. Medizin. Klinik. 32. Jahrg. 1494-1496.

Ostertag, M. und D. Spaich, 1936. Über die Pterygiumkrankheit und ihr diskordantes Vorkommen bei einem eineiigen $Z$ willingspaar. Dtsch. $Z$. Nervenheilk. 141. 1-8. 5 Textf.

Panse, Fr., 1936. Erbfragen bei Geisteskrankheiten. Nach Vorträgen an der Staatsmed. Akademie Berlin. Staatsmedizin. Abhandlg. 14. $75 \mathrm{~S} .8^{0}$. 2 Textf.

Penrose, L. S., 1936. Autosomal mutation and modification in man with special reference to mental defect. Annals of Eugenics. 7. 1-16.

Pfeiffer, W., 1936. Sippenuntersuchungen bei Kretinen. Würzburg, Med. Diss. Würzburg: Memminger. $13 \mathrm{~S}$. $8^{0}$. 1 Taf.

Pfister, R., 1936. Beitrag zur Kenntnis der diffusen Hirnsklerose. Arch Psychiatr. 105. 1-16. 6 Textf.

Picard, J. et H. Fy, 1936. Premiers résultats de quelques investigations généralogiques en Beauce. Ann. méd. psychol. 94e Année. 277.

Pittard, E. und J. J. Breitenbucher, 1936. A propos du rythme de croissance de quelques régions de la tête. Revue anthropologique. 46. Jahrg. 5-26.

Popoviein, G. und S. Biran, 1936. Nouvelles contributions à l'étude des isohémagglutinins en Roumanie. Revue anthropologique. 46. Jahrg. 181-189.

Price, B., 1936. Homogamy and intercorrelation of capacity traits. Annals of Eugenics. 7. $22-27$.

Prigozhina, A., 1936. Hereditäre Degeneration der Macula lutea. (Russisch.) Sowiet ophtalmologische Nachrichten Moskau. 8. 820-831. 2 Textf.

Quirós, M., 1936. Erbbiologischer Beitrag zur Kenntnis der Myotonie. Bonn, Med. Diss. Bonn: Trepp. $41 \mathrm{~S} .8^{\circ}$. 1 Taf.

Radleff, L. J., 1936. Sind Verschiedenheiten der Zahnbreiten bei weiblichen und männlichen Bulgaren festzustellen? Würzburg, Med. Diss. Würzburg: Mayr. $44 \mathrm{~S}$.

Reichmann, G., 1935. Die Erblichkeit des Nasenblutens bei Gefäßerweiterungen am Locus Kiesselbach. Tübingen, Med. Diss. Urach: Buhler. 21 S. $8^{0}$.

Reichmann, T., 1935. Utber einen Fall von Neurofibromatosis pigmentosa (Recklinghausen). Rostock, Med. Diss. Rostock: Neumann. 30 S. $8^{0}$.

Renk, W., 1935. Statistische Untersuchungen über die Vererbung kariesresistenter Gebisse. Tübingen. Med. Diss. Werne a. d. Lippe: Grube. $43 \mathrm{~S} .8^{0}$.

Reynolds, E. und E. A. Hooton, 1936. Relation of the pelvis to erect posture. Amer. Journ. of Physical Anthropology. 21. 253-278. 3 Textf.

Ritterskamp, P., 1936. Eine Familie mit Komptodaktylie. Münchner medizin. Wochenschr. 83. Jahrg. $724-725$.

Rittmeister, J. F., 1936. Über die Affenfurche (Vierfingerfurche), mit besonderer Berücksichtigung der Mikrodegeneration und des Problems des Mongolismus. Zeitschr. f. Anatomie u. Entwicklungsgesch. 106. 276-314. 35 Textf.

Roemer, H., 1936. Zur nosologischen und erbbiologischen Beurteilung der Puerperalpsychosen. Z. Neur. 155. 555-591.

Röll, A. und J. L. Entres, 1936. Zum Problem der Erbprognosebestimmung. Die Erkrankungsaussichten der Neffen und Nichten von Manisch-Depressiven. Z. Neur. 156. $169-202$. 1 Textf.

Rosenstein, A. M., 1936. Mikrophthalmus und Keimsehädigung. Wiener medizin. Wochenschrift. 86. Jahrg. 606 .

Roth, Fr., 1936. Erbfaktoren der Katarakta coronaria coerulea. München, Med. Diss. Würzburg: Mayr. $17 \mathrm{~S} .8^{\circ}$. 1 Taf.

Rottmann, A., 1936. Zur Pathogenese und Erbbiologie der progressiven Muskeldystrophie. Mschr. Psychiatr. 93. 309-322.

Rüffer, H., 1936. Beziehungen der Biß- und Kieferform zur Gesichtshöhe und Gesichtsbreite bei versehiedenen Rassen. Leipzig, Med. Diss. Leipzig: Moltzen. $19 \mathrm{~S} .8^{\circ}$.

Saettele, R., 1936. Untersuchungen an deutschstämmigen Schulkindern im Staate Espirito Santo in Brasilien und kurze Erörterung der Haupterkrankungen dieser Volksgruppe. Arch. f. Schiffs- u. Tropenhygiene. 40. 495-502. 
Sanders, J., 1936. Eine Familie mit Kraushaar. Genetica. 18. 97-104. 11 Textf.

Sanser, G., 1936. Kombination und Korrelation anatomischer Varietäten. Wiener klin. Wochenschr. 49. Jahrg. 645-648.

Schilling, V., 1936. Blut und Erbe. Über die Eigenschaften des Blutes, seine Aufgaben im menschlichen Körper und über seine Rolle als Vererbungsträger mit Einschluß der erblichen Blutkrankheiten. Hamburg: Hans. Verlags-Anst. $94 \mathrm{~S}$.

Schlottky, J., 1936. Zur Genealogie psychopathischer Schwindler und Lügner. Volk u. Rasse. 11. Jahrg., H. 4. $137-140$.

Scholz, P., 1936. UUber familiären Zwergwuchs. Heidelberg, Med. Diss. Berlin: Vogel. $9 \mathrm{~S} .8^{0} .3$ Textf.

Schneider, P., 1936. Über einen Fall von hereditärer Opticusatrophie (Lebersche Krankheit). Würzburg, Med. Diss. Würzburg: Becker. $24 \mathrm{~S} .8^{0}$.

Schreiber, G., 1936. L'examen medical prenuptial, ses modalités et ses consequences. Genetica. 18. 10-37.

Schtschelkanowa, T. P., 1936. Zur Frage über die Erblichkeit der Otosklerose. (Russisch.) Arch. d. sowjet oto-rhino-laryngologie Leningrad. 1. 41-46. 4 Taf.

Schulz, K., 1935. Zur Vererbung und anthropologischen Bedeutung der Blutgruppen. Zeitschr. f. Rassenphysiologie. 7. 161-164.

Schultz, B. K., 1936. Rassenkundliche Beobachtungen an den Olympiakämpfern. Volk u. Rasse. 1l. Jahrg., H. 9. 363-368. 18 Textf.

Shanklin, W. M., 1936. Blood grouping of the Manaly and Akeydat Bedonin. Amer. Journ. of Physical Anthropology. 21. 39-18.

Shanklin, W. M., 1936. Anthropolcgy of the Akeydat and the Manaly Bedonin. Amer. Journ. of Physical Anthropology. 21. 216-252.

Sjövall, B., 1936. Dystrophia musculorum progressiva. Eine erblichkeitsmedizinische und klinische Studie. Acta Psychiatrica et Neurologica. Suppl. 10. $240 \mathrm{~S}$.

Smirnow, B. et J. Skobsky, 1936. Famille turcomane présentant une amyotrophie héréditaire atypique. Revue neur. 66. 390-403.

Smith, J. Chr., 1936. Dementia praecox-Probleme. Untersuchungen hinsichtlich Häufigkeit, Erblichkeitsverhältnisse, die gegenseitige Beziehung der klinisohen Untergruppen, ihre spezielle Disposition, biologische Reaktionen und andere. Z. Neur. 156. 361-381.

Smith, J. Chr., 1936. Probleme der Dementia praecox. Untersuchungen über Häufigkeit, Erblichkeit, gemeinsame Züge der klinischen Gruppen, ihre spezielle Disposition, biologische Reaktionen u. a. Bibl. Laeg. 128. $1-28$ u. 31-46.

Snyder, L. H. and H. C. Yingling, 1935. Studies in human inheritance. XII. The application of the gene-frequency method of analysis to sex-influenced factors, with especial reference to baldness. Human Biol. 7. 608-615.

Stadtmeister, R., 1936. Neuere Erhebungen zur Pelgerschen familiären Kernanomalie. II. Das Verhalten des Knochenmarks bei der Pelgerschen familiären Kernanomalie. Deutsches Arch. f. klin. Medizin. 179. 159-162.

Staemmler, M., 1936. Nikotin und Keimdrüsen. Münchner medizin. Wochenschr. 83. Jahrg. $658-659$.

Stagnitti, G., 1936. L'ereditarietà della tubercolosi in rapporto all'essistenza del virus filtrabile. Padova: Cedam. 33 S. $8^{0}$.

Stark, G., 1935. Über angeborenen, teilweisen Riesenwuchs. München, Med. Diss. Langensalza: Thomas. $50 \mathrm{~S}$. $8^{0}$.

Steidle, E., 1936. Über ein eigentümliches angeborenes Erbleiden, eine Fibrose der Kiefer. Würzburg, Med. Diss. Würzburg: Triltsch. $11 \mathrm{~S} .8^{\mathbf{0}}$.

Steindler, R., 1935. Beiträge zur Differentialdiagnose der Myatonie congenita Oppenheim und der frühinfantilen progressiven spinalen Muskelatrophie Verding-Hoffmann. Arch. f. Kinderheilkunde. 106, H. 4. 235-241. 8 Textf.

Steiner, F., 1936. Zur Erblichkeit der Hypospadie. Münchner medizin. Wochenschr. 83. Jahrg. 1271.

Steiner, F., 1936. Beobachtungen zur Frblichkeit der Basedowschen Krankheit, das BiedlLawrenceschen Syndroms und der Cholelithiasis. Zeitschr. f. menschl. Vererbungsu. Konstitutionslehre. 20. 73-77. 
Steinhauser, 1935. Eineiige Zwillinge? Blätter f. Gefängniskunde. 66. 365-374.

Steinmann, I., 1936. Genealogische Ermittlungen in 4 Familien mit Westphal-Wilsonscher Pseudosklerose; neurologische und psychische Besonderheiten im klinischen Bild bei 4 erkrankten Geschwisterpaaren. Arch. Psychiatr. 105. 514-538.

Stefko, W., 1936. Pathologische Anatomie d. Syphilis u. kombinierte Fälle von Syphilis u. Tuberkulose der Lymphdrüsen bei Lunjäten. Beitrag zur Rassenpathologie der Syphilis. Zeitschr. f. Rassenphysiologie. 8. 52-65. 7 Textf.

Stosch, H., 1936. Vergleichende Beobachtungen zum Familienkreis von Schizophrenen und Epileptikern. Breslau, Med. Diss. Ratibor: Oberschl. Ges.-Druck. 30 S. $8^{0}$.

Strukow, A. J., 1936. Morphologische Besonderheiten des Kehlkopfes bei einigen Mongolen. Zeitschr. f. Rassenphysiologie. 8. 91-96.

Stumpfl, F., 1936. Ûber Diskordanz bei psychopathischen Zwillingen. Nervenarzt. 9. Jahrg. $385-392$.

Stumpfl, F., 1936. Über erbliche Bedingtheit von schwerem Alkoholismus: Ein Zwillingsfall. Mschr. Kriminalpsychol. 27. Jahrg. 326-328.

Tallme, K. S., 1936. Besteht eine erblich faßbare Schwäche der Niere für die Nephritis als Scharlachkomplikation? Hamburg, Med. Diss. Harburg-Wbg.: Triess. $15 \mathrm{~S} .8^{0}$.

Thums, K., 1936. Neurologische ${ }^{*}$ Zwillingsstudien. I. Mitteilg. Zur Erbpathologie der multiplen Sklerose. Eine Untersuchung an 51 Zwillingspaaren. Z. Neur. 155. 185 bis 253.10 Textf.

Tischler, M., 1936. Osteopsagyros, blaue Skleren und Vererbung. Berlin, Med. Diss. Berlin: Michel. 27 S. $8^{\circ}$.

Trotter, M., 1936. The hair of the Arabs of Central Iraq. Amer. Journ. of Physical Anthropology. 21. 423-428.

Troeger, K., 1936. Eltern- u. Geschwisterschaften von 100 paralytischen Probanden. Ein Beitrag zur Frage der Belastung bei Paralyse. Z. Neur. 156. 1-28.

Tschirn, W., 1936. Zur Frage der Huntingtonschen und Wilsonschen Krankheit im gleichen Familienstamm. Breslau, Med. Diss. Breslau: Vater. $39 \mathrm{~S} .8^{0}$.

Usher, C. H., 1935. On a few hereditary eye affections. Trans. ophthalm. Soc. U. Kingd. 55. $164-245$.

Venzke, 1936. Organische Nervenkrankheiten bei Zwillingen. Berlin, Med. Diss. Charlottenburg: K. u. R. Hoffmann. 34 S. $8^{0}$.

Venzmer, G., 1936. Sieh dir die Menschen an. Was uns die biol. Verwandtschaft zwischen Körperform und Wesenskern des Menschen verrät. 15. Aufl. Stuttgart: Franckh. $85 \mathrm{~S} .3$ Taf.

Vialetto, E., 1936. Contributo alla forma ereditaria della paralisi bulbare progressiva. Riv. sper. Freniatr. 60. 1-23.

Vogt, A., 1935. Die senile Determination des Keimplasmas, beobachtet an eineiigen Zwillingen des 55.-81. Lebensjahres. Schweizer. medizin. Wochenschr. 65. Jahrg. $576-579$.

Vorwahl, H., 1936. Selbstmord und Rasse. Münchner medizin. Wochenschr. 83. Jahrg. $767-768$.

Vonte, P. A., 1935. Die differentielle Diagnostik von Zwillingen. Eine Studie über die Nach. geburt, die Schwangerschaft und über die Methode der Untersuchungen von ein- und zweieiigen Zwillingen. Utrecht: Diss. $224 \mathrm{~S}$.

Waardenburg, P. J., 1936. Über familiär-erbliche Fälle von seniler Makula-Degeneration. Genetica. 18. 38-46.

Wahn, R., 1936. Zum Erbgang der Friedreichschen Ataxie. Z. Neur. 156. 148-168. 1 Taf.

Wakefield, E. G. and S. C. Dellinger, 1936. A report of identical albino twins of Negro parents. Ann. int. Med. 9. $1149-1153$.

Walther, E., 1935. Befunde an Zwillingsgebissen. Heidelberg, Med. Diss. Coburg: TagblattHaus. $14 \mathrm{~S} .8^{\circ}$.

Weidenmïller, K., 1936. Beitrag zur Frage der Erbbedingtheit der Spina bifida. Ein Fall von familiärer Spina bifida aperta. Zeitschr. f. menschl. Vererbungs- u. Konstitutionslehre. $20.42-65.12$ Textf. 
Weinberg, J. und J. Labstein, 1936. Beitrag zur Vererbung des manischdepressiven Irreseins. Psychiatr. Bl. Nr. 1a. 339-370.

Weinmann, H., 1936. Über die Vererbung des angeborenen Stars. Würzburg, Med. Diss. Neustadt a. d. Aisch: Schmidt. $13 \mathrm{~S} .8^{\circ}$.

Weissenfeld, F., 1936. Neue Gesichtspunkte zur Frage der Konstitutionstypen. Z. Neur. 156. $432-478$. 19 Textf.

Weitkamp, H., 1936. Über eine Kropffamilie mit gehäuften Störungen der inneren Sekretion. Hippokrates. 7. Jahrg. 321-325.

Weitz, W., 1936. Die Vererbung innerer Krankheiten. Stuttgart: Enke. XI, 197 S. $8^{\circ}$. 67 Textf.

Wellisch, S., 1936. Das vorhandene Untersuchungsmaterial im MN-System. Zeitschr. f. Rassenphysiologie. 8. $85-91$.

Welliseh, S., 1936. Stand und Ergebnisse der Blutgruppenforschung. Münchner medizin. Wochenschr. 83. Jahrg. 1124.

Weninger, M., 1936. Untersuchungen über das Hautleistensystem der Buschmänner. Ein Beitrag zur Stellung der Buschmannrasse. Mitteilgn. d. Anthropologischen Gesellsch. in Wien. 66. $30-45$.

Weyeneth, R., 1936. Sieben verschiedene Typen des Hermaphroditismus externus, glandularis et neuter beim Menschen. Virchows Arch. f. pathologische Anatomie u. Physiologie. 297. $594-626.12$ Textf.

Weygandt, 1936. Hysterie als Erbkrankheit. Z. Neur. 155. 758-782.

Wiener, A. S., et alii, 1936. The inheritance of allergie disease. Ann. of Eugenics. 7. $141-162$.

Winkel, Ch. W. F., 1936. Die Blutgruppenverteilung bei den Abessiniern. Zeitschr. f. Rassenphysiologie. 8. $189-190$.

Wolff, P., 1936. Zystisches Riesenneurinom des Dünndarms bei familiärer Neurofibromatose (Recklinghausen). Schweizer. medizin. Wochenschr. 66. Jahrg. 379.

Wördehoff, 1936. Über die Bedeutung der Vererbung in der Ätiologie der Innenohrschwerhörigkeit. Würzburg, Med. Diss. Würzburg: Mayr. $19 \mathrm{~S}$.

Worsaal, E., 1935. Über die Blutkörperchenrezeptoren $A_{1}$ und $A_{2}$ bei Neugeborenen. Zeitschr. f. Rassenphysiologie. 7. 145-160.

Zacho, A., 1936. „Unverträglichkeit“ zwischen Blutproben vom gleichen Bluttypus, beruhend auf dem Vorhandensein eines irregulären Ägglutinins gëgenüber einem bisher unbekannten Rezeptor. Zeitschr. f. Rassenphysiologie. 8. 1-11.

Zador, J., 1936. Le spasme de torsion. Parallèle des tableaux cliniques entre la race juive et les autres races. Revue neur. 66. 365-389.

Zeller, R., 1936. U̇ber familiäres Auftreten von Hyperphalangie und Polydactylie des Daumens und die Erblichkeit der Pseudoepiphysen. Bonn, Med. Diss. Bonn: Brand. 32 S. $.8^{\circ}$.

Zieve, I. et alii, 1936. On the linkage relations of the genes for allergic diseases. Ann. of Eugenics. 7. $163-178$.

Zih, A., 1936. Blutgruppen und Blutkörperchen-Senkungsgeschwindigkeit. Klin. Wochenschrift. 15. Jahrg. 1203. 1 Textf.

Zsakó, St., 1936. Schulterblatt-Entwicklungsabnormität, durch drei Generationen. Psychiatr.-neur. Wochenschr. 38. Jahrg. 394-395.

Zündel, W., 1936. Neuere Erhebungen zur Pelgerschen familiären Kernanomalie. I. Beobachtungen an zwei weiteren Familien mit Pelgerscher familiärer Kernanomalie. Deutsches Arch. f. klin. Medizin. 179. 151-158. 2 'Textf.

Zwanger, L., 1936. Vererbung der Cataracta zonularis. Tübingen, Med. Diss. Tübingen: Brecht. 18 S. $8^{\circ}$. 
III. Arbeiten über Abstammungslehre, ausgehend von Tatsachen der vergleichenden Anatomie, Physiologie (Serologie) und Entwicklnngsgeschichte, der Tier- und Pflanzengeographie

\section{a) Pflanzen}

Beatus, R., 1936. Die Veronica-Gruppe Agrestis der Sektion Alsinebe Griseb, ein Beitrag zum Problem der Artbildung. I. die Zytologie der Gruppe Agrestis. Zeitschr. f. ind. Abst.- u. Vererbgsl. 71. 353-381. 11 Textf.

Filzer, P., 1936. Pflanzengemeinschaft und Umwelt. Ergebnisse und Probleme der bot. Standortsforschung. Stuttgart: Ferd. Enke. 1. 35.

Hesmer, 1936. Die Waldentwicklung im ostpommerschen Endmoränengebiet. Forstarchiv. 12. 288-295. 7 Textf.

Kienitz, E., 1936. Wandlungen des Holzartenbildes im sächsischen Staatswalde seit dem 16. Jahrhundert, mit Ausblick auf die Pollenanalyse. Tharnd. Forstl. Jahrb. 87. $285-326,370-413,460-523,641-690$.

Markgraf, Fr., 1936. Blütenbau und Verwandtschaft bei den einfachsten Helobiae. Ber. d. deutsch. Bot. Ges. 54. 191-229. 8 Taf.

Mez, C., 1936. Morphologie und Serodiagnostik, erläutert an Blüte und Blütenstand, vom Irreversibilitätsgesetz aus gesehen. Bot. Archiv. 38. 86-104.

Rohweder, H., 1936. Die Bedeutung der Polyploidie für die Anpassung der Angiospermen an die Kalkgebiete Schleswig-Holsteins. Beih. z. bot. Zentralblatt. j4. 507-519.

Sonèges, R., 1936. Les relations embryogéniques des Crassulacées, Saxifragacées et Hypericacées. Bull. de la Soc. Botanique de France. 83. 317-329. 2 Textf.

Tumanjan, M. G., 1935. Die wildwachsenden Verwandten der kultivierten Weizen in Armenien. Zeitschr. f. Züchtung, Reihe A. 20. 352. 7 Textf.

Winkler, H., 1936. Habitus und Phylogenie. Beitr. z. Biol. d. Pflanzen. 24. 1-11. 5 Textf.

\section{IIIb) Tiere}

Adametz, L., 1936. Untersuchungen über den Schädelbau der Rinder Bocharas mit Rücksicht auf deren Herkunft und Abstammung. Zeitschr. f. Züchtung, Reihe B. 35. 239. 12 Textf.

Antonius, 0., 1936. Zur Abstammung des Hauspferdes. Zeitschr. f. Züchtung, Reihe B. 34. 359. 13 Textf.

Arnold, W., 1935. Das Auge von Hypogeophis. Beitrag zur Kenntnis der Gymnophionen. XXVII. Gegenbaurs Morphologisches Jahrb. 76, H. 4. 589-625. 22 Textf.

Bernhardt, F., 1935. Ein Spiraldarm in der Gymnophionenentwicklung. Beitrag zur Kenntnis der Gymnophionen. XXVI. Gegenbaurs Morphologisches Jahrb. 76, H. 4. 495. 6 Textf.

Bierens de Haan, J. A., 1936. Nog eens Mcdougalls' rattenproeven. Vakblad voor Biologen. 17. $170-175$.

Blaszyk, P., 1935. Untersuchungen über die Stammesgeschichte der Vogelschuppen und Federn und über die Abhängigkeit ihrer Ausbildung am Vogelfuß von der Funktion. Gegenbaurs Morphologisches Jahrb. Akad. Verlagsanst. Leipzig. 75, H. 4. 483-567. 5 Textf.

Breider, H., 1936. Eine Erbanalyse von Artmerkmalen geographisch vikariierender Arten der Gattung Limia. Zeitschr. f. ind. Abst.- u. Vererbgsl. 71. 441-499. 35 Textf.

Broek, A. J. P. van den, 1936. Das Nierensystem der Vertebraten, eine theoretische Betrachtung. Gegenbaurs Morphologisehes Jahrb. 77. 467-509. 16 Textf.

Butz, 0., 1935. Die Entstehung und Entwicklung unserer Hausschweine. Zeitschr. f. Schweinezucht. 42. 612. 7 Textf.

Connolly, C. J., 1936. The fissural pattern of the primate brain. Amer. Journ. of Physical Anthropology. 21. 301-422. 67 Textf.

Epstein, H., 1935. Abstammung des Afrikanderrindes. Nueva Zootecnica. 7. 175-182. 
Gulat, K., 1936. Die Entwicklung der Schneidezähne der Nagetiere unter besonderer Berücksichtigung der Kapillaren. Gegenbaurs Morpholog. Jahrb. 77. 382-399. 6 Textf.

Harting, K., 1935. Bemerkungen über die Entwicklung des Hornhautendothels. Zeitschr. f. Mikroskopisch-Anatomische Forschung, Akad. Verlagsges. Leipzig. 38, 1. 123 bis 130. 8 Textf.

Hartmann, M. und H. Huth, 1936. Untersuchungen über Geschlechtsbestimmung und Geschlechtsumwandlung von Ophryotrocha pucrilis. Zool. Jahrb., Abt. Allg. Zool. j6. $389-439$. 17 Textf.

Katznelson. Z. S., 1936. Entwicklung der myotomalen Muskulatur bei Urodelen. Zeitschr. f. Mikroskopisch-Anatomische Forschung. 40. 474-530. 24 Textf.

Knese, K. H., 1936. Das Kopfgelenk der aquatilen Säugetiere. Gegenbaurs Morpholog. Jahrb. 78. 314-376. 46 Textf.

Krikunov, M. und T. Molathowa, 1936. Zur Frage über die Innervation der Mm. intercostales bei den Haussäugetieren. Gegenbauers Morpholog. Jahrb. 77. 692_697. 2 Textf.

Kripp, D. v., 1935. Bau, Funktion und Ableitung des Bewegungsmechanismus der Hinterextremität bei Paarhufern und Unpaarhufern, unter besonderer Berücksichtigung der Fußwurzel. Gegenbaurs Morphologisches Jahrb. 76, H. 2. 259-278. 1 Taf. 7 Textf.

Kripp, D. v., 1935. Die mechanische Analyse der Schnabelkrümmung und ihre Bedeutung für die Anpassungsforschung. Gegenbaurs Morphologisches Jahrb. 76, H. 3. 448 bis 494. 23 Textf.

Krogh, Ch. v., 1936. Zur Morpholcgie der Primatenmilz. Anthropologischer Anzeiger. 13. Jahrg. 89-100. 2 Taf. 20 Textf.

Kuhlenbeck, H., 1936. Über die Grundbestandteile des Zwischenhimbauplans der Vögel. Gegenbaurs Morpholog. Jahrb. 77. 61-109. 55 Textf.

Markus, H., E. Stimmelmayr und G. Porsch, 1935. Die Ossifikation des Hypogeophisschädels. Beitrag zur Kenntnis der Gymnophionen XXV. Gegenbaurs Morphol. Jahrbuch. 76, H. 3. 375-420. 9 Textf.

Marcus, H. und M. Albrecht, 1936. Die erste Entwicklung von Lunge und Trachea bei Hypoglophis. Beitrag zur Kenntnis der Gymnophionen. XXVIII. (Zugleich Lungenstudie IX.) Gegenbaurs Morpholog. Jahrb. 77. 1-21. 16 Textf.

Maschkowzeff, A., 1935. Die morphologischen und phylogenetischen Beziehungen des Mesonephros zum Pronephros. Gegenbaurs Morphol. Jahrb. 75, H. 4. 568-595. 18 Textf.

Maximenko, A., 1936. Zur Phylogenese des M. serratus dorsalis caudalis bei den Säugetieren. Gegenbaurs Morpholog. Jahrb. 77. '666-691. 12 Textf.

Meinertz, Th., 1936. Die Hautmuskulatur der Säugetiere. Untersuchungen über die Hautmuskulatur der Säugetiere mit besonderer Berücksichtigung auf das superfizielle Facialịs-Gebiet. II. Das Kaninchen. 2. Nervus facialis. Gegenbaurs Morpholog. Jahrb. 77. 124-178. 21 Textf.

Meinertz, Th., 1936. Die Hautmuskulatur der Säugetiere. Untersuchungen über die Hautmuskulatur der Säugetiere mit besonderer Rücksicht auf das superfizielle FacialisGebiet. III. Der Hase mit dem Kaninchen verglichen. Gegenbaurs Morpholog. Jahrb. 77. 400-418. 8 Textf.

Meise, W., 1936. Zur Systematik und Verbreitungsgeschichte der Haus- und Weidensperlinge, Passer domesticus (L.) und hispaniolensis (T.). Journ. f. Ornithologie. 84. 631-672. 3 Textf.

Mortimer, C. H., 1936. Experimentelle und zytologische Untersuchungen über den Generationswechsel der Cladoceren. Zool. Jahrb., Abt. allg. Zool. 56. 323-388. 40 Textf.

Pool, G., 1936. Eiseniella tetraedra (Sav). Ein Beitrag zur vergleichenden Anatomie und Systematik der Lumbriciden. Vierteljahrsschr. d. naturf. Ges. in Zürich. 81. $199-216$.

Rauther, M., 1935. Zur Kenntnis der Myxinoiden-Kiemen. Gegenbaurs Morpholog. Jahrb. 75, H. 4. 613-633. 9 Textf.

Schaefer, K., 1935. Blutbildendes Knochenmark bei Urodelen. Zeitschr. f. Mikroskop.Anat. Forschung, Akad. Verlagsges. Leipzig. 38, 1. 294-317, 15 Textf. 
Sehreiber, H., 1936. Die Extrembewegungen der Schimpansenhand. 2. Zur Morphologie der Primatenhand. Gegenbaurs Morpholog. Jahrb. 77. 22-60. 11 Textf.

Sehwarz, W., 1935. Das Handgelenk der Amphibien. Gegenbaurs Morpholog. Jahrb. 75, H. 4. 634-648. 11 Textf.

Shen, T. H., 1936. Beiträge zum Studium der Geschlechtsbestimmung bei Dinophitus apatris. Zool. Jabrb., Abt. allg. Zool. Б66. 219-238. 4 Taf.

Sobotta, J., 1935. Beiträge zur Histogenese der sogenannten Ganglienleiste der Wirbeltiere. Zeitschr. f. Mikroskop.-Anat. Forschung, Akad. Verlagsges. Leipzig. 38, H. 4. 660 bis 688.19 Textf.

Stewart, T. D., 1936. The musculature of the anthropoids. I. Neck and strunk. Amer. Journ. of Physical Anthropology. 21. 141--204. 9 Textf.

Szymonowicz, W., 1936. Vergleichende Untersuchungen über die Innervation der Sinushaare bei den Säugern II. Zeitschr. f. Anatomie u. Entwicklungsgeschichte. 106. 85-97. 11 Textf.

Turkewitsch, N., 1936. Die Entwicklung der Zirbeldrüse beim Rind (Bos taurus L.). Gegenbaurs Morpholog. Jahrb. 77. 326-356. 14 Textf.

Turner, C. L., 1935. The aberrant secondary sex characters of the crayfishes of the genus Cambarus. Amer. Naturalist. 16. 863-882.

VoB, H., 1935. Vergleichende Untersuchungen über den Aufteilungsgrad der kontraktilen Masse in den Skelettmuskeln. Zeitschr. f. Mikroskop.-Anatom. Forschung, Akad. Verlagsges. Leipzig. 38, H. 3. 34l-356. 5 Textf.

\section{III c) Mensch}

Ahrens, H.-J., 1936. Die Entwicklung der Spaltlinienarchitektur des knöchernen menschlichen Schädels. Gegenbaurs Morpholog. Jahrb. 77. 357-371. 6 Textf.

Buschmakin, N., 1936. The brains of the Jakuts. Amer. Journ. of Physical Anthropology. 21. $29-37$.

Cipriani, L., 1935. Su alcuni gruppi umani de Curg (Curg. Kurubà, Jeravà ed altri). Archivio per l'anthropologia et la etnologia. 65. 87-124. 19 Textf.

Dieck, W., T. Fujita, 1935. Die Nerven der Kiefer und des Zahnfleisches beim Menschen mit Vergleichsuntersuchung der Verhältnisse beim Hunde. Gegenbaurs Morpholog. Jahrb. 76, H. 4. 570-588. 14 Textf.

Donici, A., 1935. Essai relatif à l'origine géographique des Scythes. Verhandl. d. schweizer. naturf. Ges. 116. Jahresvers. 369 .

Field, H., 1936. The Arabs of Iraq. Amer. Journ. of Physical Anthropology, 21. 49-56.

Fogelson, L. J., S. G. Zhisline, J. A. Itzikson, S. V. Keminer, J. B. Likhtzier, 1934. Adaptation of the organism to varying conditions of circulation of the blood in affections of the cardio-vascular system. (Russisch; m. engl. Zus.). Proceedings of the medicobiological institute Moscow. 3. 255-282. 3 Taf.

Frey, H., 1935. Über die Form des menschlichen Brustbeins. Gegenbaurs Morpholog. Jahrb. 76, H. 4. 516-569. 3 Textf.

Gilman, J., 1936. Research apportunities in South Africa. Amer. Journ. of Physical Anthropology. 21. 131-139.

Gould, H. N., 1936. Old Americans of the south. Amer. Journ. of Physical Anthropology. 21. $57-86$.

Gräning, W., 1936. Beitrag zur vergleichenden Anatomie der Muskulatur von Harnblase und Harnröhre. Zeitschr. f. Anatomie u. Entwicklungsgeschichte. 106. 226-250. 17 Textf.

Hafferl, A., 1936. Untersuchungen an Schädeln aus der Steiermark. Zeitschr. f. Anatomie u. Entwicklungsgeschichte. 106. 49-79. 1 Textf.

Havermans, F. M., 1936. Eidetische verschijnselen in onze phylogenie ? Mensch en Maatschapij. 12. Jahrg. 191-199.

Hochstetter, F., 1936. Beiträge zur Entwicklungsgeschichte des menschlichen Gaumens. Gegenbaurs Morhpolog. Jahrb. 77. 179-272. 46 Textf. 
Hochstetter, F., 1936. Über die von Bolk als „Verschlußleiste“, „Konkreszenzfurche“ und „Frenulum tectolabiale" des menschlichen Keimlings bezeichneten Bildungen. Gegenbaurs Morpholog. Jahrb. 78. 266-313. 29 Textf.

Krogh, Ch. v., 1936. Beiträge zur Theorie der Präzipitinreaktion und zu den serologischen Beziehungen zwischen Mensch und Pavian. Zeitschr. f. Rassenphysiologie. 8. 23-37. 14 Textf.

Papa, Gr. T., 1936. Mechanostruktur und Mechanofunktion der Dura mater des Menschen. Gegenbaurs Morpholog. Jahrb. 78. 85-187. I Taf. 32 Textf.

Puccioni, N., 1935. Qualche osservazione sulla teoria dell'Ologenesi Umana. Archivio per l'antropologia et la etnologia. 65. 59-65.

Puyggrás-Sala, J., 1936. Utber die Entwicklung der Lungenanlage des Menschen. Zeitschr. f. Anatomie u. Entwicklungsgeschichte. 106. 209-225. 16 Textf.

Ritter, E., 1936. Der Kreis der arischen Völker. Neues Volk. 4. Jahrg. H. 9. 12-13.

Roth Lutra, K. H., 1935. Neue Karten zur Rassenkunde von Pfalz und Nordbaden. Verhandlgn. d. Ges. d. phys. Anthropologie. 7. 39-48. 5 Textf.

Suschtschewski, A. W., 1936. Über die Entwicklung der Valvula coli. Gegenbaurs Morpholog. Jahrb. 78. 65-78. 6 Textf.

Steffan, P. und S. Welliseh, 1935. Die geographische Verteilung der Blutgruppen. Zeitschr. f. Rassenphysiologie. 7. 176-185.

Steffan, P. und S. Wellisch, 1936. Die geographische Verteilung der Blutgruppen. Zeitschr. f. Rassenphysiologie. 8. $39-47$.

Turkewitsch, N., 1935. Die Entwicklung des Aquaeductus cerebri des Menschen. Gegenbaurs Morpholog. Jahrb. 76, H. 3. 421-447. 10 Textf.

\section{Arbeiten über die cytologische Basis der Vererbungs- orscheinungen}

\section{a) Pflanzen}

Aase, H. C., 1935. Cytology of cereals. Bot. Review. 1. 467-496.

Afify, A., 1936. Some evolutionary aspects of a comparative cytogenetic investigation between Aconitum and Solanum. Genetica. 18. 255-276. 1 Textf.

Akemine, T., 1936. Chromosome studies on Hosta. I. The chromosome numbers in various species of Hosta. Journ. of the Fac. of Sc. Hokkaido Imp. Univ. 5. 27-32. 18 Textf.

Antonoff, S., 1936. Beitrag zum zytogenetischen Studium der Artbastarde Triticum turgidum $\times$ Triticum durum, Triticum durum $\times$ Triticum monococcum und Secale cereale $\times$ Secale montanum. Der Züchter. 8. 240-243. 7 Textf.

Arnason, T. J., 1936. Cytogenetics of hybrids between Zea Mays and Euchlaena mexicana. Genetics. 21. $40-60$.

Baldwin, J. T. jr.: 1936. Polyploidy in Sedum ternatum. J. Hered. 27. 241-248.

Beatus, R., 1936. Die Veronica-Gruppe agrestis der Sektion Alsinebe Griseb., ein Beitrag zum Problem der Artbildung. I. Die Zytologie der Gruppe Agrestis. Zeitschr. f. ind. Abst.- u. Vererbgsl. 71. 353-381. 11 'Textf.

Beatus, R., 1936. Die Tetradenstruktur der Chromosomen in den prämetaphasischen Stadien der Meiosis einiger Veronica-Arten. Ber. d. deutsch. Bot. Ges. 54. 340-345. 1 Textf.

Berg, H. v., 1936. Autotetraploidie bei Hordeum bulbosum L. Der Züchter. 8. 151-158. 7 Textf.

Bleier, H., 1936. Über Chromosomen- und Züchtungsfragen der Zuckerrübe. Zuckerrübenbau. 18. 73. 5 Textf.

Böcher, T. W., 1936. Cytological Studies on Campanula rotundifolia. Hereditas. 22. 269-277. 3 Textf.

Carlsan, J. G., 1936. Effects of several fixatives an staining reactions in Zea mays, especially with reference to the feulgen reaction. Cytologia. 7, No. 1-2. 104. 2 Taf.

Church, G. L., 1936. Cytological studies in the Gramineae. Amer. J. Bot. 23. 12-15. 
Cleland, R. E., 1936. Some aspects of the cyto-genetics of Oenothera. Bot. Review. 2. $316-348$.

Dark, S. 0. S., 1936. Meiosis in diploid and tetraploid Paeonia species. Journ. of Genetics. 32. $353-372$.

Darlington, C. D., 1936. The analysis of chromosome movements. I. Podophyllum versipelle. Cytologia. 7. 242. 6 Textf.

Darlington, C. D., 1936. The internal mechanics of the chromosomes. V. Relational coiling of chromatids at mitosis. Cytologia. 7. 248. 10 Textf.

Darlington, C. D., 1936. The limitation of crossing over in Oenothera. Journ. of Genetics. 32. $343-352.12$ Textf.

Dermen, H., 1936. Cytological study and hybridization in two sections of Verbena. Cytologia. 7, No. 1-2. 160. 43 Textf.

Doughty, L. R., 1936. Chromosome behaviour in rèlation to genetics of Agave. Journ. of Genetics. 33. 197-206. 4 Textf.

Ellenhorn, J., 1936. Verschiedene Chromosomenfärbung in der Meiosis von Gossypium peruvianum. Cytologia. 7, No. 1-2. 213. 1 Textf.

Ellison, W., 1936. Meiosis and fertility in certain British varieties of the cultivated potato (Solanum tuberosum L.). Genetica. 18. 217-254. 39 Textf.

Ellison, W., 1936. Synapsis and sterility in a Solanum hybrid. Journ. of Genetics. 32. $473-478.4$ Textf.

Emerson, S., 1936. A genetic cytological analysis Oenothera pratincola. Journ. of Genetics. 32. 315-342. 4 Textf.

Ford, C. E., 1936. Non-disjunction in Oenothera and the genesis of trisomics. Journ. of Genetics. 33. 275-304. 11 Textf.

Gazet du Chatelier, G., 1936. Les particularités cytologiques de la fleur du Sterculia platanifolia L. Cytologia. 7, No. 1-2, 176. 3 Textf.

Geitler, L., 1936. Vergleichende Untersuchungen über den feineren Kern- und Chromosomenbau der Cladophoraceen. Planta. 25. 530-578. 23 Textf.

Geitler, L., 1936. Vergleichend-zytologische Untersuchungen an Myosotis. Jahrb. f. wiss. Bot. 83. 707. 5 Textf.

Gustafsson, $\AA$., 1936. Die sekundäre Paarung zwischen Univalenten. Sv. bot. Tidskr. 30. $30-35$.

Gustafsson, ̊., 1936. Über verschiedene Sensibilität und Stabilität der Chromosomen. Botaniska Notiser. 488-512. 1 Textf.

Haga, T., 1935. Sex and chromosomes in Spinacia oleracea L. Jap. J. Genet. 10. $218-222$.

Heilborn, 0., 1936. The mechanics of so.called secondary association between chromosomes. Hereditas. 22. 167-188. 6 Textf.

Hermans, C., 1936. La prophase méiotique chez le Lilium Martagon. La Cellule. 45. 43-58. 2 Taf.

Horton, E. S., 1936. Studies in the cytology of wheat and of a wheat species hybrid. Amer. J. Bot. 23. $121-129$.

Hovasse, R., 1936. Constituants cytoplasmiques et en particulier, appareil de Golgi, chez quelques Volvocinées. Comptes rendus des séances de la Soc. de Biologie. 123. 253 bis 256. 1 Textf.

Husted, L., 1936. Cytological studies on the Peanut, Arachis. II. Chromosome number, morphology and behaviour, and their application to the problem of the origin of the cultivated forms. Cytologia. 7. No. 3. 396. 54 Textf.

Ivanié, M., 1936. Über den Bläschenkernbau und die promitotische Kernteilung eines im menschlichen Enddarm lebenden Pilzes (Blastocystis hominis Brumpt). Arch. f. Protistenkunde. 87. 242-247. 14 Textf.

Jahn, E., 1936. Myxomycetenstudien. 16. Die Kermphasen und die Zahl der Chromosomen. Ber. d. deutsch. Bot. Ges. 54. 517-528. I Taf.

Janaki-A mmal, E. K., 1936. Cyto-genetic analysis of Saccharum spontaneum L. I. Chromosome studies in some Indian forms. Indian J. agricult. Sci. 6. 1-8.

Janaki-Ammal, E. K., 1936. Cyto-genetic analysis of Saccharum spontaneum L. II. A type from Burma. Indian J. agricult Sci. 6. 9-10.

Induktive Abstammungs- und Vererbungslehre. LXXII 
Jensen, H. W., 1936. Meiosis in Rumex. I. Polyploidy and the origin of new species. Cytologia. 7, No. 1-2. 1. 1 Taf. 13 Textf.

Jensen, H. W., 1936. Meiosis in Rumex. II. The origin and behavior of the so called sexchromosomes in Rumex. Cytologia. 7. No. 1-2. 23. 2 Taf. 1 Textf.

Jnoh, S., 1936. Embryological studies on Pelvetia Wrightii Yendo and Fucus evanescens Ag. Jour. of the Fac. of Sc. Hokkaido Imp. Univ. 5. 9-23. 3 Taf.

Joshi, A. C. and B. V. Raman Rao, 1935. A study of microsporogenesis in two Menispermaceae. La Cellule. 44. 219-234. 2 Taf.

Katayama, Y., 1935. Karyogenetic studies on X rayed sex cells and their derivates in T. monococcum. Jour. of the Coll. of Agric. Imp. Univ. Tokyo. 13. 333-362. 2 Taf. 40 Textf.

Katayama, Y., 1935. Further investigations on synthezised octoploid Aegilotricum. Jour. of the Coll. of Agric. Imp. Univ. Tokyo. 13. 397-414. 1 Taf. 14 Textf.

Katayama, Y., 1936. Chromosome studies in some Alliums. Jour. of the Coll. of Agric. Imp. Univ. Tokyo. 13. 431-441. 40 Textf.

Kattermann, G., 1935. Cytologische Feststellungen bei Primula malacoides. I. Mitteilg.: Die diploiden Rassen. Die Gartenbauwissenschaft. 9. 120. 5 Textf.

Kattermann, G., 1935. Die zytologischen Verhältnisse bei Primula malacoides. II. Mitteilg.: Die tetraploiden Pflanzen. Die Gartenbauwissenschaft. 9. 159. 4 Textf.

Knapp, E., 1936. Heteroploidie bei Sphaerocarpus. Ber. d. deutsch. Bot. Ges. 54. 346 bis 361. 1 Taf.

Kraczkiewiez, $Z$., 1936. Remarques sur le mécanisme de la mitose. La Cellule. 45. 1-14. 5 Textf.

Küster, E., 1936. Über kernlose Zellen. Cytologia. 7, No. 1-2. 264.

Lamm, R., 1936. Cytological studies on inbred Rye. Hereditas. 22. 217-240. 39 Textf.

Lavialle, P., 1936. La géneration haploïde femelle chez les Dipsacées. Bull. de la soc. Botanique de France. 83. 274-277.

Lawrence, W. J. C., 1936. The origin of new forms in Delphinium. Genetica. 18. 109-115. 4 Textf.

Levan, A., 1936. Zytologische Studien an Allium Schoenoprasum. (With a summary in English.) Hereditas. 22. 1-128. 54 Textf.

Levan, A., 1936. Polyploidy and self-fertility in Allium. Hereditas. 22. 278-280.

Lilienfeld, F. A., 1936. Karyologische und genetische Studien an Fragaria. II. Ist Fragaria elatior eine autopolyploide Pflanze? Jap. Jour. of Botany. 8. 119-149. 18 Textf.

Lindschau, M. und E. Oehler, 1936 Cytologische Untersuchungen an tetraploiden Aegilops-Artbastarden. Der Züchter, 8. 113-117. 6 Textf.

Love, R. M., 1936. Occurrence of haploid pollen mother cells in a vulgare wheat Nature. 138. 589 .

McAulay, A. L. et alii, 1936. Chromosome number of Eucalyptus. Nature. 138. 550. 1 Textf.

Müntzing, A., 1936. Über die Entstehungsweise 56chromosomiger Weizen-Roggen-Bastarde. Der Züchter. 8. 188-191. 2 Textf.

Nandi, H. K., 1936. The chromosome morphology, secondary association, and origin of cultivated rice. Journ. of Genetics. 33. 315-336. I Taf. 29 Textf.

Nawaschin, M., 1936. Chromosomenanordnung und Chromosomenanomalien in somatischen Metaphasen und ihre Bedeutung für die Theorie der Chromosomenindividualität. Ber. d. deutsch. Bot. Ges. 54. 279-290. 4 Textf.

Negodi, G., 1936. Cariologia e filogenesi nel genere Fumaria (Papaveraceae). Riv. Biol. 20. $224-236$.

Nishiyama, J., 1936. Cytogenetical studies in Avena. I. Chromosome association in hybrids between Avena barbata Pott. and autotetraploids of A. strigosa Schreb. Cytologia. 7, No. 1-2. 276. 7 Textf.

Noguchi, T., 1936. On the cytological studies in Reineckia carnea Kunth. The Botanical Magazine. 50. 225-232. 44 Textf.

Oehlkers, Fr., 1936. Untersuchungen zur Physiologie der Meiosis III. Zeitschr. f. Botanik. 30. 253-276. 6 Textf. 
Offerijns, F. J. M., 1936. Meiosis in the pollen mother cells of some Cannas. Genetica. 18. $1-60.100$ Textf.

Okuno, S., 1936. Chromosome numbers in some sporophyll-bearing ferns. The Botanical Magazine. 50. 332-337. 12 Textf.

Olmo, H. P., 1936. Cytological studies of monosomic and derivative types of Nicotiana tabacum. Cytologia. 7, No. $1-2$. 143. 21 Textf.

Peto, F. H., 1936. Hybridization of Triticum and Agropyron. II. Cytology of the male parents and $\mathrm{F}_{1}$ generation. Canad. J. Res. 14 Sect. C. 203-214.

Pierce, W. P., 1936. The relation between cell, nuclear and chromosome dimensions in a sterile violet species-hybrid. Bull. Torrey bot. Club. 63. 115-138.

Polivková, J., 1936. A report at meiosis in Clematis Jackmanii: The development and structure of its eight gemini. Cytologia. 7, No. 1-2. 35. 1 Taf. 2 Textf.

Resende, F., 1936. Cytologischer Nachweis von Postreduktion bei einer Phanerogame. Planta. 25. 665-666. 1 Textf.

Richardson, M. M., 1936. Structural hybridity in Lilium Martagon album $\times$ L. Hausonii. Journ. of Genetics. 32. 411-450. 1 Taf. 55 Textf.

Riley, H. P., 1936. The effect of X-rays on the chromosomes of Tradescantia gigantea. Cytologia. 7, No. 1-2. 131. 14 Textf.

Rosenthal, Ch., 1936. Chromosomenstudien an Pulsatilla. Jahrb. f. wiss. Bot. 83. 809 bis 844. 10 Textf.

Roy, B., 1936. On the somatic chromosomes in Latyrus. Cytologia. 7, No. 3. 424. 13 Textf.

Satô, D., 1935. Analysis of karyotypes in Scilla with special reference to the origin of aneuploids. The Botanical Magazine. 49. 298-305. 4 Textf.

Satô, D., 1936. Analysis of karyotypes of Scilla permixta and the allied species with special reference to the dislocation of the chromosomes. The Botanical Magazine. 50. 447 bis 456. 31 Textf.

Shimotomai, N. und T. Takemoto, 1936. Über die Morphologie der Chromosomen bei 6 Arten von Chrysanthemum. The Botanical Magazine. 50. 324-331. 6 Textf.

Szakien, B., 1936. Prophase méiotique dans l'Equisetum silvaticum et l'Equisetum palustre. La Cellule. 45. 15-26. I Taf.

Stranb, J., 1936. Untersuchungen zur Physiologie der Meiosis II. Zeitschr. f. Botanik. 30. 1-57. 1 Taf. 32 Textf.

Tanaka, N., 1935. Cytological studies in Asaraceae. I. Meiosis in Heterotropa nipponica and H. tamaensis. II. Chromosome numbers in Heterotropa and Asarum. The Botanical Magazine. 49. 709-716. 43 Textf.

Tatebe, T., 1936. Genetic and cytological studies in the $F_{1}$ hybrid of scarlet or tomato eggplant (Solanum integrifolium Poir.) $\times$ eggplant (Solanum melongena L.). The Botanical Magazine. 50. 457-462. 20 Textf.

Tatuno, S., 1935. Heterochromosomen bei Lebermoosen I. Heterochromosomen bei einigen Arten der Jungermaniales. The Botanical Magazine. 49. 628-635. 45 Textf.

Tatuno, S., 1935. Ein Beispiel der hyperhaploiden Pflanzen und die Dyadenbildung bei Calobryum rotundifolium. The Botanical Magazine. 49. 892-898. 12 Textf.

Tatuno, S., 1936. Heterochromosomen bei Lebermoosen. The Botanical Magazine. 50. 341-347. 24 Textf.

Tatuno, S., 1936. Geschlechtschromosomen bei einigen Lebermoosen IV. The Botanical Magazine. 50. 401-405. 22 Textf.

Tatuno, S., 1936. Geschlechtschromosomen bei einigen Lebermoosen II. Jour. of Science. Hiroshima Univ., Ser. B, Div. 2. 3. 1-8. 22 Textf.

Thomas, P. T., 1936. Genotypic control of chromosome size. Nature. 138. 402. 1 Textf.

Tischler, G., 1936. Die Bedeutung der „Polyploidie“ für pflanzengeographische Probleme. Forsch. u. Fortschr. 12. 37--38.

Upcott, M., 1936. The mechanics of mitosis in the pollen tube of Tulipa. Proc. of the Royal Society. 121 B. $207-220 . \quad 1$ Taf.

Upcott, M. and L. La Cour, 1936. The genetic structure of Tulipa. Journ. of Genetics. 33. 237-254. 18 Textf. 
Wada, B., 1936. Mikrurgische Untersuchungen lebender Zellen in der Teilung. III. Die Einwirkung der Plasmolyse auf die Mitose bei den Staubfadenhaarzellen von Tradescantia reflexa. Cytologia. 7. 198.2 Taf.

Wada, B., 1936. Mikrurgische Untersuchungen lebender Zellen in der Teilung. IV. Die Einwirkung der Austrocknung auf die Mitose bei den Staubfadenhaarzellen von Tradescantia reflexa. Cytologia. 7, No. 3. 363. 2 Taf.

Wakar, B. A., 1936. Cytologische Untersuchung über $F_{1}$ der Weizen-Queckengras-Bastarde. Cytologia. 7, No. 3. 293.48 Textf.

Wanscher, J. H., 1934. Secondary (chromosome) associations in Umbelliferae and Bicornes. New Phytologist. 33. 58-65.

Webber, J. M., 1936. Chromosomes in Sphaeralcea and related genera. Cytologia. 7, No. 3. 313. 20 Textf.

Westergãrd, M., 1936. On the satellites in the eversporting Matthiola races. C. r. Trav. Labor. Carlsberg, Sér. physiol. 21. 195-204.

Yamasaki, Y., 1936. Some observations on the microsporogenesis of the haploid plant of Triticum vulgare Host. Jap. Jour. of Botany. 8. 151-153. 1 Taf.

Yuasa, A., 1936. Studies in the cytology of Pteridophyta. IX. On the nature of the ,,borderbrim". The Botanical Magazine. 50. 151-158. 12 Textf.

Zeeuw, J. de, 1936. Recherches sur les noyaux euchromocentriques et leur division (Lupinus luteus et L. hirsutus). La Cellule. 44. 387-410. 2 Taf.

\section{IVb) Tiere}

Ahrens, W., 1936. Das dynamische Verhalten der Chromatinschleifen im Stadium des Buketts und das Reduktionsproblem. Zool. Anz. 116. 49-61. 4 Textf.

Bauer, H., 1936. Eine für Drosophila neue Form des Y-Chromosoms bei D. repleta. Die Naturwissenschaften. 24. Jahrg., H. 34. 540. 1 Textf.

Bryden, Wm., 1936. Some observations upon the mitotic and meiotic divisions in the Wistar Rat. II: Changes in temperature over localised areas. Cytologia. 7, No. 3. 389. 6 Textf.

Dobzhansky, Th. and C. C. Tan, 1936. Studies on hybrid sterility. III. A comparison of the gene arrangement in two species, Drosophila pseudoobscura and Drosophila miranda. Zeitschr. f. ind. Abst.- u. Vererbgsl. 72. 88-114. 1 Taf. 6 Textf.

Dubinin, N. P. et alii, 1936. Occurrence and distribution of chromosome aberrations in nature. Nature. 137. 1036.

Ekblone, T., 1936. Studien über die Morphologie der,Chromosomen des Myrneus miriformis. Zeitschr. f. Zellf. u. mikr. Anat. 24. 707-713. 1 Taf. 4 Textf.

Fagerlind, F., 1936. Die Chromosomenzahl von Alectorolophus und Saison-Dimorphismus. Hereditas. 22. 189-192. 6 Textf.

Favrelle, M., 1935. Formule chromosomique et spermatogenèse du Phalces longiscaphus (Orthoptère Phasmidae). La Cellule. 44. 175-186. 1 Taf. 2 Textf.

Föyn, B., 1936. Über die Kernverhältnisse der Foraminifere Myxotheca arenilega Schaudinn. Arch. f. Protistenkunde. 87. 272-295. 19 Textf.

Fujii, S., 1936. Salivary gland chromosomes of Drosophila virilis. Cytologia. 7, No. 1--2. 272. 1 Taf. 1 Textf.

Georgévitsch, J., 1936. Über Diplo- u. Haplophase im Entwicklungskreise des Myxosporids Zschokkella rovignensis Nemeczek. Arch. f. Protistenkunde. 87. 151-154. 13 Textf.

Greenshields, F., 1936. Chromosomal relationship between males and females in Hymenoptera symphyta. Nature. 137. 662.

Gregory, P. T., 1936. The floral morphology and cytology of Eletaria cardamomum. Journ. of the Linnean Society. 50. 363-392. 3 Taf. 10 Textf.

Grineberg, H., 1938. A case of complete reversion of a chromosomal rearrangement in Drosophila melanogaster. Nature. 138. 508.

Hillebrand, P., 1936. Untersuchungen über die Chromosomen bei drei verschiedenen Rassen von Hausschweinen (Deutsches weißes Edelschwein, veredeltes Landschwein und Berkshire). Breslau, Phil. Diss. Ohlau i. Schl.: Eschenhagen. 2 S S. 80. 
Homedes Ranquini, J. und J. M. de Frutos, 1935. Studie über die Chromosomen des Maultieres. (Spanisch.) Nueva Zootecnia. 4. 209-212.

Hsï, F., 1935. Evolution sexuée chez le Chirocephalus nankinensis Shen (Phyllopode, Anostracé). La Cellule. 44. 235-250. 2 Taf.

Huskins, C. L. and E. M. Hearne, 1936. Spermatocyte chiasma frequency in strains of mice differing in susceptibility or restistance to the spontaneous occurrence of malignant tumors. Canad. J. Res. 14, Sect. D. 39-58.

Ivanié, M., 1936. Zur Kenntnis der Vermehrungsruhestadien bei Chilodon uncinatus Ehrbg. Arch. f. Protistenkd. 87. 159-171. 1 Taf.

Ivanić, M., 1936. Die Kernteilung bei Opalina ranarum Stein und Opalina obtrigona Stein. Arch. f. Protistenkd. 87. 172-184. I Taf.

Ivanić, M., 1936. Zur Kenntnis der Vermehrungs- u. Wiedervermehrungsruhestadien erster, zweiter und dritter Ordnung bei einem Heliozoon (Vampyrellidium vagans Zopf). Arch. f. Protistenkd. 87. 248-262. I Taf.

Ivanić, M., 1936. Structure du noyau au repos et sa division au début de la division multiple (schizogonie) chez le Trypanosoma rotatorium Mayer. La Cellule. 44. 349-366. 1 Taf.

Kerkis, J., 1936. Chromosome conjugation in hybrids between Drosophila melanogaster and Drosophila simulans. Amer. Naturalist. 70. 81-86.

Koller, P. C., 1936. The origin and behaviour of Chiasmata. XI. Dasyurus and Sarcophilus. Cytologia. 7, No. 1-2. 82. 23 Textf.

Koller, P. C., 1936. The genetical and mechanical properties of the sex-chromosomes. II. Marsupials. Journ. of Genetics. 32. 451-472. 17 Textf.

Koller, P. C., 1936. Cytological studies on the reproductive organs. Chromosome behaviour in the male Grey Squirrel (Sciurus calorinensis, leucotus). Proc. of the Royal Society of Edinburgh. 56. 196--208. 12 Textf.

Koller, P. C., 1936. Chromosome behaviour in the male Ferret and Mole during anoestrus. Proc. of the Royal Society. 121B. 192-206. 2 Taf.

Kostoff, D., 1936. The genoms of Triticum Timopheevi Zhuk, Secale cereale L. and Haynaldia villosa Schur. Zeitschr. f. ind. Abst.- u. Vererbgsi. 72. 115-118.

Lacroix, P., 1935. Recherches cytologiques sur les centres nerveux chez les Invertébrés. II. Astacus fluviatilis. La Cellule. 44. 251-270. 4 Textf.

Mather, K., 1936. The determination of position in crossing-over. I. Drosophila melanogaster. Journ. of Genetics. 33. 207-236. 6 Textf.

Matthey, R., 1936. La formule chromosomiale chez les Apodermus. Bull. de la Soc. vandoises des sc. nat. $\mathbf{5} 9$. $119-121$.

Matthey, R., 1936. Les hétérochromosomes chez les Mammifères. Archives de Biologie. 42. 319-383. 5 Taf. 9 Textf.

MeConnell, C. H., 1936. Mitosis in Hydra. Mitosis in the indifferent interstitial cells of Hydra. Arch. f. Entwicklungsmech. 13\%. 202-210. 22 Textf.

MeDongall, M. St., 1936. Etude cytologique de trois espèces du genre Chilodonella Strand. Bull. biologique de la France et de la Belgique. 70. 308-331. 6 Taf.

Metz, E. W., 1936. Factors influencing chromosome movements in mitosis. Cytologia. 7, No. 1-2. 219. 6 Textf.

Moffet, A. A., 1936. The origin anf behaviour of chiasmata diploid and tetraploid Culex pipiens. XIII. Cytologia. 7, No. 1-2. 184. 26 Textf.

Neuhaus, M. T., 1936. Production of attached X-chromosomes in Drosophila melanogaster males. Nature. 137. 996.

Pätau, Kl., 1936. Cytologische Untersuchungen an der haploid-parthenogenetischen Milbe Pediculoides ventricosus Newp. Berl. Zool. Jahrb., Abt. allg. Zool. 56. 277-322. 1 Taf. 19 Textf.

Phillips, H. M., 1936. Cytological study of Macrostomum tuba von Graff. Zool. Anz. 114. 322-330. 25 Textf.

Reverberi, G., 1936. Analisi dei primi momenti dello sviluppo in nova ibride di Ascidie. Pubblic. della Stazione zool. di Napoli. 15. 175-193. 17 Textf.

Reverberi, G., 1936. La segmentazione dei frammenti dell'novo non fecundato di Ascidie. Pubblic. della Stazione zool. di Napoli. 15. 198-216. 8 Textf. 
Risley, P. L., 1936. Centrioles in germ cells of turtles, including observations on the ,manchette" in spermiogenesis. Zeitschr. f. wiss. Zool. 148. 133-158. 41 Textf.

Risley, P. L., 1936. The chromosomes of the male Musk Turtle, Sternotherus odoratus L. Cytologia. 7. 232. 13 Textf.

Russo, A., 1936. Mitosi ed Amitosi, divisioni sessuali o di categoria in un Ciliato (Cryptochilum echini Mps.). Biolog. Zentralblatt. 56, 5/6. 226. 2 Textf.

Saez, F. A., P. Rojas und E. de Robertis, 1936. Der meiotische Prozeß bei Buto arenarium. Zeitschr. f. Zellforschg. u. mikr. Anat. 24. 727-777. 80 Textf.

Schiwago, P. I. und L. S. Peschkowskaja, 1936. Zum Problem des Verhaltens des Karyotyps in der Ontogenese. I. Karyologische Studien am embryonalen Vogelsoma. Genetica. 18. 74-108. 19 Textf.

Sehmidt, W. J., 1936. Doppelbrechung von Chromosomen und Kornspindel in der lebenden Zelle. Die Naturwissenschaften. 24. Jahrg., H. 29. 463. 1 Textf.

Seiferle, E., 1936. Die sog. interstitiellen Zellen des Eierstockes und ihre Beziehungen zu Stroma und Ovarialzyklus, im besonderen beim Schwein. Zeitschr. f. Zellf. u. mikr. Anat. 25. $421-475$. 15 Textf.

Seshachar, B. R., 1936. The spermatogenesis of Ichthyophis glutinosus (Linn.). Part I. The spermatogonia and their division. Zeitschr. f. Zellf. u. mikr. Anat. 24. 662-706. 60 Textf.

Sidorow, B. N., N. N. Sokolow, I. Eu. Trofimow, 1936. Crossing-over in heterozygoten Inversionen. Genetica. 18. $291-312.6$ Textf.

Subramaniam, M. K. and R. Gopala Aiyar, 1936. Some observations on the possible mode of evolution of the network like Golgi apparatus of vertebrate somatic cells from discrete Golgi bodies of Invertebrates. La Cellule. 45. 59-74. 14 Textf.

Tittler, I. A., 1935. Division, encystment and endomyxis in Urostyla grandis Ehrbg., with an account of an amicronucleate race. La Cellule. 44. 189-218. 44 Textf.

Unger, H., 1936. Beitrag zur Chromosomenforschung der Vögel. Zeitschr. f. Zellf. u. mikr. Anat. 25. 476-500. 20 Textf.

Cpeott, M.; 1936. The origin and behavior of chiasmata. XII. Eremurus spectabilis. Cytologia. 7, No. 1-2. 118. 20 Textf.

Wald, H., 1936. Cytologic studies on the abnormal development of the eggs of the claret mutant type of Drosophila simulans. Genetics. 21. 264-281.

White, M. T. D., 1936. Chromosome cycle of Ascaris megalocephala. Nature. 137. 783. 1 Textf.

\section{IVe) Mensch}

Andres, A. H. and B. V. Jir, 1936. Somatic chromosome complex of the human embryo. Cytologia. 7, No. 3. 371. 1 Taf. 22 Textf.

Chroustschoff, G. K., 1934. Cytological studies of leucocyte cultures in man. (Russisch; m. engl. Zus.) Proceedings of the medico-biological institute Moscow. 3. 213-234. 2 Taf. 7 Textf.

Haase-Bessell, G., 1936. Kernsymbiose-Polyploidie in Beziehung auf menschliche Verhältnisse. Zeitschr. f. menschl. Vererbungs- u. Konstitutionslehre. 20. 78-89.

Jacobj, W., 1935. Die Zellkerngröße beim Menschen. Zeitschr. f. mikr.-anat. Forschung, Akad. Verlagsges. Leipzig. 38, 1. 161-240.

Levit, S. G., 1934. On cytological abnormalities in man. (Russisch; m. engl. Zus.) Proceedings of the medico-biological institute Moscow. 3. 235-238. 2 Textf.

Schairer, E., 1935. Kernmessungen und Chromosomenzählungen an menschlichen Geschwülsten. Tübingen, Med. Hab. Schr. Berlin: Springer. $38 \mathrm{~S} .8^{\circ} .7$ Textf.

\section{Angewandte Vererbungslehre in Züchtung, Soziologie und Medizin}

\section{a) Pflanzen}

Åkerman, ̊̊., 1936. Die Verbesserung der Backfähigkeit des schwedischen Weizens durch Züchtung. Der Züchter. 8. 174-179. 2 Textf.

Åkerman, ̊̊., G. Andersson und J. E. Lindberg, 1935. Studien über die Winterfestigkeit des Roggens. Zeitschr. f. Züchtung, Reihe A. 20. 137. 6 Textf. 
Alabouvette, L., 1936. Organisation générale de l'amélioration et de la sélection des plantes en France. Berichte Intern. Kongr. Pflanzenz., Wageningen. 1. 40-52.

Andersson, G., 1936. Gefrier- und Abhärtungsversuche mit Roggen. Der Züchter. 8. 214-217.

Anderson, J. A., 1936. Studies on the nature of rust resistance in wheat. VII. Chemical analyses of hybrid lines of wheat differing in their rust reactions. Canad. J. Res. 14, Sect. C. $1-10$.

Anon., 1936. Sveriges Utsädesförening 1886-1936. En minnesskrift. Sveriges Utsädesförenings Tidskrift. $46 . \quad 153-394 . \quad 36$ Textf.

Arehibald, E. S., 1936. Organization of plant breeding in Canada. Berichte Intern. Kongr. Pflanzenz., Wageningen. 1. 134-137.

Armstrong, J. M., 1936. Hybridization of Triticum and Agropyrum. I. Crossing results and description of the first generation hybrids. Canad. J. Res. 14, Sect. C. 190-202.

Becker, K. E., 1936. Krebsfeste Kartoffelsorten: Deutsche Landwirtschaftliche Presse. 63. 158.

Becker, W. A. und J. H. Siemaszko, 1936. Über das Verhalten der Cytoplasmaeinschlüsse der Equisetumsporen während der Zellteilung. La Cellule. 45. 27-42. 1 Taf.

Bittera, N. v., 1935. Beiträge zur Sortenfrage der Luzerne. Pflanzenbau. 12. Jahrg. 122.

Bleichert, H. v., 1935. Kritische Untersuchungen zur Unterscheidung deutscher Winterroggensorten. Zeitschr. f. Züchtung, Reihe A. 20. 443.

Bleier, H., 1936. Über Chromosomen- und Züchtungsfragen der Zuckerrübe. Zuckerrübenbau. 18. 73 . 5 Textf.

Blinoff, L. F., 1935. Die Bestäubung und Fruchtbarkeit der Apfelbäume. Die Gartenbauwissenschaft. 9. 460.4 Textf.

Bond, T. E. T., 1936. Phytophthora infestans (Mont.) Debary and Cladosporium fulvum Cooke on varieties of tomato and potato and on grafted solanaceus plants. Ann. appl. Biol. 23. 11-29.

Bond, T. E. T., 1936. Disease relationships in grafted plants and Chimaeras. Biological Reviews. 11. 269-285.

Bonne, C., 1935. Über die Züchtung einer aus der Erde herauswachsenden Zuckerrübe sowie deren Verarbeitungsfähigkeit. Zuckerrübenbau. 17. 165.

Bordakov, L. P., 1936. Züchtung der Baumwolle. Zeitschr. f. Züchtung, Reihe A. 21. 68. 5 Textf.

Bremer, H., 1936. Zur Epidemiologie und Bekämpfung des Spargelrostes. Die Gartenbauwissenschaft. 10. 51 . 5 Textf.

Broekema, C., 1936. The general organization of plantbreeding in the Netherlands. Ber. Intern. Kongr. Pflanzenz., Wageningen. 1. 90-92.

Broekema, C., 1936. The general organization of plantbreeding. Report Intern. Congress of Plantbreeders, Wageningen. 2. 39-52.

Brückner, G. und E. Jung, 1936. Von der Kornkäferanfälligkeit verschiedener Weizensorten. Zeitschr. f. d. gesamte Getreide-, Mühlen- u. Bäckereiwesen. 23. 177.

Buchinger, A., 1936. Die Saugkraft als Selektionsfaktor in der Weizenzüchtung mit besonderer Berücksichtigung grundlegender Fragen auf dem Gebiete der Saugkraftbestimmung. Zeitschr. f. Züchtung, Reihe A. 21. 148. 9 Textf.

Bukasov, S. M. and V. Lechnovitz, 1935. Importancia en la fitotecnia de las papas indigenas de la America del sur. Rev. argent. Agronom. 2. 173-183.

Burger, H., 1935. Einfluß der Herkunft des Samens auf die Eigenschaften forstlicher Holzgewächse. Mitt. d. schweiz. Anstalt f. forstl. Versuchsw. 19. 103-132. 10 Textf.

Burger, H., 1936. Zuwachs u. Nadelmenge bei verschiedenen Föhrenrassen in Eglisan Schweiz. IX. Kongreß d. int. Verb. forstl. Forschungsanst. Ungarn, Verlag RöttigRomwalter Sopron. $5 \mathrm{~S}$.

Codd, L. E. W., 1936. Rice Breeding 1933-1936. Agricultural Journ. of British Guiana. 7. $315-328$.

Deshpande, R. B., 1935. Pungency in chillies (Capsicum annuum): A mendelian character. Current Sci. 4. 418. 
Diehl, R., 1936. Le problèmes actuels de l'amélioration et des champs d'expériences de pommes de terre. Ber. Intern. Kongr. Pflanzenz., Wageningen. 1. 63-71.

Dorsey, M. J., 1936. What is a ,basis plant patent"? J. Hered. 27. 213-216.

Dudok van Heel, J. P., 1936. Les problèmes actuels de l'amélioration de la betterave à sucre. Comptes rendus Congrès intern. de sélectionneurs de plantes, Wageningen. 2. 74-86. 1 Textf.

Eidmann, E., 1936. Saatgutprüfung auf biochemischem Wege. Zeitschr. f. Forst- u. Jagdw. 68. 422-442. 3 Textf.

Einset, 0., 1935. Cross pallination trials with bud mutations of the apple. Die Gartenbauwissenschaft. 9.157.

Engledow, F. L. and B. P. Pal., Hybrid vigour in wheat. Indian J. agricult. Sc. 5. 693 bis 704 .

Ferwerda, F. P., 1936. Die Befruchtungsverhältnisse bei den in Niederländisch-Indien angebauten Kaffeearten. Der Züchter. 8. 92-102. 3 Textf.

Figna, R., 1936. Aktuelle Fragen der Kartoffelzüchtung. Ber. Intern. Kongr. Pflanzenz., Wageningen. 1. 20-22.

Frandsen, H. N., 1936. The general organization of plantbreeding in Denmark. Ber. Intern. Kongr. Pflanzenz., Wageningen. 1. 23-26.

Frederiksen, Th., 1936. Gegenwärtige Probleme der Kartoffelveredelung. Ber. Intern. Kongr. Pflanzenz., Wageningen. 1. 28-30.

Freistedt, P., 1935. Neue Zielsetzungen in der Gerstenzüchtung. Zeitschr. f. Züchtung, Reihe A. 20. 169.3 Textf.

Frets, H. P., 1936. Hereditary variability in the $F_{8}$ seed generation after cross-fertilization of bean races. Proc. roy. Acad. Amsterd. 39. 432-440.

Fruergaard, J. S., 1936. Aktuelle Probleme der dänischen Weizenzüchtung. Ber. Intern. Kongr. Pflanzenz., Wageningen. 1. 26-28.

Fulton, G. L., 1936. Plantbreeding in Western Australia. Ber. Intern. Kongr. Pflanzenz., Wageningen. $1.2-4$.

Garber, R. J., R. B. Dustman and C. R. Burnham, 1936. Yield and composition of eared and earless maize plants in a selfed line segregating barren stalks. Journ. amer. Soc. Agronomy. 28. 85-91.

Geyer, H., 1936. Probleme der deutschen Kartoffelzüchtung. Ber. Intern. Kongr. Pflanzenz., Wageningen. 1 . $36-38$.

Ginneken, P. J. H. van, 1936. Problemes actuels relatifs a l'amélioration de la betterave à sucre. Ber. Intern. Kongr. Pflanzenz., Wageningen. 1. 98-101.

Goetz, 0., 1935. Zur Frage mangelnden Ertrags der Obstbäume. Gartenflora. 84. 15-18.

Granhall, I., 1936. Untersuchungen an schwedischen Landsorten von Hafer. Der Züchter. 8. $211-214$. 1 Textf.

Granhali, I. and ^. Åkerman, 1936. Present problems of wheat breeding in Sweden. Ber. Intern. Kongr. Pflanzenz., Wageningen. 1. 128-130.

Gratia, A. et P. Manil, 1936. Pourquoi le virus du tabac et le virus $X$ de la pomme de terre ne passent-ils pas a la descendance par les graines? Comptes rendus des séances de la Soc. de Biologie. 123. 509-510.

Guba, E. F., 1936. Resistance to Cladosporium fulvum. Phytopathology. 26. 382-386.

Hackbarth, J., 1936. Versuche über Photoperiodismus. III. Die photoperiodische Reaktionsweise einiger Lupinenarten. Der Züchter. 8. 81-92. 12 Textf.

Hoeck, F., 1935. Urform und Züchtung. Betrachtung, Klarstellung, Zielsetzung echter Gartenliebhaberei. Gartenflora. 84. 323-324. 5 Textf.

Hoffmann, R., 1936. Versuche zur Klärung des Keimverlaufes bei der Pappel. Forstw. Centralbl. 58. Jahrg. 574-581. 9 Textf.

Hudson, P. S., 1936. The breeding of cereals in Great Britain. Ber. Intern. Kongr. Pflanzenzüchter, Wageningen. 1. 77-78.

Hülsenberg, H., 1935. Beitrag zur Züchtung einer nematodenfesten Zuckerrübe. Landwirtschaftl. Jahrb. 81. 505. 3 Textf.

Husain, M. A., A. N. Puri and R. N. Trehan, 1936. Cell sap acidity and the incidence of white-fly (Bemesia gossypipoda) on cottons. Current Sci. 4. 486-487. 
Husfeld, B., 1936. Organisation der deutschen Pflanzenzüchtung. Ber. Intern. Kongr. Pflanzenz., Wageningen. 1. 31-34.

Jelinek, J., 1936. Les problèmes actuels de la sélection du blé. Ber. Intern. Kongr. Pflanzenzüchter, Wageningen, 1. 15-17.

Jeswiet, J., 1936. Results of crossing in sugarcane and other Saccharum species for the sugarcane culture in Java. Report Intern. Congr. of Plantbreeders, Wageningen. 2. $68-73$.

Johann, H., 1935. Histology of the caryopsis of yellow dent corn, with reference to resistance and susceptibility to Kernel rots. J. agricult. Res. 51. $855-883$.

Johnson, L. P. V., 1935. The inheritance of delayed germination in hybrids of Avena fatna and Avena sativa. Canad. J. Res. 13, Sect. B. 367-387.

Journée, C., 1936. L'Amélioration des plantes en Belgique. Ber. Intern. Kongr. Pflanzenz., Wageningen. 1. 6-11.

Jung, E., 1935. Haltung und Leistung der beiden Seiten geneigter Roggenähren. Zeitschr. f. Züchtung, Reihe A. 20. 307. 4 Textf.

Kampe, 1936. Sortenbereinigung im Gemüsebau. Mitteilgn. f. d. Landwirtschaft. 51. 254.

Klapp, E., 1936. Aufgaben der Futterpflanzenzüchtung. Mitteilgn. f. d. Landwirtschaft. 51. 25. 6 Textf.

Koenig, P. und R. Rave, 1935. Reiträge zur Tabak-Systematik und -Genetik. I. Sortenmerkmale am deutschen Tabak. Landwirtschaftl. Jahrb. 81. 425. 7 Textf.

Kostecki, E., 1936. La production grainière en Pologne. Ber. Intern. Kongr. Pflanzenz., Wageningen. 1. $109-116$.

Küderling, 0. E., 1935. Untersuchungen über die Feldresistenz einzelner Weizensorten gegen Puccinia glumarum tritici. Zeitschr. f. Züchtung, Reihe A. 21. 1. 3 Textf.

Li, H. W., C. J. Meng and T. N. Liu, 1936. Field results in a millet breeding experiment. Journ. amer. Soc. Agronomy. 28. 1-15.

Lindberg, J. E. und H. Kajmer, 1936. Zur Quahitätsbeurteilung des Weizens. Der Züchter. 8. $191-196$.

Listowski, A., 1936. Die Unterscheidung der Gerstensorten durch Phenolfärbung der Körner. Angew. Botanik. 18, H. 2. 142.

Lüdecke, H., 1936. Ertrag und Beschaffenheit verschiedener Gerstensorten bei wechselnden Kaligaben unter Berücksichtigung des aufgenommenen Kalis. Die Ernährung der Pflanze. 32. 273, 246. 6 Textf.

Ludewig, K. und J. Voss, 1936. Morphologische Sortenstudien an Erbsen, Ackerbohnen und Lupinen. Angew. Botanik. 18, H. 3. 262. 18 Textf.

MacLeod, D. J. and L. C. Young, 1936. Potato breeding in Canada. Ber. Intern. Kongr. Pflanzenz., Wageningen. 1. 137-140.

Maurer, E. und A. Storek, 1936. Untersuchungen zur Züchtung einer giftfreien Primel vom „Obconica“-Typus. Die Gartenbauwissenschaft. 10. 1. 15 Textf.

Mayer Gmelin, H. K. H. A., 1936. Die aktuellen Fragen der Weizenzüchtung. Kongreßbericht Intern. KongreB d. Pflanzenz., Wageningen. 2. $13-36$.

MeKinney, H. H., 1935. Evidence of virus mutation in the common mosaic tobaco. J. agricult. Res. 51. 951-981.

MeMillan, J. R. A. Me., 1936. Plantbreeding in Australia. Ber. Intern. Kongr. Pflanzenz., Wageningen. 1. $1-2$.

Melle, van, 1936. Mutations somatiques. Leur valeur et leur rôle dans l'amélioration des plantes. Rev. Bot. appl. 16. 97-104.

Merkenschlager, F., 1936. Die Konstitution der Sojabohne. Die Ernährung der Pflanze. 32. 189.4 Textf.

Meunissier, A., 1936. Les problèmes actuels de l'amélioration de la sélection et des champs d'expérience de blé. Ber. Intern. Kongr. Pflanzenz., Wageningen. 1. 52-62.

Mihályi Zoltán, 1936. Die Herkunftsfrage bei den Weißkiefernpflanzungen Rumpfungarns im Lichte der Saatgutprüfung. Dissertation. (Ungarisch u. Deutsch.) Erdészeti Kiserletek. 38. 114. 20 Textf.

Milatz, R., 1936. Der Hafer im Sortenregister. Landwirtschaftl. Jahrbücher. 83. 1. 13 Taf. 5 Textf. 
Miles, L. G., 1936. Plantbreeding in Queensland. Ber. Intern. Kongr. Pflanzenz., Wageningen. 1. 4-5.

Müller, K. 0., 1936. Zur Kenntnis des Sommer-Wintertypus bei Triticum vulgare. Angew. Botanik. 18, H. 2. 231.

Münch, E., 1936. Das Lärchensterben. Forstw. Centralbl. 58. Jahrg. 469-494, 537-562, $581-590.15$ Textf.

Murphy, H. C., T. R. Clanton and F. A. Coffmann, 1936. Hybrid selections of oats resistant to smuts and rusts. J. amer. Soc. Agronomy. 28. 370-373.

Neatby, K. W., 1936. Factor relations in wheat for resistance to Puccinia graminis tritici, Puccinia glumarum and Frysiphe graminis. Phytopathology. 26. 360-374.

Negrul, A. M., 1936. Variabilität und Vererbung des Geschlechts bei der Rebe. Die Gartenbauwissenschaft. 10. 215. 18 Textf.

Newton, M. and T. Johnson, 1936. Stripe rust, Puccinia glumarum, in Canada. Canad. J. Res. 14, Sect. C. 89-108.

Nicolaisen, W., 1935. Lassen sich die Winterfestigkeit und die Frühreife unserer Wintergersten noch steigern? Mitteilgn. f. d. Landwirtschaft. 50. 1049.

Nicolaisen, W., 1935. Untersuchungen mit Herkünften des Haferflugbrandes in Rahmen der Immunitätszüchtung. Zeitschr. f. Züchtung, Reihe A. 20. 318.

Nieves, R., 1936. Die Vererbung der Widerstandsfähigkeit gegen den Steinbrand (Tilletia tritici Rasse 5 M. A.) in der Kreuzung Barletta $\times$ Florence. (Spanisch.) Physis (Buenos Aires). 12. $51-63$.

Nilsson, F., 1936. Bodenreaktion und Sorten. Der Züchter. 8. 199-201. 2 Textf.

Nilsson, F. und G. Eriesson, 1936. Potatisodling och potatisförsök i Västernorrlands län. Sveriges Utsädesförenings Tidskrift. 46. 43-61, 87-115. 2 Textf.

Nilsson-Ieissner, G., 1936. General organisation of plantbreeding in Sweden. Ber. Intern. Kongr. Pflanzenz.. Wageningen. 1. 126-128.

Nilsson-Leissner, G., 1936. Die Prüfung der Neuzüchtungen von Weidepflanzen beim Schwedischen Saatzuchtverein. Der Züchter. 8. 182-185. I Textf.

Nuding, J., 1935. Leistung und Ertragsstruktur von Winterweizensorten in Reinsaat und. Mischung in verschiedenen deutschen Anbaugebieten. Pflanzenbau. 12. Jahrg. 382, 403. 3 Textf:

Nusbaum, Ch. J., 1935. A cytological study of the resistance of apple varieties to Gymnosporangium juniperi-virginianae. J. agricult. Res. 51. 573-596.

Oettingen, H. v., 1935. Die Zuchtmethoden I. W. Mitschurins. Pflanzenbau. 12. Jahrg. 477.

Olsson, P. A., 1936. Über die Methodik der Rübenzüchtung. Der Züchter. 8. $208-211$.

Oortwijn Botjes, 0., 1936. Aktuelle Problemer bei der Veredlung der Kartoffeln. Ber. Intern. Kongr. Pflanzenz., Wageningen. 1. 95--98.

Padwick, G. W., 1936. Biologie strains of Ophiobolus graminis Sacc. Ann. appl. Biol. 23. $45-56$.

Papadakis, J. S., 1936. L’Organisation générale de l'amélioration des plantes en Grèce. Ber. Intern. Kongr. Pflanzenz., Wageningen. 1. 81--84.

Papadakis, J. S., 1936. Problèmes actuels de l'amélioration du blé. Ber. Intern. Kongr. Pflanzenz., Wageningen. 1. 84-86.

Pesola, V. A., 1936. Die Organisation der Pflanzenzüchitungsarbeit in Finnland (Suomi), einschl. Weizen, Kartoffeln und Zuckerrüben. Ber. Intern. Kongr. Pflanzenz., Wageningen. 1. 120 - 125 .

Plickert, K., 1936. Die Züchtung der großblumigen superbissima-Petunien. Der Züchter. 8. 255-260. 2 Textf.

Quanjer, H. M., 1936. Actual problems of potatobreeding. Report Intern. Congress Plantbreeders, Wageningen. 2. 5-11.

Rademacher, B., 1935. Genetisch hedingte Unterschiede in der Neigung zu physiologischen Störungen beim Hafer (Flissigkeit, Dörrfleckenkrankheit, Urbarmachungskrankheit, Blattröte). Zeitschr. f. Züchtung, Reihe A. 20. 210. 5 Textf.

Rademacher, B. und H. Klee, 1936. Herabminderung der Schäden durch die Weizengallmücken Contarinia tritici Kirby und Sitodplosis mosellana Géhin auf dem Wege der Sortenwahl und Züchtung. Zeitschr. f. Züchtung, Reihe A. 21. 209. 
Rhind, D., 1935. A note on photo-periodism in sesanum. Indian J. agricult. Sci. 5. 729 bis 736 .

Rhoades, M. M. and B. MeClintock, 1935. The cytogenetics of maize. Bot. Review. 1 . $292-325$.

Riede, W., 1935. Deutsche Sojazüchtung. Mitteilgn. f. d. Landwirtschaft. 50. 804.

Roemer, Th., 1935. Nacktgerste. Mitteilgn. f. d. Landwirtsch. 50. 1093.

Roemer, Th., 1935. Blütenbiologische Forschungen an Kulturpflanzen. Pflanzenbau. 12. Jahrg. 223. 3 Textf.

Rudloff, C. F., 1936. Einiges über die Veredlung der Obstgewächse. Münchner medizin. Wochenschr. 62. Jahrg. 1093-1094.

Rudloff, C. F. und H. Schanderl, 1935. Befruchtungsbiologische Studien an Aprikosen, Pfirsichen und Mandeln. Die Gartenbauwissenschaft. 9. 500.

Rudorf, W., 1935. Untersuchungen über den Einfluß veränderter Tageslängen auf Sorten von Sojabohnen (Soja hispida Moench) und Buschbohnen (Phaseolus vulgaris L.). Zeitschr. f. Züchtung, Reihe A. 20. 251. 6 Textf.

Rudorf, W. und G. Stelzner, 1935. Untersuchungen über lichtperiodische und Temperaturnachwirkung bei Sorten von Salat (Lactuca sativa var. capitata L.) und die Möglichkeit ihrer Ausnutzung im Gemüsebau. (Vorläufige Mitteilung). Die Gartenbauwissenschaft. 9. 142. 3 Textf.

Salaman, R. N., 1936. Recent work on potatobreeding in Great Britain. Ber. Intern. Kongr. Pflanzenz., Wageningen. 1. $79-80$.

Searls, Ed. M., 1935. The relation of foliage color to aphid resistance in some varieties of caming peas. J. agricult. Res. 51. $613-619$.

Sengbusch, R. v., 1935. Züchtung von Lupinen mit nichtplatzenden Hülsen? Mitteilgn. f. d. Landwirtschaft. 50. 1113.4 Textf.

Sengbusch, R. v., 1936. Probleme der Süßlupinenzüchtung. Forsch.dienst. 1. 580-583.

Sengbusch, R. v., 1936. Ein Beitrag zum Eiweißproblem. Deutsche medizin. Wochenschr. 62. Jahrg. $648-650$.

Siebert, K., 1935. Die Zattelwicke, ihre Zucht und ihr Wert als eiweißreiche Futterpflanze. Pflanzenbau. 12. Jahrg. 83.

Snell, K., 1936. Physiologische Untersuchungen zur Unterscheidung und Kennzeichnung der Weizensorten. Angew. Botanik. 18, H. 4/5. 361.

Snell, K. und H. Geyer, 1936. Die Kartoffelsorten der Reichssortenliste, ihre Erkennung, Unterscheidung und wirtschaftliche Verwertung. Berlin: Parey. 84 S. $8^{0}$. 30 Textf.

Schlumberger, 0., 1936. Prüfung von Kartoffelsorten auf Schorfwiderstandsfähigkeit. Mitteilgn. f. d. Landwirtschaft. 51. 57.

Schmidt, H., 1936. Korbweidenzucht. Mitteilgn. f. d. Landwirtschaft. 51. 81. 2 Textf.

Sehmidt, W., 1936. Rassenbiologisehe Fragen bei unsern Waldbäumen. Der Naturforscher. 13. $253-258.7$ Textf.

Schneider, F., 1935. Die Züchtung von Winterzuckerrüben. Zuckerrübenbau. 17. 125. 3 Textf.

Schneider, F., 1936. Probleme der Zuckerrübenzüchtung Deutschlands. Berichte Intern. Kongr. Pflanzenz., Wageningen. 1. 38-39.

Stadnik, J., 1936. L'Organisation générale del a sélection des plantes en T'chécoslovaquie. Ber. Intern. Kongr. Pflanzenz., Wageningen. 1. 12-15.

Stakman, E. C., 1936. The problem of specialisation and variation in phytopathogenic Fungi. Genetica. 18. 372-389.

Stakman, E. C., M. N. Levine, J. J. Christensen und K. Isenbeck, 1936. Die Bestimmung physiologischer Rassen pflanzenpathogener Pilze. Nova acta Leopoldina. 3. 282-336. 5 Taf.

Stapp, C. und H. Hähne, 1936. Zur Frage der Resistenz von Buschbohnensorten gegen den Erreger der Fettfleckenkrankheit Pseudomonas medicaginis var. phaseolicola Burkh. Angew. Botanik. 18, H. 3. 249.

Stehlik, V., 1936. Aktuelle Fragen über Veredlung von Zuckerrüben in der Tschechoslowakei. Ber. Intern. Kongr. Pflanzenz., Wageningen. 1. 17-20. 
Stevenson, T. M. and J. S. Clayton, 1936. Investigations relative to the breeding of con-marin-free sweet clever, Melilotus. Canad. J. Res. 14, Sect. C. 153-165.

Straib, W., 1936. Über Gelbrostanfälligkeit und -resistenz der Gerstenarten. Arb. aus d. biolog. Reichsanstalt $f$. Land. u. Forstwirtschaft. 21. 467.

Straib, W., 1936. Infektionsversuche mit biologischen Rassen des Gelbrostes auf Gräsern. Arb. aus d. biolog. Reichsanstalt f. Land- u. Forstwirtschaft. 21. 483.

Sylvén, N., 1936. Klöver- och timotejutsäde för olika delar av landet. Sveriges Utsädesförenings Tidskrift. $46.80-86$.

Sylvén, N., 1936. Die natürliche Auslese im Dienste der Rotkleezüchtung. Der Züchter. 8. $179-182$. 3 Textf.

Tedin, 0., 1936. The present problems of potato-breeding. Ber. Intern. Kongr. Pflanzenz., Wageningen. 1. 130-131.

Todaro, F., 1936. Organisation générale de la sélection de plantes en Italie, le blé, la pomme de terre et la betterave à sucre. Ber. Intern. Kongr. Pflanzenz., Wageningen. 1. $87-89$.

Torrie, T. H., 1936. Inheritance studies of several qualitative and quantitative characters in spring wheat crosses between varieties relatively susceptible, resistant to drought. Canadian Journ. of Research. 14. 368-385.

Torssell, R., 1936. Faktoren, die die Samenbildung der Luzerne beeinflussen. Der Züchter. 8. $196-198$.

Tschermak, E. von, 1936. Die allgemeine Organisation der Pflanzenzüchtung in Österreich. Ber. Intern. Kongr. Pflanzenz., Wageningen. 1. 102-106.

Tschermak, E. von, 1936. Die jetzigen Probleme der Weizenzüchtung. Ber. Intern. Kongr. Pflanzenz., Wageningen. 1. 106-107.

Tschermak, E. von, 1936. Die jetzigen Probleme der Kartoffelzüchtung. Ber. Intern. Kongr. Pflanzenz., Wageningen. 1. 107-108.

Ullmann, W., 1936. Natürliche und künstliche Bastardierung zwischen Gräserarten und -gattungen. Forsch.-dienst. 1. 655-684.

Unglaub, H., 1935. Die Prïfung einiger Sorten des Walschen Weidelgrases (Lolium italicum) für den Anbau im mittleren Ostdeutschland. Pflanzenbau. 12. Jahrg. 12. 8 Textf.

Vilmorin, R. de et A. Meunissier, 1936. La sélection chez la betterave à sucre. Ber. Intern. Pflanzenz. Kongr., Wageningen. 1. 72-76.

Voss, J., 1936. Über Phenolfärbung und Carotinoidgehalt von Weizen und ihre Verwendung zur Sortenunterscheidung. Angew. Botanik. 18. 149. 5 Textf.

Voss, J., 1936. Experimentelle Auslösung des Schossens und Prüfung der Schoßneigung der Rübensorten (Beta vulgaris L.). Angew., Botanik. 18. 370. 11 Textf.

Vries, o. de, 1936. Probleme und Erfolge der Pflanzenzüchtung bei den mehrjährigen Kulturen in Niederländisch-Indien, insbesondere beim Kautschuk. Kongreßbericht Intern. Kongreß der Pflanzenz., Wageningen. 2. 58-68. 7 Textf.

Vries, O. de und W. Feekes, 1936. Aktuelle Probleme bei der Weizenzüchtung in den Niederlanden. Ber. Intern. Kongr. Pflanzenz., Wageningen. 1. 92-95.

Wahlen, F., 1936: Die Organisation der Pflanzenzucht in der Schweiz. Ber. Intern. Kongr. Pflanzenz., Wageningen. 1. 117-119.

Walstedt, I., 1936. Present problems of sugar-beet breeding in Sweden. Ber. Intern. Kongr. Pflanzenz., Wageningen. 1. 131-133.

Wegener, H., 1936. Die Einfuhr und Zucht fremder Gartenblumen im 16. Jahrhundert. Gartenflora. 85. 84-86. 4 Textf.

Wegener, H., 1936. Die Methoden der Pflanzenzucht im 16. u. 17. Jahrhundert. Gartenflora. 85. $138-140.4$ Textf.

Weiner, J. L. and B. A. Madson, 1936. Relative resistance of bacterial wilt of certain commercial and selected lots of alfalfa. J. agricult. Res. 52. 547--555.

Wenk, H., 1936. Kartoffelzüchtungsfragen. Prakt. Blätter f. Pflanzenbau u. Pflanzenschutz. 14. Jahrg. 2. 4 Textf.

Wettstein, W. v., 1936. Die Pappeln der Anlagen und Parke. Gartenflora. 85. 35-38. 11 Textf.

Wettstein, W. v., 1936. Über die Kanadische Pappel. Gartenflora. 85. 185-186. 
Winge, ö., 1936. Linkage in Pisum. C. r. Trav. Labor. Carlsberg Sér. physiol. 21. 271--393. Woodworth, C. M., 1936. Inheritance of seedling stem color in a boomcorn-sorghum cross. J. amer. Soc. Agronomy. 28. 325-327.

Zimmermann, K., 1936. Die Züchtung von Lupinen mit nichtplatzenden Hülsen. I. Anatomie und Morphologie der Lupinenhülsen. Der Züchter. 8. 231-240. 18 Textf.

Zuhr, E. und H. Wildner, 1935. Über die Ertragsleistungen englischer Markstammkohlsorten. Pflanzenbau. 12. Jahrg. 156, 207.

\section{Vb) Tiere}

Antonius, 0., 1935. Über die Tigerfarbe des Pferdes, insbesondere des Norikers. Zeitschr. f. Gestütkunde u. Pferdezucht. 30. 57, 131. 1 Taf. 1 Textf.

Brandt, A. E., 1936. A note on dominant white and crest in poultry. Flecks and comb shape make possible identification of heterozygotes. J. Hered, 27. $79-82$.

Burmeister, W., 1936. Fortpflanzung, Vererbung und Zuchtverfahren in der Kaninchenzucht. Lehrmeister-Bücherei. 1078-1080. 144 S., 80. 27 Textf.

Butz, 0., 1935. Inzucht. Vorzüge - Gefahren. Zeitschr. f. Schweinezucht. 43. 197.

Carstens, P., 1936. Der gegenwärtige Stand der Leistungszucht in unserer deutschen Rindviebhaltung. Forsch.dienst. 1. 63-66.

Claussen, P., 1936. Die männlichen Erblinien des Angler Rindes. Herdbuchkontrollverband Angeln. $116 \mathrm{~S} .8^{0}$.

Constantinesco, G. K., 1935. Sur l'hérédité dans l'élévage des animaux domestiques. Verh. 12. internat. tierärztl. Kongr. 3. 422-434.

Dalling, T. and G. H. Warrack, 1936. Observations on fowl paralysis. The Veterinary Journal. 92. 310-319.

Dschaparidse, D., 1935. Die Zucht und Leistung des Hannover-braunschweigischen Landschweines (das deutsche Weideschwein). Journ. f. Landwirtschaft. 83. 161.

Dschaparidse, D., 1936. Beitrag zur Vererbung beim Schwein in der ersten Kreuzung. Zeitschr. f. Züchtung, Reihe B. 34. 335. 8 Textf.

Dschaparidse, D., 1936. Die Milchleistung der Schweine (Sammelreferat). Zeitschr. f. Züchtung, Reihe B. 34. 349.

Frölich, G., 1936. Blutlinienzucht bei Schweinen. Zeitschr. f. Schweinezucht. 43. 503.

Gilch, 1936. Leistungszucht. Der Ziegenzüchter. 30. Jahrg., Nr. 5. 37.

Gramatzki, D., 1936. Die Bedeutung der Perfectionist xx-Linie für die ostpreußische Warmblutzucht. Sankt Georg. 37. Jahrg., Nr. 20. 15. 9 Textf.

Gumppenberg, v., 1934. Deutschlands Schafzucht in Vergangenheit und Gegenwart. Süddeutsche Landw. Tierzucht. 28. 409.

Haugg, 1934. Die Tierzucht in Italien und Spanien. Süddeutsche Landwirtsch. Tierzucht. 28.388.

Henseler, H., 1936. Wesen und Bedeutung der Inzucht im Sinne von Verwandtschaftszucht als Zuchtverfahren. Forsch.dienst. 1. 533-536.

Henseler, H., 1936. Zwillingsforschung beim Rind. Deutsche Landwirtsch. Presse. 63. 388. 1 Textf.

Herre, W., 1936. Über den Nasenspiegel des Karakulschafes. Zeitschr. f. Züchtung, Reihe B. 34. 399. 9 Textf.

Hink, A., 1935. Zwillinge in der Tierzucht. Süddeutsche Landw. Tierzucht. 29. 342.

Hink, A., 1935. Zwillinge in der Tierzucht. Deutsche landwirtschaftl. Tierzucht. 39. Jahrg. 573. 4 Textf.

Iljin, N. A., 1936. Artificial Thallium moult in sheep. Journ. of Genetics. 33. 305-314. 5 Taf.

Koch, W., 1936. Über Mauleselzucht. Deutsche landwirtschaftl. Tierzucht. 40. Jahrg. 56.

Krallinger, H. F., 1936. Der Stand der Forschung auf dem Gebiet der Vererbung wirtschaftlich wichtiger Eigenschaften der Haustiere. Forsch.dienst. 1. 217-222.

Kronacher, C. und F. Hogreve, 1936. Beitrag zur Kenntnis etwaiger Beziehungen zwischen Blutgruppenzugehörigkeit and Milchleistung beim Rind. Zeitschr. f. Züchtung, Reihe B. 35. 89. 
Kronacher, C. und R. Hundsdörfer, 1936. Züchtungsbiologische Beobachtungen und die Ergebnisse fünfjähriger Leistungsprüfungen an der Schweineherde des Versuchsund Forschungsgutes Koppehof. Zeitschr. f. Züchtung, Reihe B. 34. 277. 2 Textf.

Kronacher, C. und J. Kliesch, 1936. Wie weit ist eine vermehrte Schweinefetterzeugung auf dem Wege der Gebrauchskreuzung möglich? Zeitschr. f. Züchtung, Reihe B. 34.327.

Kronacher, C., unter Mitarbeit von D. Sanders, 1936. Neue Ergebnisse der Zwillingsforschung beim Rind. Zeitschr.f. Züchtung, Reihe B. 34. 133. 205 Textf.

Lamprecht, 1936. Utber die Vererbung der Schweinefarben in Rassekreuzungen. Forsch.dienst. 1. 205-217.

Langlet, J., 1935. Ein Verfahren zur Durchführung der Erbkontrolle bei Karakulböeken. Zeitschr. f. Schafzucht. 24. 185.

Langlet, J., 1936. Zwillingsgeburten in der Karakul-Vollblutzucht. Zeitschr. f. Schafzucht. 25. 41. 5 Textf.

Langlet, J., 1936. Einiges über Haut, Haar und Lockenbildung beim Karakulschaf. Zeitschr. f. Schafzucht. 25.253.

Letard, E., 1935. Les applications de la génétiques à l'élevage des animaux domestiques. Verh. 12. internat. tierärztl. Kongr. 3. 437-449.

Meyer, F., 1936. Untersuchungen über die Milchleistung in sechs schwarzbunten Herden der Provinz Sachsen. Kühn-Archiv. 40. 79. 11 Textf.

Moskovtis, E., 1936. Die internationale Lage und die Probleme der Pferdezucht. Nueva Zootecnia. 7. $253-280$.

Munro, S. S., 1936. The relation of production to mortality in the domestic fowl. J. agricult. Sci. 26. $101-113$.

Mut, W., 1935. Hirtenhunde. Die ältesten Hunderassen der Welt. Norddeutsche Schäfereizeitung. 27. 4:

Nachtsheim, G., 1936. Was ist eine reine Rasse? Der Kaninchenzüchter. 12. Jahrg. 353, 369, 399. Je 9 Textf.

Papadopoulo, D. 0., 1936. Die Schafschläge der Insel Kreta. (Das Sitiaschaf und das Szakiaschaf.) Zeitschr. f. Züchtung, Reihe B. 35. 107. 14 Textf.

Roemmele, O., 1935. Das Zungenschlagen der Rinder - ein Erbfehler. Untersuchungen und Heilungsversuche über dieses Leiden. Süddeutsche Landw. Tierzucht. 29. 339. 1 Textf.

Samim, V., 1936. Kreuzung zwischen dem ungarischen Rambouillet- und dem albanischen Zackelschaf. Zeitschr. f. Schafzucht. 25. 11. 5 Textf.

Schäper, W., 1935. Über todbringende Erbanlagen (Letalfaktoren) in der Schweinezucht. Zeitschr. f. Schweinezucht. 42. 723. 2 Textf.

Sehäper, W., 1936. Konstitutionsforschung und Krankheitsbekämpfung in der Tierzucht. Zeitschr. f. Züchtung, Reihe B. 35. 1.

Seheingraber, M., 1934. Milchschafrassen. Zeitschr. f. Schafzucht. 23. 293, 319. 23 Textfiguren.

Scherbatoff, N., 1935. Russische Traberzucht. Zeitschr. f. Gestütkunde u. Pferdezucht. 30. 95. 3 Textf.

Schilke, 1936. Fahne, die erfolgreichste ostpreußische Mutterstute. Eine Spitzenleistung in Vererbung und Fruchtbarkeit. Sankt Georg. 37, Nr. 14. 16. 3 Textf.

Schmidt, J., E. Lauprecht und H. Staubesand, 1936. Untersuchungen über die Vererbung der Trächtigkeitsdauer, des Geburtsgewichtes und der Zitzenzahl beim Schwein. Zeitschr. f. Züchtung, Reihe B. 35. 55. 10 Textf.

Schürkamp, H., 1936. Vom Schimmel zum Schimmel. Eine zuchtgeschichtliche Betrachtung. Deutsches Kaltblut. 9. 255.

Siebeneick, H., 1936. Untersuchungen über die Vererbung der Miloh- und Fettleistung durch den Bullen ,Mozart 4622" in der Provinz Sachsen. Kühn-Archiv. 40. 105.

Smith, T. M., 1936. Sheep breeding experiments of the government stock farm and agricultural station of Palestine. The Veterinary Journ. 92. 174-175.

Tapias, M., Betrachtungen zum biometrischen Studium der Viehzüchtung. (Spanisch.) Nueva Zootecnia. 4. 146-151. 
Williams, W. L., 1936. Observation on some aspects of horse breeding. The Veterinary Journal. 92. 119-126.

Winters, L. M., 1935. 6 Jahre Studium über Rassenkreuzung bei Schweinen. (Spanisch.) Nueva Zootecnica. 7. 167-173.

Wodzicki, Kazimierz, 1936. Ưber die Unbeständigkeit der Hühner der Faverollesrasse auf Grund der Spaltung einiger morphologischer Merkmale in einer Population von Faverolleshennen. Zeitschr. f. Züchtung, Reihe B. 34. 241. 14 Textf.

Wowra, 1935. Eine Beschreibung der deutschen Schweinerassen. Zeitschr. f. Schweinezucht. 42. 177. 12 Textf.

Zeeb, 1936. Die Züchtung der Ziege. Der Ziegenzüchter. 30. Jahrg., Nr. 9. 81.

\section{Ve) Mensch}

Anonymus, 1935. Erb- und Rassenpflege. Deutsches Reich: Gesetz zur Änderung des Gesetzes zur Verhütung erbkranken Nachwuchses vom 26.6.35. Reichsgesundheitsblatt 1935. 10. Jahrg., Nr. 31. 662.

Anonymus, 1935. Schwangerschaftsunterbrechung aus rassehygienischen Gründen. Neues Volk. 3. Jahrg., Nr. 8. 40-41.

Anonymus, 1935. Zehn Gebote für die Gattenwahl. Neues Volk. 3. Jahrg., Nr. 10. 10-11.

Anonymus, 1936. Anleitung zur erbbiologischen Bestandsaufnahme in den Heil- u. Pflegeanstalten. Psychiatr.-neur. Wochenschr. 38. Jahrg. 220-222.

Anonymus, 1936. Die Nürnberger Gesetze in Übersichtstafeln. Neues Volk. Heft 5. 20.

Anonymus, 1936. Dithmarscher Geschlechterbund. Neues Volk. Heft 6. 36-39.

Anonymus, 1936. Kinderzahl und Begabung. Neues Volk. 4. Jahrg. H. 10.

Anonymus, 1936. The Bureau of human heredity (London). J. belge de Neur. 36e Ann. 637.

Anossow, G., 1936. Zur Geschichte des delinquente nato. Mschr. Kriminalpsychol. 27. Jahrg. 313-325.

Ardashnikow, S. N., 1934. On the genetics of leukemia. (Russisch; m. engl. Zus.) Proceedings of the medico-biological institute Moscow. 3. 169-188. 4 Taf. 6 Textf.

Arndt, Gro, 1936. Über den Zusammenhang zwischen sozialer Lage und den Kiefer- und Zahnstellungsanomalien bei Volksschulkindern des Stadt- und Landkreises Neiße. Greifswald, Med. Diss. Greifswald: Adler. $20 \mathrm{~S}$. $8^{\circ}$.

Baboukhine, E. et G. Tehistiakow, 1935. Constitution et tuberculose. (Russisch.) Les problemes de tuberculose Moscou. 7. 99-120. 8 Taf. 6 Textf.

Balthasar, K., 1935. Vererbung und Schicksal. Deutsche medizin. Wochenschr. 61. Jahrg. $2051-2055$.

Bandel, R., 1936. Alcohol consumption and alcoholism in connection with race, profession, age and season. Forschungen zur Alkoholfrage. 122-129.

Bassow, L., 1935. Kriminalitāt und geistige Abnormitāt in W. Deutsche medizin. Wochenschrift. 61, Jahrg.

Bauer, J., 1935. Dangerous slogans from the fields of eugenics and genetics. Marriage Hyg. 2. 139-144.

Bauex, J., 1935. Gefährliche Schlagworte auf dem Gebiet der Erbbiologie. Schweizerische medizin. Wochenschr. 65. Jahrg. 633-635.

Bauer, J., 1936. Über die Beziehungen der Vererbungslehre zur Endokrinologie. Schweizer. medizin. Wochenschr. 66. Jahrg. 456-460.

Bauer, J., 1936. Zur Beurteilung der durch Sterilisierung erzielbaren eugenischen Resultate. Wiener medizin. Wochenschr. 86. Jahrg. 881-883.

Bauermann, A., 1936. Die Vererbung von Mißbildungen an Fingern und Zehen und ihre medizinisch-gerichtliche Bedeutung. München, Med. Diss. Leipzig: Edelmann. $26 \mathrm{~S} .8^{\circ}$.

Bieling, R., 1935. Gestaltungsfaktoren der Tuberkulose. (Verhandlungsber. d. deutsch. Tuberkulose-Tagung 1935 in Bad Kreuznach.) Beiträge zur Klinik d. Tuberkulose. Julius Springer, Berlin. 86. 8. (Schluß-)Heft. 501-527. 8 Textf.

Bijlmer, H. J. T., 1936. De verhouding van de eugenese tot de geneeskunde. Erfelijkheid bij de mens. 2. 161-168. 
Binswanger, L., 1936. Anthropologie, Psychologie, Psychopathologie. Schweizerische medizin. Wochenschr. 66. Jahrg. $679-681$.

Bissik, L. J., 1934. On the roles of heredity and environment in the physiology and pathology of childhood. (Russisch; m. engl. Zus.) Proceedings of the medico-biological institute Moscow. 3. 33-56. 13 Taf.

Bijlmer, H. J. T., 1936. Het bestaansrecht van de eugenese. Mensch en Maatschappij. 12. $39-49$.

Blacker, C. P., 1936. The future of our population. The Eugenies Review. 28. $204-212$.

Bluhm, A., 1936. Die rassenhygienischen Aufgaben des weiblichen Arztes. Berlin: C. Metzner. Schriften zur Erblehre und Rassenhygiene. 99 S. $8^{0}$.

Boeters, D., 1936. Belastungsstatistik einer schlesischen Durchschnittsbevölkerung. Untersuchungen an 211 Familien. Z. Neur. 155. 675-701.

Boeters, H., 1936. Untersuchungen über den Familienaufbau und Fruchtbarkeitsziffern bei rußlanddeutschen Bauern. Arch. f. Rassen- u. Gesellschaftsbiologie. 30. 36-42.

Bogaert, L. van, 1936. L'hérédité hétérophéne et sa valeur nosographique. Bull. Acad. Méd. Belg. VI. s. 1. $9-16$.

Bohne, G., 1957 Rechtsfragen zur Sterilisation und Kastration. Deutsche medizin. Wochenschrift. 61. Jahrg. 1167-1170.

Bossik, L. J., E. J. Passynkoff and J. B. Gurevich, 1934. Therapeutic studies of identical twins. (Russisch; m. engl. Zus.) Proceedings of the medico-biological institute Moscow. 3. 119-131. 4 Taf. 7 Textf.

Böttger, E., 1936. Der Pflichtenkreis des Arztes bei der Sterilisation gemäß § 226a St.G.B. Zeitschr. f. Rassenphysiologie. 8. 49-51.

Brandt, H. 0., 1936. Das Geschlecht der Fugger. Ein biologischer Überblick. Zeitschr. f. Rassenkunde. 4. 113-124. 3 Textf.

Breger, J., 1935. Die Rückwirkung der Geschlechtskrankheiten auf die Rasse. Reichsgesundheitsblatt. 10. Jahrg., Nr. 36. 791-794.

Brugger, C., 1936. Die Fruchtbarkeit der erblich Schwachsinnigen. Schweizer Archiv f. Neurologie u. Psychiatrie. 37. 229-237.

Brugger, C., 1936. Die eugenische Bedeutung der chronischen Alkoholiker. Schweizerische medizin. Wochenschr. 66. Jahrg. 381-383.

Bühler, E., 1935. Sichtbares Erbgut. Neues Volk. 3. Jahrg., Nr. 11. 8-12. 7 Textf.

Burckhardt, 1936. Erblehre und Zahnheilkunde. Köln, Med. Diss. Krefeld: v. Ackern. 46 S. $8^{\circ}$.

Burgdörfer, F., 1936. Verstädterung im Licht der Bevölkerungsstatistik und Bevölkerungspolitik. Volk und Rasse. 11. Jahrg., H. 5. 169-178. 6 Textf.

Bürger-Prinz, H., 1936. Hohe Begabung und Erbbiologie. Der Naturforscher. 13. 181 bis 184 .

Cattell, R. B., 1936. Is national intelligence declining ? Eugenics Review. 28. 181-203.

Charles, E., 1936. The effect of present trends in fertility and mortality upon the future population of Scotland and upon its age composition. Proc. roy. Soc. Edinburgh. 56. $6-12$.

Claussen, F., 1935. Zur Eröffnung des Instituts für Erbbiologie und Rassenhygiene der Universität Frankfurt, Deutsche medizin. Wochenschr. 61. Jahrg. 1209-1210.

Cotte, K. H., 1935. Ủber Zusammenhänge zwischen sozialer Schichtung der Eltern und Durchbruchszeiten der bleibenden Zähne bei Schulkindern. Göttingen, Med. Diss. Ellrich: Krause. $19 \mathrm{~S} .8^{\circ}$.

Croon, R., 1935. Erblichkeitsfragen bei Trinkern. Gießen, Med. Diss. Gießen: v. Münchow. 24 S. $8^{\circ}$.

Davidenkow, S. N., 1934. Die Probleme des Polymorphismus der ererbten Krankheiten des Nervensystems. Klinisch-genetische Untersuchung. (Russisch; m. deutscher Zus.) Leningrad, Institut der Experimentalmedicin U.S.S.R. 1. 139. F. in octavo. 5 Taf. 40 Textf.

Eckert, G., 1936. Die Zahl der Asiaten in der Südsee. Arch. f. Wanderungswesen. 8. Jahrg. 94-99. 
Eickstedt, E. v., 1936. Können Rassendiagnosen überhaupt exakt gestellt werden ? Zeitschr. f. Rassenkunde. 4. 145-157. 1 Textf.

Engel, R., 1936. Ärztliche Forderungen zum Sterilisationsgesetz. Erlangen, Med. Diss. Dresden: Risse-Verlag. $13 \mathrm{~S} .8^{0}$.

Ewald, G., 1936. Nochmals die Epilepsie im Sterilisationsverfahren. Medizin. Klinik. 32. Jahrg. $1131-1133$.

Finnisehe Regierung, 1935. Sterilisierungsgesetz vom 3.6. 1935. Reichsgesundheitsblatt. 10. Jahrg. 761-762.

Frets, G. P., 1936. Erbliche Belastung in der Durchschnittsbevölkerung. Genetica. 18. 66-96. 5 Taf. 15 Textf.

Frick, W., 1936. Das nordische Gedankengut in der Gesetzgebung. Volk u. Rasse. 11. Jahrg., H. 8. 317-320. 1 Textf.

Friedl, E., 1935. Über den Zusammenhang zwischen sozialer Lage und Zahnreihenanomalien bei den Schulkindern Regensburgs. Würzburg, Med. Diss. Wertheim a. M.: Bechstein. 8 S. $8^{\circ}$.

Friese, 1936. Kleine Beiträge: Wissenschaftliche Erbpflege oder Erbkurpfuscherei ? Volk u. Rasse. 11. Jahrg., H. 7. 298-301.

Fürst, Th., 1936. Die Verwertung der konstitutionsbiologischen Diagnostjk für die soziale Volkspflege. Hippokrates. 7. Jahrg. 341-344.

Geldner, E., 1935. Zur Frage der Erbkranken auf dem Gebiete der Orthopädie. Zum Gesetz zur Verhütung erbkranken Nachwuchses vom 14. Juli 33. München, Med. Diss. Speyer a. Rh.: Pilger-Druckerei. $40 \mathrm{~S} .8^{\circ}$.

Geller, W., 1936. Was kann die physiologische Chemie zur Diagnostik der Erbkrankheiten beitragen? Psychiatr.-neur. Wochenschr. 38. Jahrg. 307-312.

Gemmel, A., 1936. Úber den Einfluß der sozialen Verhältnisse auf den Zustand des Kindergebisses. Würzburg, Med. Diss. Würzburg: Mayr. 24 S. 80.

Gerlach, H. J., 1936. Ein seltener Fall angeborener multipler Mißbildungen und seine Beziehungen zum Gesetz zur Verhütung erbkranken Nachwuchses (Fibuladefekt, Klumpfuß, Spalthand). Rostock, Med. Diss. Rostock: Neumann. 21 S. $\mathbf{8}^{\circ}$.

Göllner, H., 1935. Die jüdischen Mischehen im Reich und in Berlin. Reichsgesundheitsblatt. 10. Jahrg., Nr. $46.980-983$.

GroB, W., 1936. Drei Jahre rassenpolitische Aufklärungsarbeit. Volk u. Rasse. 11. Jahrg., H. 8. 331-337. 6 Textf.

Grothe, H., 1936. Die Wanderungsbewegung der Kulturvölker im Lichte geopolitischer Betrachtung. Archiv f. Wanderungswesen. 8. Jahrg. 83-88.

Günther, H. F. G., 1936. Die Verstädterung. Volk u. Rasse. 11. Jahrg., H. 5. 167-168.

Gurevitch, J. B., 1936. Heredity and environment in the variability of the size of the heart. (Russisch.) Bulletin de biologie et de médecine expérimentale de l'U.S.S.R. Moscou. 1. 9. 2 Taf.

Gütt, A., 1936. Gesundheits- und Ehe-Gesetzgebung im Dritten Reich. Volk u. Rasse. 11. Jahrg., H. 8. 321. 4 Textf.

Gütt, A., 1936. Leibesübung im Dienst der Rassenpflege. Deutsche medizin. Wochenschr. 62. Jahrg., Olympiafestschr. 45-47.

Gütt, A., 1936. Stellungnahme zum Gesetz zur Abänderung des Gesetzes zur Verhütung erbkranken Nachwuchses. Reichsgesundheitsblatt. 10. Jahrg. 663.

Haag, F. E., 1936. Zur sippenmäßjgen Bestandesaufnahme des deutschen Volkes. Volk u. Rasse. 11. Jahrg, H. 4. 145-147.

Haberlandt, H. F. O., 1936. Die Frühsterilisation. Deutsche medizin. Wochenschr. 62. Jahrg. 1502 .

Harmsen, 1936. Die Durchführung des Gesetzes zur Verhütung erbkranken Nachwuchses in den Anstalten der Inneren Mission. Z. psych. Hyg. 9. 20-22.

Hartnack, W., 1936. Das deutsche Volk lebt rom aufgeschobenen Tode. Aus: „Die Ungeborenen“, Verlag J. F. Lehmann, München. Volk u. Rasse. 11. Jahrg. 119-124. 4 Textf.

Hartnack, W., 1936. Volksschullehrer mit oder ohne Abitur? Volk u. Rasse. 11. Jahrg. $141-143$. 
Hartnack, W., 1936. Abwanderung der Begabung vom Lande und der Kleinstadt in die Großstadt. Volk u. Rasse, 11. Jahrg. $182-186$.

Hartnack, W., 1936. Verschärft oder mildert sich die soziale Gegenauslese? Volk u. Rasse. 11. Jahrg. 374-378. 1 Textf.

Haselhorst, G., 1935. Unsere bisherigen Erfahrungen mit der eugenischen Sterilisierung der Frau. Deutsche medizin. Wochenschr. 61. Jahrg. 1683-1686.

Haubold, 1935. Übersicht über die wichtigsten neueren gesundheitspolitischen Maßnahmen und Gesetze der Reichsregierung. Reichsgesundheitsblatt. 10. Jahrg. 693-695 u. $890-892$.

Hellhammer, Fr,, 1935. Untersuchungen über Zahn- und Mundschleimhauterkrankungen bei der Hitlerjugend der Unterbanıe I u. II des Bannes 99, unter Berücksichtigung sozialer Verhältnisse. Münster, Med. Diss. Botrop i. W.: Postberg. 13 S.

Hilgers, J., 1936. Ein Beitrag zur Erbbiologie der seltenen angeborenen Körperfehler an den Gliedmaßen. Orthop. 64. 288-298.

Hinnichsen, V., 1936. Genie, Irrsinn und Ruhm im ungarischen Geistesleben. Schweizerische medizin. Wochenschr. 66. Jahrg. 551-552.

Hodermann, W., 1936. Erbbiologische, auslanddeutsche Sippenkunde. Neues Volk. 4. Jahrg., H. $11.20-21$.

Hodson, C. B. S., 1936. International federation of Eugenic organizations. The Eugenics Review. 28. 217-219.

Hohlfeld, J., 1936. Wanderungen des Blutes. Arch. f. Wanderungswesen. 8. Jahrg. 123 bis 125 .

Hooton, E. A., 1936. Plain statements about race. Science (N. Y.). 1. 511-513.

Huxley, T. S., 1936. Eugenics and Society. Eugenics Review. 28. 11-31.

Institut für Sehwedischen Auslandsdienst, 1936. Kurze Darstellung der Schwedischen Auswandererbewegung. Arch. f. Wanderungswesen. 8. Jahrg. 89-94.

Jesz, F., 1936. Verkennung der Rassenfrage. Neues Volk. 28-30. Heft 8.

JeR, F., 1935. Die Erblichkeitsgesetze als Grundlage unserer Weltanschauung. Neues Volk. 3. Jahrg., Nr. 12. 18-20.

Jones, D. C., 1936. Eugenic aspects of the mersey side survey. Eugenics Review. 28. $103-114$.

Juda, A., 1936. UUber die Häufigkeit des Vorkommens der sogenannten ,physiologisehen Dummheit" in Familien von schwachsinnigen und normalen Schülern. Ist es möglich, derartige Fälle nach ihrer Zugehörigkeit zur einen oder anderen Gruppe erbbiologisch zu werten? Allg. Z. Psychiatr. 104. 347-383.

Judin, T. J., 1935. A contribution to the theory of rast constitutional cycles and polihybridity in the inheritance of psychoses. (Russisch; $m$. franz. u. engl. Zus.) Sowiet Psychoneurologie Charkow. 6. 30-39. 1 Taf.

Keiter, F., 1935. Bevölkerungswissenschaft als Hygiene. Reichsgesundheitsblatt. 10. Jahrgang, Nr. 36. 788-791.

Keiter, F., 1936. Die Standesherkunft berühmter Männer. Volk u. Rasse. 11. Jahrg., H. 4. 124-129. 3 Textf.

Keller, L., 1936. Die fragliche Wirkung hochgradiger Inzucht unter besonderer Berücksichtigung eines bestimmten Genes. München, Med. Diss. München: Wolf. 13 S., $8^{0}$.

Kleine, H. O., 1936. Zur Kritik des deutsehen Erbgesundheitsgesetzes in Österreich. Ziel u. Weg. 6. Jahrg. 585-586.

Klunker, J., 1936. Genügen unsere heutigen Kenntnisse über den Diabetes mellitus zu dessen Einreihung unter die Erbkrankheiten im Sinne des Gesetzes vom 14. Juli 1933 ? München, Med. Diss. München: Gässler. $8 \mathrm{~S} .4^{0}$.

Knab, K., 1936. Erbbiologische Bestandesaufnahme der Insassen der öffentlichen Heil- $u$. Pflegeanstalten u. offene Fürsorge für Geisteskranke. Psychiatr.-neur. Wochenschr. 38. Jahrg. 211-212.

Knorr, W., 1936. Kinderreichenauslese durch das Rassenpolitische Amt der NSDAP in Sachsen. Volk u. Rasse. 11. Jahrg., H. 7. 269-275. 1 Textf.

Koch, H., 1936. Das Vinderen Biologiske Laboratorium. Ein Rückblick: 1915 bis 1935. Kampf um die Rassenhygiene. Volk u. Rasse. 11. Jahrg., H. 6. 250-254. 1 Textf. 
Kranz, H., 1936. Lebensschicksale krimineller Zwillinge. Berlin: Springer. IV, 251 S. $4^{0}$. Kraus, H., 1936. Zur Frage der eugenischen Schwangerschaftsunterbrechung. Medizin. Klinik. 32. Jahrg. 862-864. 4 Textf.

Kreyenberg, 1936. Über psychische Regelwidrigkeiten bei Taubstummen und ihren Sippen und ihre Begutachtung für das Erbgesundheitsgericht. Allg. Z. Psychiatr. 105. $102-103$.

Labhardt, A., 1936. Medizinische und nicht-medizinische Indikationen zur Sterilisation. Schweizerische medizin. Wochenschr. 66. Jahrg. 50-52.

Lange, J. und F. Exner, 1936: Bemerkungen zu Stumpfl: Erbanlage und Verbrechen. Mschr. Kriminalpsychol. 27. Jahrg. 329-339.

Lange, J. und F. Exner, 1936. Die beiden Gründbegriffe der Kriminologie. Mschr. Kriminalpsychol. 27. Jahrg. 353-374.

Lange, M., 1936. Das Ehegesundheitsgesetz und die angeborenen körperlichen Mißbildungen. Münchner medizin. Wochenschr. 83. Jahrg. 1420. 12 Textf.

Lehmann, W., 1936. Der Anteil von Erbe und Umwelt bei der Krankheitsentstehung und die Frage der äußerlich gesunden Erbanlagenträger. Medizin. Klinik. 32. Jahrg. 930-932. 2 Textf.

Levin, A. E. and B. A. Kuchur, 1934. The role of hereditary factors in the etiology of ulcerous disease. (Russisch; m. engl. Zus.) Proceedings of medico-biological institute Moscow. 3. 148-153. 3 Taf.

Levit, S. G. and L. N. Pessikova, 1934. The genetics of diabetes mellitus. (Russisch; m. engl. Zus.) Proceedings of the medico-biological institute Moscow. 3. 132-147. 9 Taf. 9 Textf.

Licausi, E., 1936. L'educazione fisica e l'eugenica. Communicazione con prefazione di P. Capasso. 2. edit. Napoli; Pansiero sanitario. $29 \mathrm{~S} .16^{\circ}$.

Lienau, A., 1936. Úber Schizophrenie und Epilepsie im Lichte des Erbgesundheitsobergerichtes. Allg. Z. Psychiatr. 105. 99-100.

Linden, H., 1936. Die neuen gesetzlichen Maßnahmen auf dem Gebiet der Erb- und Rassenpflege. Z. psych. Hyg. 9. 33-47.

Loeffler, L., 1936. Der Auslesegedanke als Forderung in der Medizin. Münchener medizin. Wochenschr. 83. Jahrg. 673-676.

Lottig, 1936. Erbbiologische Grundsätze im Adoptionsverfæhren. (Landesjugendverband Hamburg.) Allg. Z. Psychiatr. 105. 100-102.

Luxenburger, H., 1936. Zur Frage der Erbberatung in der Familie Schizophrener. Medizin. Klinik. 32. Jahrg. 1136-1138.

Luxenburger, H., 1936. Der heutige Stand der empirischen Erbprognose in der Psychiatrie als Grundlage für Maßnahmen der praktischen Erbgesundheitspflege. Zbl. Neur. 81. 1 -30. 82. $1-18$.

Malkova, N.N., 1936. A clinics-genetic study of bronchial asthma and other allergie diseases. (Russisch.) Bulletin de biologie et de médecine expérimentale de l'U.S.S.R. Moscou. 1. $7-8$.

Mayer, A., 1936. Die Bekämpfung des Alkoholismus in den neuen deutschen Erbgesundheitsgesetzen. Forschungen z. Alkoholfrage. $71-77$.

Meier, E. u. M. v. Mezynski, 1935. Das Ergebnis der ärztlichen Untersuchungen von Ehestandsdarlehensbewerbern Im dritten und vierten Vierteljahr 1934. Reichsgesundheitsblatt. 10. Jahrg., H. 35. 770-773.

Meinhof, 1936. Die Tătigkeit des Erbgesundheitsgerichts Hamburg im Jahre 1935. Allg. Z. Psychiatr. 105. 98-99.

Meteling, M., 1936. Erbhygienische Untersuchungen an Hilfsschulkindern des Stadtund Landkreises Recklinghausen. Münster, Med. Diss. Quakenbrück: Kleinert. 18 S. $8^{\circ}$.

Mezynski, M. von, 1935. Das Ergebnis der ärztlichen Untersuchungen von Ehestandsdarlehensbewerbern im zweiten Vierteljahr 1935. Reichsgesundheitsblatt. 10. Jahrg., H. 49. $1015-1016$.

Mudrow, L., 1936. Heiratsalter, Kinderzahl und verwandte biologische Verhältnisse bei ehemaligen Abiturientinnen. Arch. f. Rassen- u. Gesellschaftsbiologie. 30. 1-30. 3 Textf. 
Mühlmann, W. F., 1936. Das Begabungsproblen bei den Naturvölkern. Zeitschr. f. Rassenkunde. 4. $88-90$.

Miiller, K. V., 1936. Handwerker und Arbeiter in lebensgesetzlicher Bedeutung. Volk $u$. Rasse. 11. Jahrg., H. 5. 192-197. 1 Textf.

Naegeli, 1936. Grundsätzliche wichtige Ergebnisse der Konstitutionslehre und Konstitutionspathologie. Norsk Mag. Laegevidensk. 97. 217-223.

Neuendorff, G. H., 1936. Volk in Bildung (Psychologische Betrachtungen und Beobachtungen über Iberoamerika). Zeitschr. f. Rassenkunde. 4. 72-78.

Neukamp, F., 1936. Einige Vorschläge für Erb- und Ehegesundheitssachen. Mschr. Kriminalpsychol. 27. Jahrg. 243-252.

Nordmeyer, K., 1936. Allgemeine Inoperabilität bei den eugenischen Sterilisierungen. Medizin. Klinik. 32. Jahrg. 1428-1429.

Petermann, B., 1936. Ưber Ansatz und Reichweite des rassenmäBigen Anteils am Aufbau der seelisch geistigen Wirklichkeit. Zeitschr. f. Rassenkunde. 4. $78-86$.

Pietrusky, N., 1936. Über die praktische Brauchbarkeit der Blutfaktoren M und N für den Vaterschaftsausschluß, zugleich ein Beitrag zum Nachweis des defekten N-Rezeptors $\left(\mathrm{N}_{2}\right)$. Münchner medizin. Wochenschr. 83. Jahrg. 1123-1124.

Pratje, A., 1935. Die wissenschaftliche Auswertung der rassenkundlichen S. A.-Untersuchungen. Verhandlg. d. Ges. f. physische Antbropologie. 7. 31-38.

Quehl, H., 1936. Zur Abwanderung der Begabten vom Dorfe. Volk u. Rasse. 11. Jahrg., H. 9. 378-379.

Reichs- u. Preuß. Ministerium d. Innern, 1935. Runderlaß betr. Grundsätze für die Errichtung u. Tätigkeit der Beratungsstellen für Erb- u. Rassenpflege. Reichsgesundheitsblatt. 10. Jahrg. 73-74.

Reichs- u. PreuB. Ministerium d. Innern, 1935. Gesetz zum Schutz des deutschen Blutes und der deutschen Ehre. Reichsgesundheitsblatt. 10. Jahrg. 882.

Reichs- u. Preuß. Minister des Innern, 1936. Runderlaß betr. Kommentare zum Gesetz zur Verhütung erbkranken Nachwuchses, zum Blutschutz- und Ehegesundheitsgesetz. Reichsgesundheitsblatt. 11. Jahrg. 575.

Reichs- u. Preuß. Minister d. Innern, 1936. Runderlaß betr. Durchführung des Blutschutzgesetzes. Reichsgesundheitsblatt. 11. Jahrg. 757.

Reichsminister für Justiz, 1936. Verfügung betr. erb- und rassenkundliche Untersuchungen. Reichsgesundheitsblatt. 11. Jahrg. 771.

Reichsministerium des Innern, 1936. Die Ausführungsbestimmungen des Gesetzes zum Schutze der Erbgesundheit des deutschen Volkes. Archiv f. Rassen- u. Gesellschaftsbiologie. 30. $81-85$.

Reiehsregierung, 1935. 4. Verordnung zur Ausführung des Gesetzes zur Verhütung erbkranken Nachwuchses. Reichsgesundheitsblatt. 10. Jahrg. 706-707.

Reiehsregierung, 1935. 1. Verordnung des Führers u. Reichskanzlers zur Ausführung des Gesetzes zum Schutze des deutschen Blutes und der deutschen Ehe. Reichsgesundheitsblatt. 10. Jahrg. 1002.

Reuter, F., 1936. Aufartung durch Ausmerzung. Sterilisation und Kastration im Kampf gegen Erbkrankheiten. Berlin: R. Hopping. 112 S. 80. 4 Taf.

Roemer, H., 1935. Die Durchführung und weitere Ausgestaltung des Sterilisierungsgesetzes. Z. psych. Hyg. 8. 131-141.

Roemer, H., 1936. Die Leistungen der psychiatrischen Kliniken und der öffentlichen Heilu. Pflegeanstalten bei der Durchführung des Gesetzes zur Verhütung erbkranken Nachwuchses im 1. Jahr des Vollzuges 1934. Z. psych. Hyg. 9. 47-52.

Roemer, H., 1936. Zur Durchführung der erbbiologischen Bestandesaufnahme in den Heilund Pflegeanstalten. Zeitschr. f. psychische Hygiene. 28. 110-120.

Ruffmann, G., 1935. Wie groß ist die Anzahl der Erbblinden in Deutschland ? Marburg, Med. Diss. Marburg: Zetl. 36 S. $8^{0}$.

Ruttke, F., 1936. Rückgang der Buschmänner in Südafrika. Wirkung von Rassenvermischung? Archiv f. Rassen- u. Gesellschaftsbiologie. 30. 77-78.

Ruttke, F.. 1936. Internationale Föderation eugenischer Organisationen. Volk u. Rasse. 
Sailer, 0., 1936. Epilepsie und Durchführung des Gesetzes zur Verhütung erbkranken Nachwuchses. Erlangen, Med. Diss. Weiden: Schlosser. 26 S. $8^{0}$.

Schattky, J., 1936. Der Auslesegedanke in der deutschen Bauernsiedlung. Deutsche medizin. Wochenschr. 62. Jahrg. 1596-1599.

Scheidt, W., 1936. Die rassenhygienischen Aufgaben des Jugendarztes. Gesundheit $u$. Erziehung. 49. Jahrg. 161-167.

Schemmel, L., 1936. Herkunft und Persönlichkeit von 400 Insassinnen des Arbeitshauses Aichach. Mschr. Kriminalpsychol. 27. Jahrg. 161-169.

Schiff, $\dot{P}$. et Du Tillet, 1936. Hérédité précessive et stérilisation eugénique dans la manie. Ann.-méd. psychol. 94^ Année. 277-278.

Schill-Krämer, E., 1935. Entwicklung und Bewegung des hinterpommerschen Geschlechts v. Bonin in der Zeit von 1300-1930. Familiengeschichtliche Blätter. 23. Jahrg. $335-346$.

Schmidt-Klevenow, 1936. Das Problem der unehelichen Kinder. Volk u. Rasse. 11. Jahrg., H. 5. $221-223$.

Schriftl. d. dentseh. med. Wochensehrift, 1936. Die Diagnose der Erbkrankheiten. Fine Aufsatzreihe. Leipzig: G. Thieme. 115 S. 7 Textf.

Schultz, K., 1936. Die rassenbiologische Bedeutung der Leibesübungen. Volk u. Rasse. 11. Jahrg., H. 8. 339. 6 Textf.

Schwanitz, F., 1936. Die Verstädterung in biologischer Betrachtung. Volk u. Rasse. 11. Jahrg: H. 5. 179-181.

Seggel, K. A., 1936. Der Leipziger Blutspendernachweis. II. Erfahrungen aus dem 2. Jahr seines Bestehens. Münchner medizin. Wochenschr. 83. Jahrg. 1129-1131.

Sekla, B., 1936. Eugenics in Czechoslovakia. Eugenics Review. 28. 115-118.

Senat d. freien Stadt Danzig, 1935. Verordnung betr. Abänderung der Rechtsverordnung zur Verhütung erbkranken Nachwuchses. Reichsgesundheitsblatt. 10. Jahrg. 935.

Soboleva, G. V., 1934. The morphological peculiarities exist in ulcerous patients. (Russisch; m. engl. Zus.) Proceedings of the medico-biological institute Moscow. 3. 154-168. 29 Taf.

Spohr, W., 1935. Die Stellung des Arztes in Verfahren vor den Erbgesundheitsgerichten. Klin. Wochenschr. 14. Jahrg. 1328-1332.

Spranger, 1935. Die Ausschaltung wertvollen Erbgutes durch hochwertige Ledige. Reichsgesundheitsblatt. 10. Jahrg., H. 36. 794-796.

Spranger, 1935. Was muß der Amtsarzt über die Eheschließung zwischen Ariern und Nichtariern wissen? Reichsgesundheitsblatt. 10. Jahrg., H. 48. 1104-1006. 1 Taf.

Stark, H., 1936. Erbfragen in der Orthopädie. Medizin. Klinik. 32. Jahrg. 1189-1192.

Steinwallner, B., 1935. Geisteskrankheit und Eherecht. Medizin. Klinik. 31. Jahrg. $1450-1451$.

Steinwallner, B., 1936. Neue dänische Erbgesundheitsgesetzgebung. Psychiatr.-neur. Wochenschr. 38. Jahrg. 191-193.

Steinwallner, B., 1936. Ein psychiatrisch-bemerkenswertes Gesetz Lettlands. Psychiatr.neur. Wochenschr. 38. Jahrg. 241.

Steinwallner, B., 1936. Zum gegenwärtigen Stande der Sterilisierungsgesetzgebung in Nordamerika. Psychiatr.-neur. Wochenschr. 38. Jahrg. 335-338.

Steinwallner, B., 1936. Über den Stand der Gesundheitsgesetzgebung anderer Länder. Allg. Z. Psychiatr. 104. 412-415.

Stefan, H., 1936. Epilepsie und Erbgesundheitsgesetz. Medizin. Klinik. 32. Jahrg. 1133 bis 1136.

Stemmler, W., 1936. Die Durchführung der erbbiologischen Bestandesaufnahmen in den Heil- und Pflegeanstalten. Zeitschr. f. psychische Hygiene. 9. 97-110.

Stumpfl, Fr., 1936. Die Ursprünge des Verbrechens, dargestellt am Lebenslauf von Zwillingen. Leipzig: G. Thieme. $176 \mathrm{~S}$. $8^{\circ}$. 3 Textf.

Szondi, L., 1936. Der Neurotiker im Lichte der psychoanalytischen, neuro-endokrinen und erbpathologischen Forschungen. Eine Konfrontation der 3 Richtungen. Schweizer Arch. f. Neurologie u. Psychiatrie. 37. 313-334. 
Thiel, W., 1935. Sterilitätsbegutachtungen bei Erbkranken durch Salpingographie. Dtsch. medizin. Wochenschr. 61. Jahrg. 1476-1480.

Tirala, L. G., 1936. Sport und Rasse. Frankfurt a. M.: Bechhold. 207 S. $8^{\circ}$. 123 Textf.

Vad, G., 1936. Eugenische Maßnahmen in Dänemark. Volk u. Rasse. 11. Jahrg., H. 6. $245-249$.

Valentin, B., 1936. Erbkrankheiten. (Eine ărztliche Stellungnahme aus dem Jahre 1769.) Klin. Wochenschr. 15. Jahrg. 1143-1144.

Vieth-Knudsen, K. A., 1936. Die Bevölkerungsfrage im Norden. Volk u. Rasse. 11. Jahrg., H. 6. 235-245. 4 Textf.

Vowinckel, E., 1936. Erbgesundheitsgesetz und Ermittlung kindlicher Schwachsinnszustände mit den Entwicklungstests von „Bühler-Hetzer". Arch. f. Kinderheilkunde. Beih. H.9. $54 \mathrm{~S} .8^{0}$. 28 Textf.

Wahle, F., 1936. Fremules Blut in germanischem Adel der geschichtlichen Frühzeit. Zeitschr. f. Rassenkunde. 4. 200-201.

Wehling, B. H., 1936. Westfälische Weltwanderungen. Arch.f. Wanderungswesen. 8. Jahr. gang. $99-103$.

Weidner, S., 1936. Ủber Zusammenhänge zwischen sozialer Lage und Kiefer- und Zahn. reihenanomalien bei den Schulkindern Heinsbergs bei Aachen. Würzburg, Med. Diss. Würzburg: Triltsch. $32 \mathrm{~S}$. $8^{\circ}$.

Wenzel, A., 1936. Die Verbreitung der Zahncaries bei der Duisburg-Hamborner Schuljugend, mit besonderer Berücksichtigung der sozialen Schichtung. Münster, Med. Diss. Essen: Reismann-Grone. $26 \mathrm{~S}$.

Wibanit, F., 1936. Het bestaansrecht van de eugenese. Mensch en Maatschapij. 12. Jahrg. $217-222$.

Wiegand, A., 1936. Das Gesetz zur Verhütung erbkranken Nachwuchses vom 14. Juli 1933 und die Pädagogik. Gesundheit u. Erziehung. 49. Jahrg. H. 10.

Wirth, E., 1936. Erfordert bei der Erbbegutachtung die Diagnose der erblichen Taubheit unbedingt den Nachweis der erblichen Belastung? Münchner medizin. Wochenschr. 83. Jahrg. 1304-1306.

Wälker, H., 1936. Die Wirkung der städtischen Arbeitsteilung auf Auslese, Gattenwahl und Familie. Volk u. Rasse. 11. Jahrg., H. 5. 199. 3 Textf.

Wulkow, H., 1936. Die Körpermaße der Lebensversicherten. Berlin: Mittler. $125 \mathrm{~S} .4^{0}$.

Zeller, W., 1936. Der Jugendarzt, seine Aufgaben und Methoden. Gesundheit u. Erziehung. 49. Jahrg. $129-136$.

Ziehm, A., 1936. Psychiatrische Nachuntersuchungen von Erbkranken nach ihrer Unfruchtbarmachung und Entlassung aus der Heil- und Pflegeanstalt Berlin-Buch. Berlin, Med. Diss. Brandenburg: Wolters. 34 S. $8^{0}$.

Ziemann, H., 1936. Beitrag zum Bevölkerungsproblem der primitiven Rassen. Arch. f. Schiffs- $u$. Tropenhygiene. 40. 235-242.

Zimmermann, L., 1936. Die Bedeutung der altdeutschen Stadt für das Werden des deutschen Volkes. Volk u. Rasse. 11. Jahrg., H. 5. 187-191. 1 Textf. 